\title{
A Comparison of Life Cycle Energy and Carbon Impacts for Passive Detached Accessory Dwelling Units and Their Design Implications
}

\author{
By \\ Deva Siva Veylan \\ BCom, University of Alberta, 2006
}

\begin{abstract}
A Major Research Project
presented to Ryerson University

in the partial fulfillment of the

requirements for the degree of

Master of Building Science
\end{abstract}

Toronto, Ontario, Canada, 2019

(C) Deva Siva Veylan 2019 


\section{Author's Declaration For Electronic Submission Of A Major Research Project}

I hereby declare that I am the sole author of this major research project. This is a true copy of the major research project, including any required final revisions, as accepted by my examiners.

I authorize Ryerson University to lend this thesis to other institutions or individuals for the purpose of scholarly research

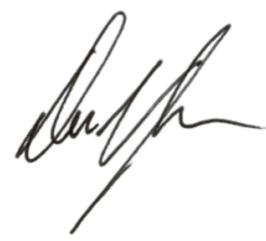

I further authorize Ryerson University to reproduce this major research project by photocopying or by other means, in total or in part, at the request of other institutions or individuals for the purpose of scholarly research.

I understand that my major research project may be made electronically available to the public.

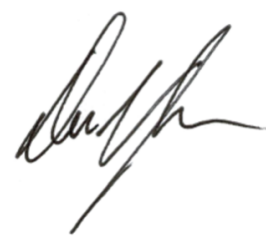




\title{
A COMPARISON OF LIFE CYCLE ENERGY AND CARBON IMPACTS FOR PASSIVE DETACHED ACCESSORY DWELLING UNITS AND THEIR DESIGN IMPLICATIONS
}

\section{Master of Building Science 2019 - Deva Siva Veylan - Ryerson University}

\begin{abstract}
Detached accessory dwelling units are a building typology that, when built to passive design standards, can help reduce GHG emissions while addressing the socioeconomic pressures facing many housing markets. Energy performance metrics like those used in passive design standards are based on per unit of floor area and lead to a size-bias against smaller housing typologies. A life cycle assessment of cost-optimal passive house sizes ranging from $230 \mathrm{~m}^{2}\left(2,500 \mathrm{ft}^{2}\right)$ to 30 $\mathrm{m}^{2}\left(300 \mathrm{ft}^{2}\right)$ is performed to understand their total life cycle energy use and GHG emissions implications. Additionally, an analysis using BEopt examines operational energy use for 10 costoptimal passive house sizes ranging from $230 \mathrm{~m}^{2}\left(2,500 \mathrm{ft}^{2}\right)$ to $30 \mathrm{~m}^{2}\left(300 \mathrm{ft}^{2}\right)$ across all 17 climate zones and examines how cost-optimal passive design changes with house size. The results show that per-occupant energy use and GHG emissions are similar or better for small house sizes and that cost-optimal passive design does not change significantly with house size.
\end{abstract}




\section{Acknowledgements}

Firstly, I would like to thank my supervisor, Dr. Russell Richman, for helping me develop the work presented herein. Thank you for your guidance through this process. Your dedication to your students and to building science is remarkable.

I would also like to thank Dr. Mark Gorgolewski for helping open my mind to the wider implications of building science. Additionally, I'd like to thank Graham Wright, head scientist at PHIUS for his input and for pointing me in the right direction with this research.

A special thank you goes to my parents, Aran and Tara Veylan. Without your support this would not have been possible, and I would not be where I am now. I am eternally grateful for the opportunities and guidance you've given me.

Finally, I'd like to thank my wife, Sitara Alahan to whom I dedicate this work. Thank you for your unwavering love, patience, and support. 


\section{Table of Contents}

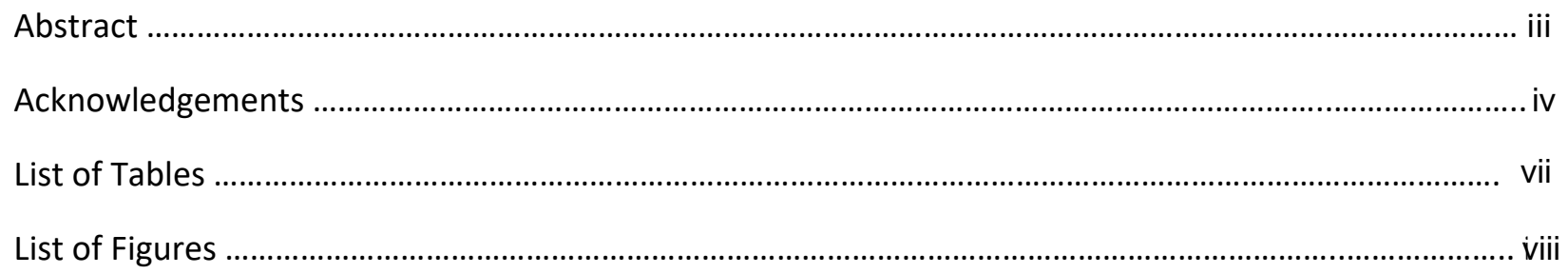

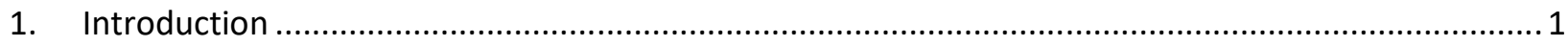

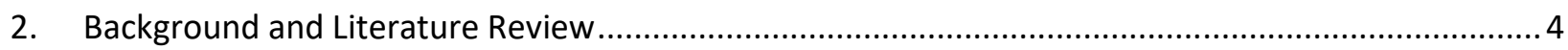

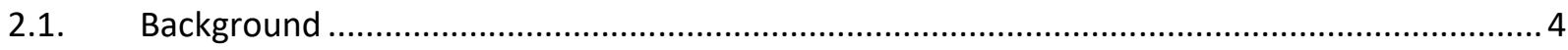

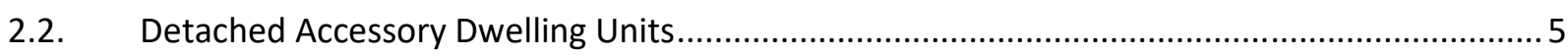

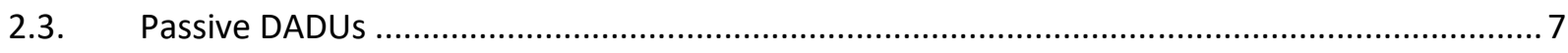

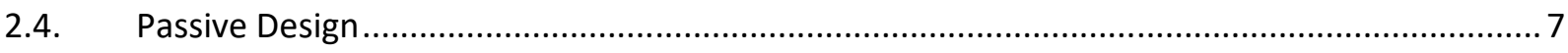

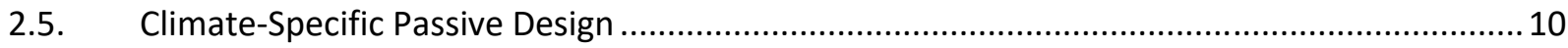

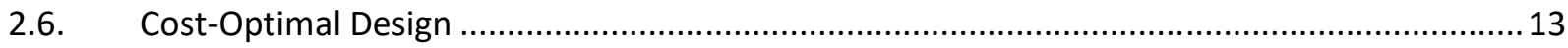

2.7. Operational Vs. Embodied Energy .................................................................................. 14

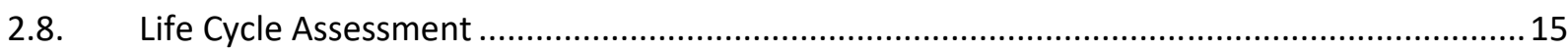

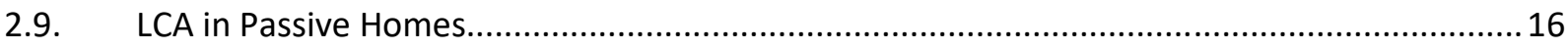

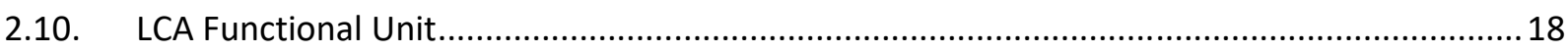

2.11. Building Size and Performance .................................................................................. 19

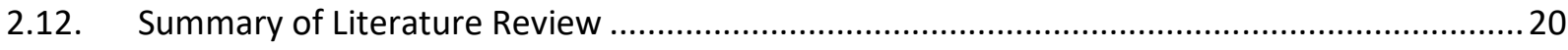

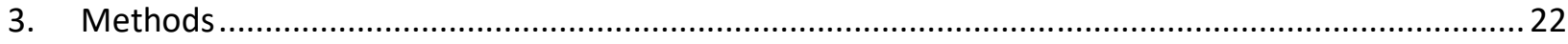

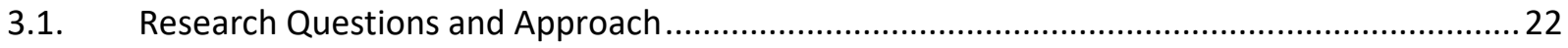

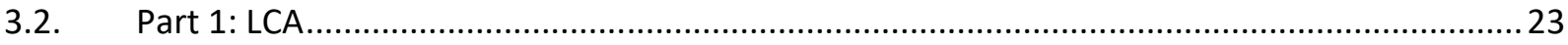

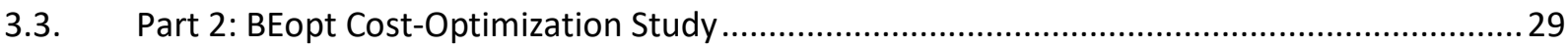

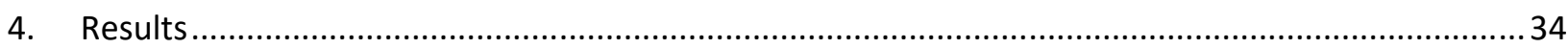

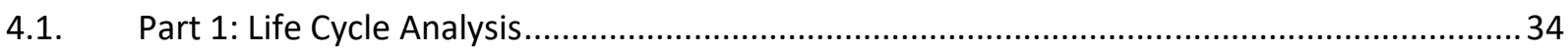

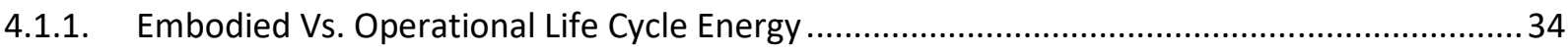

4.1.2. Embodied Vs. Operational Life Cycle GHG Emissions ....................................................... 37

4.1.3. Total Life Cycle Energy and Emissions Per-Area ..................................................................39 
4.1.4. Total Life Cycle Energy Use and GHG Emissions Per-Occupant .............................................41

4.1.5. Total Life Cycle Energy and Emissions Per-Set Occupancy Rate .............................................43

4.1.6. Embodied Energy Use and GHG Emissions Impact............................................................ 45

4.2. Part 2: BEopt Cost-Optimal Passive Design Study .............................................................46

4.2.1. Building Energy Use Intensity Per-Area by Size and Climate Zone .......................................47

4.2.2. Building Energy Use Intensity Per-Occupant by Size and Climate Zone .................................48

4.2.3. Building Energy Use Intensity Per-Set Occupancy Rate by Size and Climate Zone...................50

4.2.4. Cost-optimal Passive Design Differences Based on Building Size .........................................51

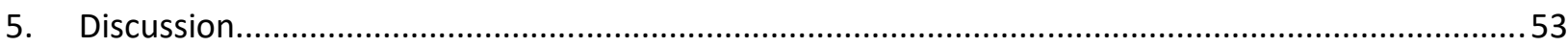

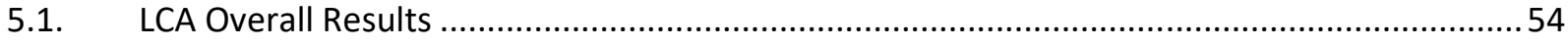

5.2. Research Question \#1: Life Cycle Impacts of Passive DADUs ...............................................56

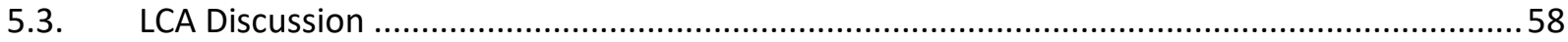

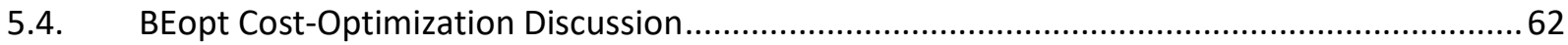

5.5. How Cost-Optimal Passive Design Changes Based On Housing Size ......................................64

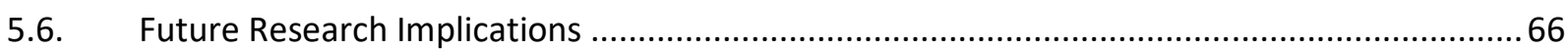

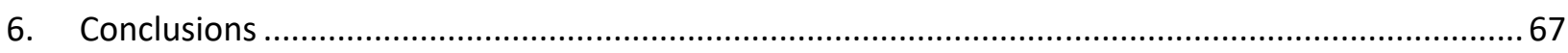

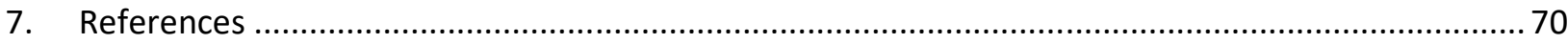

Appendix A: LCA Material Quantity Take-Off Models ........................................................................... 73

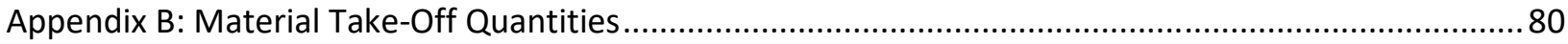




\section{Tables}

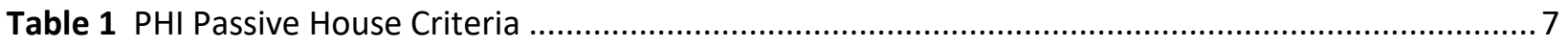

Table 2 PHIUS+ 2015 Performance Criteria for Certification................................................................ 11

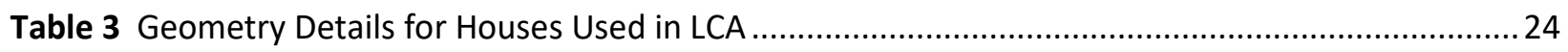

Table 4 Grid Emissions Intensities for Locations Used in LCA based on Athena Impact Estimator Inputs ....... 25

Table 5 Nominal R-values of Building Envelopes of Houses Used in LCA ............................................ 25

Table 6 Material Choices for High, Medium, and Low Embodied Energy Build Packages ...................... 27

Table 7 Geometry Details for Houses Used for BEopt Optimization Study.............................................. 31

Table 8 Locations and Weather Data Used in BEopt Optimization Study ............................................. 32

Table 9 Occupants Per Single-Detached House by Number of Bedrooms ............................................ 43 
Figures

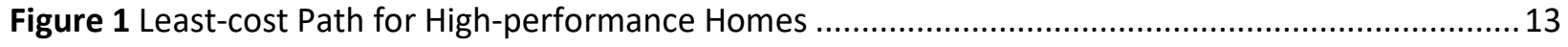

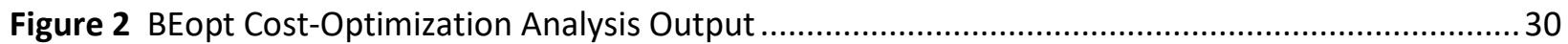

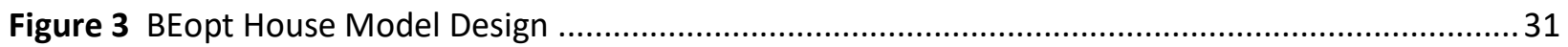

Figure 4 Embodied and Operational Life Cycle Energy for Various Passive House Sizes in Toronto......... 34

Figure 5 Embodied and Operational Life Cycle Energy for Various Passive House Sizes in Halifax............35

Figure 6 Embodied and Operational Life Cycle Energy for Various Passive House Sizes in Lethbridge .... 35

Figure 7 Embodied and Operational Life Cycle GHG Emissions for Various Passive House Sizes in Toronto .. 37

Figure 8 Embodied and Operational Life Cycle GHG Emissions for Various Passive House Sizes in Halifax .... 38

Figure 9 Embodied and Operational Life Cycle GHG Emissions for Various Passive House Sizes in Lethbridge....... 38

Figure 10 Total Life Cycle Energy for Cost-Optimal Houses per m2 iCFA ............................................. 40

Figure 11 Total Life Cycle GHG Emissions for Cost-Optimal Houses Per m2 iCFA ................................... 40

Figure 12 Total Life Cycle Energy for Cost-Optimal Houses per Occupant.............................................41

Figure 13 Total Life Cycle GHG Emissions for Cost-Optimal Houses per Occupant................................. 42

Figure 14 Total Life Cycle Energy for Cost-Optimal Houses per Set Occupancy.......................................44

Figure 15 Total Life Cycle GHG Emissions for Cost-Optimal Houses per Set Occupancy ......................... 44

Figure 16 Average Embodied Energy for Cost-Optimal Houses .........................................................45

Figure 17 Average Embodied GHG Emissions for Cost-Optimal Houses ............................................. 46

Figure 18 Cost-Optimal Passive Building Energy Use Intensity by Size and Climate Zone ...................... 47

Figure 19 Cost-Optimal Passive Building Energy Use Intensity by Size Averaged for All Climate Zones... 48

Figure 20 Cost-Optimal Passive Building Energy Use Intensity by Occupant and Climate Zone ............... 49

Figure 21 Cost-Optimal Passive Building Energy Use Intensity by Occupant Average for All Climate Zones ... 49

Figure 22 Cost-Optimal Passive Building Energy Use Intensity by Set Occupancy and Climate Zone........50

Figure 23 Cost-Optimal Passive Building Energy Use Intensity by Set Occupancy Averaged for All Climate Zones 51

Figure 24 Overall Envelope U-value by Building Size and Climate Zone for Cost-Optimal Passive Houses ..... 52

Figure 25 Overall Cost-Optimal Passive Envelope U-value for Building Size .........................................52 


\section{Introduction}

As of 2017, the majority of the large population centers in Canada and the United States rank among the least affordable housing markets on the planet (Cox \& Pavletich, 2017). High housing prices and a lack of buildable lots in these cities are the driving the resurgence of a housing typology that has been around since the early 1900's; the detached accessory dwelling unit (DADU) (Bady, 2017). According to a report to Edmonton's urban planning committee, "there were 55 new garage or garden suite units in mature and established neighbourhoods in 2016, 23 in 2015 and 16 in 2014", which demonstrates the exponential growth of this type of DADUs in some markets (Neufeld, 2017, p.5). Other markets that are now allowing laneway houses and other forms of DADUs include Vancouver, Seattle, and Toronto, among others.

DADUs are known by many names, including in-law suites, carriage homes, laneway houses, granny flats, and others. DADUs can offer full kitchens, up to three bedrooms, and can be as large as $120 \mathrm{~m}^{2}\left(1,300 \mathrm{ft}^{2}\right)$, though they are usually significantly smaller than single detached homes (Bady, 2017). They offer several social benefits, including affordable housing, additional income to the homeowner, property value enhancement, and can provide supported living for elderly relatives. DADUs are also considered by some to be a positive move towards a more sustainable built environment due to increased urban density, reduced resource use, and less embodied energy per occupant compared to single detached houses (Brown \& Watkins, 2012).

Although DADUs have many social, economic, and environmental benefits, not all believe, however, that they provide benefits in terms of lessening the environmental impacts associated with housing. This is due, in-part, to the fact that on a per- $\mathrm{m}^{2}$ basis, buildings with small footprints generally have higher embodied and operational energy (Wright, Klingenberg, \& Pettit, 2014). 
The use of per-area energy intensity metrics to quantify a building's energy efficiency and greenhouse gas (GHG) emission performance is common and is relied on for passive building certification standards including the Passive House Institute US (PHIUS) PHIUS+ 2015 Passive Building Standard and the Passive House Institute's (PHIs) Passive House Standard.

The PHIUS +2015 Passive Building Standard is based on area-weighted energy targets that creates a disincentive to build smaller buildings. This bias is based on the belief that "less materialsefficient forms such as detached 'tiny houses' will have more difficulty" meeting the certification energy thresholds (Wright et al., 2014, p.19). In buildings with small interior conditioned floor areas (iCFAs), the certification thresholds of annual heating/cooling demand and peak heating/cooling loads become significantly more difficult to meet. This is due, in part, to the higher surface-to-volume ratio of buildings with lower iCFAs, and baseloads associated with occupant energy use being spread over a smaller floor area, which increases their contribution per-unit area energy use. Unfortunately, little attention has been given to whether the size bias against smaller houses based on per-area energy intensity is justified, and published research is limited.

This research explores how house size affects a passive house's embodied and operational energy use and GHG emissions. To more fully understand this relationship, different functional units are considered. It is likely that on a per square meter of iCFA $\left(\right.$ per- $\left.\mathrm{m}^{2}\right)$ basis, smaller houses do in fact have higher total life cycle energy use and GHG emission impacts than their larger counterparts. This study explores whether, when energy use and GHG emissions are analysed on a per-occupant basis, smaller houses perform better than larger ones. To fully understand how DADUs perform from an energy and emissions standpoint, a full life cycle assessment (LCA) is completed. The system boundaries considered include everything from initial product effects to effects beyond a building's life. Comparing the life cycle effects of average and smaller passive 
DADUs using per-area and per-occupant functional units allows for a more complete understanding of the sustainability issues at play. If passive DADUs are as beneficial on sustainability grounds than their larger counterparts, then a size bias against them is unjustified and should be eliminated.

If smaller sizes of passive houses should be encouraged due to their better energy and emissions performance, then the next consideration for passive designers and builders is how cost-optimal passive design changes as house size shrinks. This question has significant implications in bringing DADU and other small housing typologies into the passive house fold. If the optimal design is significantly different for DADUs, their integration will pose more challenges for passive researchers, technical committees, designers and builders. It is possible, however, that passive design principals and their suitability are universal, regardless of house size.

This research attempts to clarify these issues and does so by first performing an LCA on various sizes of passive houses at and below the average American new house size of $230 \mathrm{~m}^{2}\left(2,500 \mathrm{ft}^{2}\right.$ in 2017) to determine how its life cycle energy and emissions performance on a per-area and peroccupant basis is influenced by house size (United States Census Bureau, 2017). Next, this study performs a multi-objective cost-optimization analysis on passive-designed houses in all 17 AHRAE climate zones determine if the results from the LCA are likely to be consistent amongst various climate zones, and how the cost-optimal passive design changes with house size below the $230 \mathrm{~m}^{2}\left(2,500 \mathrm{ft}^{2}\right)$ average. 


\section{Background and Literature Review}

\subsection{Background}

Demographics in North America are changing considerably, as households have gotten smaller over the past 60 years. At the same time, however, house sizes have become considerably larger (Nichols \& Adams, 2013). With little diversity offered in housing typologies, social and economic pressures have led to a housing crisis in many cities in North America.

These crises are often attributed to a lack of supply due to baby boomers ageing in place, land use restrictions, and foreign investment in real-estate and has caused housing prices to rise dramatically in many cities over the past decade (Devlin, 2017). There are many social and economic consequences that arise when median house prices surge ahead of wage growth. Among some of these consequences are adult children with young families being forced to live with parents and in-laws for longer periods as they try to save for mortgage deposits; people are waiting longer to have children, and large amounts of income is required for mortgage payments or rent leaving far less disposable income (Roy, Maynard, \& Weiss, 2008).

DADUs have been proposed as one solution to the housing crisis. Wegmann and Chapple (2014) show that although $2 \%$ to $25 \%$ of properties have an accessory dwelling unit (ADU), little research has been done involving this type of housing arrangement.

DADUs are not without their faults, however, as the Canadian Mortgage and Housing Corporation (CMHC) in 2016 observes that small spaces can limit privacy within the home, lack room for children to play, and limit the ability to entertain guests (Canada Mortgage and Housing Corporation, 2016). The CMHC also found other issues at play, including the difficulty in financing and insuring this type of home. The potential for increased number of cars parking on 
streets, traffic congestion in residential neighborhoods, and overcrowding in neighborhoods were also mentioned as drawbacks. Galassini (2014), however, pointed to a 1998 Seattle City Council study that suggested DADUs did not have much of a negative impact on neighborhoods. Though DADUs do have some drawbacks, they are widely regarded as a beneficial typology.

\subsection{Detached Accessory Dwelling Units}

A renaissance is occurring with DADUs - "As the negative, social, environmental, and economic consequences of urban sprawl have become better understood, a broad consensus in favour of smart growth goals has emerged" and that this is defined as "higher density in walkable developments clustered in urban centres that offer transportation alternatives" (Wegmann \& Chapple, 2014, p.1).

The role DADUs can play in reaching smart growth goals in our cities is significant. Galassini (2014) notes that increases in urban density in cities is generally achieved through the development of duplexes and large MURBs through up-zoning. Citizens who own single family homes have fought to keep these neighborhoods unchanged. She suggests that the accessory dwelling unit can achieve a "hidden density" that avoids this opposition, as they have a minimal impact on the character of existing neighborhood. These advantages necessitate that DADUs become a more prominent tool for growth in our cities and to increase urban density (Galassini, 2014).

One of the major benefits of increasing urban density is reduced GHG emissions. In a study focusing on the city of Toronto, Norman et al. (2006) found that increasing residential density can contribute to GHG emissions reductions and broader energy conservation improvements. Though this study focused only on Toronto, the authors recommend similar studies be done for other urban 
centres around the world to better understand and quantify urban density effects on GHG emissions.

In a larger scale study by Clark (2013), an increase in population density in urban cores is found to correlate with a reduction in GHG emissions due mainly to transport reductions. This positive impact is, however, offset by diminished housing affordability and increased roadway congestion (Clark, 2013).

In the most comprehensive study to date that examines the effect of increased urban density on energy efficiency and GHG emissions, Gudipudi et al. (2016) examine the conflicting results and challenges seen by other studies on the topic. They found that different methods, scopes, and boundary conditions led to these conflicting results. Though the study ignores urban heat island effect on emissions and uses a less granular emissions inventory then the Hestia Project (that quantified, on an hourly basis, all fossil fuel $\mathrm{CO}_{2}$ emissions for buildings, industrial and electricity production facilities, inroad segments for an urban landscape), it did analyse all inhabited areas in the United States. The results of this study show that doubling population density reduces total $\mathrm{CO}_{2}$ emissions for buildings and transportation by least $42 \%$ (Gudipudi et al., 2016). This result shows the importance of reducing urban sprawl through smart growth measures, which is something that can be accomplished through a wider adoption of the DADU in urban landscapes.

\subsection{Passive DADUs}

Reducing GHG emissions in the built environment can occur though smart growth strategies, as well as through building the sprawl-reducing DADU to low-energy or passive standards. Uptake in passive-certified small houses (below $85 \mathrm{~m}^{2}$ ) has been limited. Though there are several very small passive houses (including five PHIUS-certified projects under $85 \mathrm{~m}^{2}$ ) this number is small 
in comparison to the approximately $400 \mathrm{PHI}$ and PHIUS-certified project North America. Some builders of laneway houses in markets that allow DADUs follow passive design principals, however few seek certification under passive certification programs. This is likely due to some of challenges faced in the laneway market, including restricted site parameters that block solar access and make reaching the strict certification thresholds nearly impossible.

\subsection{Passive Design}

Passive design was first pioneered in Canada in 1977 with construction of the Saskatchewan Conservation House by a design and construction team that included Robert Besant, Oliver Drerup, Rob Dumont, David Eyre, and Harold Orr. In the same year, Gene Leger built the Leger House in Pepperell, Massachusetts to similar standards. The passive design principles developed in these projects included airtight, super-insulated envelopes, heat recovery ventilation, and the elimination of thermal bridges. In the early 90's, Dr. Wolfgang Feist, a German physicist and founder of the Passivhaus Institute (PHI), built on these passive design principles and codified them into a system called Passivhaus (PH). A PHI-certified PH must meet the targets presented in Table 1 PHI Passive House Criteria (Passive House Institute, 2016).

Table 1 PHI Passive House Criteria (Passive House Institute, 2016) 


\begin{tabular}{|c|c|c|c|c|c|c|}
\hline & & & \multicolumn{3}{|c|}{ Criteria } & Alternative Criteria \\
\hline \multicolumn{7}{|l|}{ Heating } \\
\hline Heating demand & {$\left[\mathrm{kWh} /\left(\mathrm{m}^{2} \mathrm{a}\right)\right]$} & $\leq$ & \multicolumn{3}{|c|}{15} & - \\
\hline Heating load & {$\left[\mathrm{W} / \mathrm{m}^{2}\right]$} & $\leq$ & \multicolumn{3}{|c|}{-} & 10 \\
\hline \multicolumn{7}{|l|}{ Cooling } \\
\hline Cooling + dehumidification demand & {$\left[k W h /\left(m^{2} a\right)\right]$} & $\leq$ & \multicolumn{3}{|c|}{ 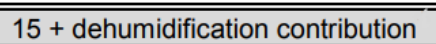 } & variable limit value \\
\hline Cooling load & {$\left[\mathrm{W} / \mathrm{m}^{2}\right]$} & $\leq$ & \multicolumn{3}{|c|}{-} & 10 \\
\hline \multicolumn{6}{|l|}{ Airtightness } & \\
\hline \begin{tabular}{|l|} 
Pressurization test result $n_{50}$ \\
\end{tabular} & {$[1 / \mathrm{h}]$} & $\leq$ & \multicolumn{3}{|c|}{0.6} & \\
\hline \multicolumn{3}{|l|}{ Renewable Primary Energy (PER) } & Classic & Plus & Premium & \\
\hline PER demand & {$\left[\mathrm{kWh} /\left(\mathrm{m}^{2} \mathrm{a}\right)\right]$} & $\leq$ & 60 & 45 & 30 & $\begin{array}{c} \pm 15 \mathrm{kWh} /\left(\mathrm{m}^{2} \mathrm{a}\right) \text { deviation } \\
\text { from criteria... }\end{array}$ \\
\hline $\begin{array}{r}\text { Renewable energy generation } \\
\text { (with reference to } \\
\text { projected building footprint) }\end{array}$ & {$\left[\mathrm{kWh} /\left(\mathrm{m}^{2} \mathrm{a}\right)\right]$} & $\geq$ & - & 60 & 120 & $\begin{array}{c}\text {.... with compensation of the } \\
\text { above deviation by different } \\
\text { amount of generation }\end{array}$ \\
\hline
\end{tabular}

These energy and air tightness targets surpass code-built houses anywhere in the world. According to Dequaire (2012), "no other standard meets the level of achievement of the PH standard" due to its "clear focus on the building itself, with the requirements on demand, air tightness another secondary requirements on the quality of equipment" (Dequaire, 2012, p. 390).

Though passive design principles can be applied nearly anywhere in the world, the PH standard, faces challenges in its application. Schnieders et al. (2015) discuss how PH certification "can be realised in different, rather extreme climates, leading to the conclusion that they can be built nearly anywhere in the world" (Schnieders et al., 2015, p. 87). This article discusses six residential design-only case studies in locations around the world, however, only one case designed for a very cold climate (Yekaterinburg, Russia). The proposed design for this cold climate is a multi-unit residential building (MURB), and to meet certification thresholds, needs movable shades to allow significant solar heat gain while preventing overheating, as well as unheated stairwells, elevators, and basement. These extensive and inconvenient design sacrifices point to the challenges in meeting the PH certification thresholds in very cold climates. Additionally, there is no mention of the economics of this design in the case study. 
While it is possible to design residential buildings to meet $\mathrm{PH}$ requirements in very cold climates, few projects have been certified. Other studies show that less stringent design standards may make more economic sense compared to the rigid PH standards. Though their study uses admittedly inexpensive natural gas (which disfavours passive designs) and finds the rate of increasing energy costs (which is hard to predict) as having a significant effect on the study's outcome, Audenaert et al. (2008) show that less stringent low-energy design sometimes makes more economic sense then strict PH design requirements.

Further to this, "the economic viability of a passive house is not a factual thing, but rather a construct in the mind of the investor" (Galvin, 2014, p. 156). Galvin's 2014 study shows that the economic case for the PHI approach is unknowable at worst and unclear at best. This points to the need for more cost-effective passive design strategies for wider adoption, especially in more extreme climates than the continental European climates in which the PH standard was developed.

Since the 1990's, when PHI developed the PH standard, there has been further research and field experience with passive design and construction, notably in North America, where climactic conditions are far more varied then in Europe. According to Klingenberg et al. (2016), North America has a much more varied climate than Europe's. Even locations with similar heating degree days often have much colder winter. Good solar potential leads designers making up for the colder winters by over-glazing on the south façade. This leads to higher peak heating and cooling loads and overheating. The more and better glazing required in these cold climates, along with greater insulation levels resulted in higher costs for construction. They state that it is "not possible, in all climates, to optimize for both cost and peak loads at the same time" (Klingenberg et al. 2016, p. 508).

In 2014, Wright et al. found the following: 
A single rigid performance metric developed in Germany has led to limited uptake of passive building principles in many regions of the United States. It has also sometimes promoted design decisions that had negative affects on economic feasibility in thermal comfort. (p. x)

Several other experts also questioned the economic feasibility of the rigid PH standard in North America. In a 2009 unpublished critique, Dr. John Straube discusses the merits and the challenges of the PH standard as applied in North America. He describes in detail how several of the PH recommendations are unnecessary, impractical, or overly-costly. These include:

- Over ventilation compared to ASHRAE 62.2, 2007 recommendations

- Necessary upgrade packages are costly in comparison to similar performing cost-optimal upgrade packages

- The deployment of renewables is not taking into account, where they may achieve a less costly and more impactful effect on energy use (though this has subsequently been addressed in the newest version of the PH standard.)

In the regions of North America that have a similar climate to that of continental Europe (e.g. the Pacific North West), there has been a relatively high uptake of the PH standard in the marketplace, however in the more extreme climate zones in North America, passive designers and builders face significant challenges in meeting the PH standard in the most cost-effective manner.

\subsection{Climate-Specific Passive Design}

In recognition of those challenges, and in an attempt to make passive certification more practical and cost-effective in the widely-varying North American climate, PHIUS developed a climatespecific passive certification standard called the PHIUS+ 2015 Passive Building Standard 
(PHIUS+ 2015). In the 2014 collaboration between PHIUS and the United States Department of Energy (DOE) called Climate-Specific Passive Building Standard, Wright et al. (2014) built upon a solid building science foundation and passive design principles to create a new passive building standard more suitable for North American climates. This study led to the development of the current PHIUS +2015 and upcoming PHIUS +2018 Passive Building Standard. This certification program was designed to eliminate some of the challenges associated with the application of the PH standard in more extreme climates. These challenges include the inability to tunnel through the cost barrier, lower fuel prices in North America, the inability to take solar photovoltaic into account, among others. PH projects facing these challenges in cold climates to often lead to "overglazed designs, large interior temperature swings, and overheating issues" (Wright et al., 2014, p. $10)$.

In 2014, Wright et al. provide an example:

To meet the European criteria in Edmonton, passive solar gains must be maximised, and the system must be size using the ASHRAE loads and a significant cooling system installed. the correct design decision to optimize thermal comfort would be to stay away from high solar gains and go for higher R-values instead; however, peak loads and annual demand criteria are so aggressive that this strategy will not get the project certified. (p. 19)

PHIUS +2015 is a climate-specific program, where performance criteria for certification change based on the location of the project seeking certification. The main performance criteria are presented in Table 2 PHIUS+ 2015 Performance Criteria for Certification.

Table 2 PHIUS+ 2015 Performance Criteria for Certification 


\begin{tabular}{ll}
\hline Performance Criteria & Target \\
\hline Annual Heating Demand & $\leq \mathrm{A}\left(\mathrm{kWh} / \mathrm{m}^{2 *} \mathrm{yr}\right)$ \\
Annual Cooling Demand & $\leq \mathrm{B}\left(\mathrm{kWh} / \mathrm{m}^{2 *} \mathrm{yr}\right)$ \\
Peak Heating Load & $\leq \mathrm{C}\left(\mathrm{W} / \mathrm{m}^{2 *} \mathrm{hr}\right)$ \\
Peak Cooling Load & $\leq \mathrm{D}\left(\mathrm{W} / \mathrm{m}^{2 *} \mathrm{hr}\right)$ \\
Airtightness & $\leq 0.05 \mathrm{cfm} / \mathrm{ft}^{2}$ envelope @50Pa \\
Source Energy Demand & $\leq 6200 \mathrm{kWh} / \mathrm{yr} /$ person \\
\hline
\end{tabular}

Some passive design practitioners feel that PHIUS +2015 is an unnecessary and damaging departure from the original German PH standard. In an unpublished and undated critique of PHIUS 2015 that best illustrates the opinions of those defending the original PHI standard, Barry (n.d.) argues that the Climate-Specific Passive Building Standards study lacks cost and performance data from real projects, and generally lacks evidence supporting the complaints against the establish PH standard. This claim is only partially true, and her counter-claim that DOE studies are emerging that document actual performance data, and that this performance is "incredibly close to the predictions modelled in the PHPP" is off the mark (Bronwyn Barry, n.d.). The studies she cites are located in AHRAE climate zones 3 and 5, which are comparable to those of continental Europe, where the original PH standard was developed, and not in the extreme climate zones that PHIUS+ 2015 is designed to address in a cost-effective and performanceoptimized manner.

Both passive building standards are an attempt to drive residential design and construction towards net zero building performance in an attempt to eliminate the climate change-causing GHG emissions from our buildings. Both certification standards help us move along this path. It is clear that in all but the very most extreme climate it is technically feasible to build net-zero buildings where energy produced is equal to the energy used over the course of a year. The main hurdle, therefore, is an economic one and a cost-optimal approach that works well in all climates is critical. 


\subsection{Cost-Optimal Design}

According to the National Renewable Energy Laboratory in 2019, cost-optimal design helps to maximize energy savings while minimizing the total cost of ownership which includes the combined cost of utility bills and mortgage payments as shown in Figure 1 Least-cost Path for Highperformance Homes (National Renewable Energy Laboratory, 2019) (National Renewable Energy Laboratory, 2019).

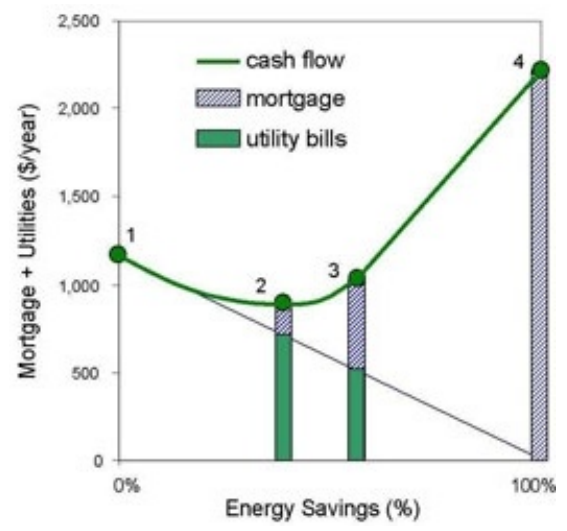

Figure 1 Least-cost Path for High-performance Homes (National Renewable Energy Laboratory, 2019)

There are several benefits to cost-optimal building design. In a study on residential energy efficiency, Morrissey and Horne (2011) suggest that the most cost-effective building design through its life cycle "always results in a design that is more energy efficient than current energy code requirements," and that these "findings have significant policy implications, particularly in view of present debates which frequently present higher energy efficiency standards as prohibitive from the cost perspective" (Morrissey \& Horne, 2011, p. 915). These researchers also suggest that further research be done looking at the relationship between house size and the cost-benefit of energy efficiency investments, which is a focus of this study.

Cost-optimal design strategies can help create policy, improve energy efficiency standards, and contribute to the body of knowledge (BOK) moving forward, and have been explored in a number 
of studies by researchers including Marszal and Heiselberg (2011), Galvin (2014), Badea et al. (2014), Islam et al. (2015), Stephan and Stephan (2016), and Tokarik and Richman (2016).

\subsection{Operational Vs. Embodied Energy}

Given the economic barriers currently impeding the wider market penetration of net-zero buildings, the economic benefits of cost-optimal passive design are self-evident. However, along the path to net-zero for building, as operational energy use and associated GHG emissions move toward zero, embodied energy and carbon becomes an increasingly important consideration. Operational energy and carbon emissions are defined as the energy use and GHG emissions associated with a building's operational space heating, cooling, and other energy uses within the home throughout its lifetime. Embodied energy and carbon is defined as the energy use and carbon emissions associated with the manufacturing of the materials used to build the home, the transportation of those materials to site, the construction of the home, its maintenance, and the demolition and disposal or recycling of the materials at the end of the building's useful life.

Consensus among researchers who have studied operational versus embodied energy exists. In a wide-ranging review of 90 LCA studies of conventional, low-energy, passive, and nearly zero energy residential buildings, Chastas et al. (2016) found that as a building's operational energy is reduced, the total life cycle energy reduction could reach up to $50 \%$. The study also found that for passive and nearly zero energy buildings, embodied energy's share of total life cycle energy reaches $26 \%$ to $57 \%$, and $74 \%$ to $100 \%$, respectively. In a 2015 study exploring embodied energy

for buildings, Georges et al. (2015) find that "although the calculation of embodied energy has considerable uncertainties, preliminary results clearly indicate that they contribute significantly to the total $\mathrm{CO}_{2}$ e emissions and therefore they deserve to be minimised" (Georges et al. 2015, p. 92). 
Theoretically, a zero-energy building has zero associated operational energy use and GHG emissions. Therefore, the embodied energy's share in the total life cycle energy use of the building would reach $100 \%$. It is clear that on the path to net-zero, embodied energy becomes a critical consideration in controlling energy use and carbon emissions. This trend for embodied energy contribution "indicates that a whole life cycle energy analysis may be needed in the methodological framework of current energy efficiency regulations" and standards (Chastas et al., 2016, p. 267). Passive design certification programs currently do not consider embodied energy in their certification requirements, thought as the programs mature, it is likely that embodied energy will be added to performance criteria for certification in these programs.

\subsection{Life Cycle Assessment}

LCA is an investigation of how much a product, such as a building, impacts the environment. It involves accounting for the "inputs and outputs throughout the life cycle of that product, from its birth, including design, raw material extraction, material production, part production, and assembly, through its use, and final disposal" (The Environmental Literacy Council, 2015). Though not a new discipline, LCA is undergoing refinement as the tool for understanding the full energy and emissions impacts of buildings through their entire life cycle. In a survey of 96 practicing building designers completed in April 2013, Han and Srebric (2015) found that LCAs are used far less often in building design then energy simulation. This may be, in part, due to the challenges and ambiguities associated with performing LCAs.

According to Anand and Amor (2017), "analysing buildings using LCA is one of the most complex applications of LCA," and that the discipline faces 15 significant challenges and research opportunities (Anand \& Amor, 2017, p. 414). Studies have been performed in the past several 
years that attempt to understand the strengths, weaknesses, and challenges associated with LCA. Chau et al. (2015) identify methodology, boundaries, practices, and databases as challenges that impact the usefulness of LCAs as a decision-making tool in sustainable building design. De Wolf et al. (2017) indicate that uncertainties in embodied energy and GHG emissions are associated with two weaknesses in implementation by practitioners: Databases and methodology. Available databases that form the foundation of LCA, according to the authors, are also sparse and unreliable (De Wolf et al., 2017)

In response to these challenges Soust-Verdaguer et al. (2016) review a large number of LCAs and have developed simplification strategies that allow for more effective comparison of results for LCAs of single-family homes. The review found that the most effective simplifications include:

- Optimization of the data collection process

- Reduction of the functional units used for analysis

- Limitation of the analysis to relevant stages and modules

- Simplification of the scenario definition

- Use of databases and generic data sources

- Use of calculation methods

- Reduction of environmental indicators

This study incorporates these methodological recommendations into the design and implementation of its LCA.

\subsection{LCA in Passive Homes}

The higher insulation requirements of passive design lead to thicker building envelopes that require more materials to construct. Passive-built houses can therefore lead to greater embodied energy and carbon impacts compared to their code-built counterparts. This difference is revealed in LCAs 
comparing passive buildings to other, less well-insulated types, and there are several studies that have explored this effect.

In most case studies that include LCA of passive houses, they are generally found to perform well on a life cycle-basis, however it depends on several factors including location, fuel mix, building typology and others. Dahlstrøm et al. (2012) found through an LCA that wood framed singledetached houses built to PH standards provide "a consistent and clear reduction of cumulative energy demand of 24 to $38 \%$ in comparison to the conventional building standard" (Dahlstrøm et al., 2012, p. 470). Other case studies like that of Sartori and Hestnes (2007) have found that in some cases, passive houses can have lower life cycle energy then net-zero houses over a 50 year building life. This is likely due, however, to the limited 50-year timeframe of the study as well as the significant embodied energy associated with renewable energy systems in the net-zero house.

In other cases, however, the increased embodied energy associated with passive buildings do not provide net energy savings. Stephan et al. (2013) show that a poorly-insulated apartment has a lower life cycle energy use then a very energy efficient passive-built house in the suburbs. Though Stephan et al. (2013) are comparing very different typologies, this study shows that passive houses do not necessarily use less energy than all other housing options, and that an LCA that includes more energy impacts than operational energy alone must be employed to draw more complete conclusions about the sustainability of a building.

In a 2015 study exploring the life cycle impacts of passive building envelopes, Andres (2015) discusses the importance of this approach and states that "incorporation of regional based electricity grid carbon emissions factors into the PH standard would assist designers in selecting mechanical systems and fuel types with lower life cycle operating carbon impact, thus satisfying the underlying principles of the PH standard" (Andres, 2015, p. 107). 


\subsection{LCA Functional Unit}

One approach to interpreting potentially conflicting LCA results is through understanding the role of the functional unit in results analysis. Due to the large variability in form, function, and design of buildings, the most common functional unit used to compare buildings is the per- $\mathrm{m}^{2}$ or per- $\mathrm{ft}^{2}$ of floor area basis. This functional unit is the simplest way of comparing the energy performance of buildings and gives the result as an energy intensity per-unit area, allowing broad comparisons of both similar and different building typologies.

This functional unit, however convenient, can be an oversimplification, leading to misinterpretation of comparisons of performance between buildings. Some studies have shown that energy consumption per-person can decrease with an increasing number of occupants (Bastos et al., 2014). A change in a building's energy use profile due to occupancy rates can lead to a dramatically different interpretation of a building's energy performance when per-unit area is the only functional unit used for analysis. Understanding this effect is a focus of this study.

The study by Bastos et al. (2014) analyses building energy performance based on per-floor-areaper-year and per-inhabitant-per-year functional units from block-scale statistical data. The study finds that larger dwellings have lower GHG emissions and energy requirements on a per- $\mathrm{m}^{2}$ basis with similar levels of occupancy. When analysed using a per-occupant functional unit, larger buildings performed more poorly. Due to this result, the authors recommend the use of both functional units for analysis as "results expressed on a basis of built area or occupancy show the opposite trends" and could lead to differing conclusions (Bastos et al., 2014, p.352). 


\subsection{Building Size and Performance}

While it is intuitive that larger buildings generally use more energy to operate than much smaller examples, when comparing relatively similar-sized buildings, the picture becomes less clear. Conventional wisdom dictates that larger buildings are more energy and material efficient. In the PHIUS +2015 standard, for example, overall building size was not a factor considered in the development in the equations used to calculate per-area iCFA performance criteria for certification in the PHIUS +2015 program. For this reason, large buildings have the same per-area energy targets as small ones. This leads to a size bias in favour of larger sized houses and against smaller ones (given the same occupancy), as larger buildings will have an easier time meeting the energy performance criteria for certification.

As house size increases, economies of scale are expected for energy and material use. For a 2005 article, Wilson and Boehland (2005) interview the director of research at the National Association of Home Builders, Gopal Ahluwalia. Ahluwalia postulates that "because larger houses tend to have taller ceilings and more features, larger houses may actually consume proportionally more materials" (Wilson \& Boehland, 2005, p. 278). They suggest that "even if Ahluwalia's intuition is not correct and larger houses are more material-efficient per-unit area of floor, the higher ceilings and added features in large houses may mean that material use efficiency improvements with increased floor area of a house are not proportionate — that is, that the increased material efficiency one would expect from purely geometrical calculations is not realized" (Wilson \& Boehland, 2005, p. 278). These contentions are largely based on opinion and postulation, however, and given the lack of consensus on the subject, further research in this area is needed and is a focus of this study.

Wilson and Boehland (2005) also find that a smaller house built to moderate energy performance standards consumes significantly less heating and cooling energy than a very-low-energy large 
house. They find that reductions in embodied energy are easier to achieve by making the house smaller rather than by using low embodied energy materials.

While building energy codes and passive building standards aim to reduce the carbon emissions associated with buildings, Viggers et al. (2017) suggest that building size must be considered to mitigate the effects of increases in dwelling size. Additionally, a study analysing the energy use of a passive house that the focus of current certifications and directives on operational energy demand by Stephan et al. (2013) finds that operational energy accounts for less that $40 \%$ of the total life cycle energy consumption for the case study house. Therefore, ignoring the associated embodied energy can lead to an increase in overall energy demand in the built environment. In addition, a large, very efficient house can exceed the energy use of code-built but smaller house, certifications and regulations for energy efficiency won't necessarily lead to less overall energy consumption (Stephan et al. 2013).

\subsection{Summary of Literature Review}

Though literature relating directly to the focus of this study is sparse, which points to a gap in knowledge, several studies touch on some of its aspects and are discussed. The various social, economic, and environmental benefits of DADUs are explored, with the conclusion that DADUs can increase urban density which leads to lower overall GHG emissions. Further reduction in GHG emissions for DADUs can be achieved through passive design, which is discussed in detail, including a description of the original PH certification program out of Germany and the PHIUS+ 2015 program developed in North America, as well as examines the differences between them. As this study focuses on the more varied North American climate and economic conditions, the benefits of climate-specific passive design and the cost-optimal design are explored and discussed. 
To understand the energy use and GHG emissions implications for residential buildings, the differences between operational and embodied energy are discussed. It is found that the main focus for passive design is on a reduction of operational energy. As operational energy use decreases on the path to net-zero, embodied energy becomes an increasingly important consideration. Understanding the full energy implications through LCA is explored, as is the current BOK. Challenges with LCA have led to researchers developing simplification strategies to increase the effectiveness and comparability of LCAs and these strategies are adopted in the development of the methods used in completing this study. The literature reviewed demonstrates that when full LCA is performed on passive houses they can, but do not necessarily, lead to an overall reduction in energy use through the lifetime of the building. This points to the need for the implementation of LCA for a more complete understanding of building energy use and GHG emissions. Interpretation of these LCA results can be affected by the functional unit that is chosen for the analysis, and several studies are presented that show the need for per-occupant-based analysis in addition to the more common per-area-based analysis. Additionally, the effect of building size on its life cycle energy use and carbon emissions is often ignored, while research shows it to be a necessary consideration. The knowledge contained in the reviewed studies helps direct the methods used in this study. 


\section{Methods}

\subsection{Research Questions and Approach}

While the reviewed literature informs the design of this study, the methods used are developed to answer two research questions:

1. How does energy consumption and GHG emissions for passive DADUs compare to that of larger houses on a full life cycle basis?

2. How does cost-optimal passive design change for houses as the floor area reduces from $230 \mathrm{~m}^{2}\left(2,500 \mathrm{ft}^{2}\right)$ incrementally down to $30 \mathrm{~m}^{2}\left(300 \mathrm{ft}^{2}\right)$ ?

As discussed in Section 2.2, passive-built DADUs are shown to be an advantageous typology for various social, economic, and environmental reasons. Aside from zoning restrictions, a barrier to their adoption are passive building standards that discourage smaller building footprints. To eliminate this barrier, research is required exploring the differences in energy use and GHG emissions in the context of cost-optimal passive design. If passive DADUs have lower embodied and operational energy use and GHG emissions than their larger counterparts, then the size bias against them justified. However, if DADUs have lower embodied and operational energy use and GHG emissions than larger houses then the size bias against them is not justified, and an advantageous typology is being unnecessarily discouraged. As mentioned in Section 2.10 of the literature review, the conventional functional unit to analyse and understand embodied and operational energy use and GHG emissions is on a per- $\mathrm{m}^{2}$ or per- $\mathrm{ft}^{2}$ basis. As Bastos et al. (2014) recommend, the functional units used in the analysis performed as part of this study include both per-unit of floor area and per-occupant. 
The results from the study are all analysed using three functional units:

1. Per- $m^{2}$ of iCFA: This is the conventional functional unit used to compare buildings' embodied and operational energy use and GHG emissions performance.

2. Per-Occupant: The number of occupants is defined at the number of bedrooms in a house plus 1.

3. Set-Occupancy: The occupancy for all house sizes is set to 2.05 occupants (see Section 4.1.5 for discussion).

To answer this study's two research questions, this study is divided into two parts:

Part 1: An LCA using Envisioneer and Athena Impact Estimator software (Athena) to explore and compare the life cycle energy and carbon impacts of various sizes of houses below the $230 \mathrm{~m}^{2}\left(2,500 \mathrm{ft}^{2}\right)$ national average.

Part 2: A cost-optimization analysis using BEopt software to explore energy implications for various sizes of passive houses below the $230 \mathrm{~m}^{2}(2,500$ $\mathrm{ft}^{2}$ ) average for all climate zones, as well as to understand how costoptimal passive design changes with shrinking house size.

\subsection{Part 1: LCA}

The goal of the LCA is to determine how the embodied and operational energy use and GHG emissions for passive DADUs compares to that of larger houses on a full life cycle basis. Operational energy data is collected from cost-optimal BEopt results and used for the LCA. A limitation in BEopt software requires that actual modelled house floor area differs slightly from the nominal house floor areas chosen for this study, as building geometry drawing tools in BEopt have a maximum resolution of two linear feet, which leads to minor differences between nominal 
building area and modeled building area. Table 3 Geometry Details for Houses Used in LCA presents the housing sizes analysed as part of the LCA with corresponding nominal and modelled house sizes. The upper boundary of house size set to the average house size in the United states at 230 $\mathrm{m}^{2}\left(2,500 \mathrm{ft}^{2}\right)$, while the minimum size is set at $30 \mathrm{~m}^{2}\left(300 \mathrm{ft}^{2}\right)$ which is near the minimum reasonable size for a fully self-contained DADU.

Table 3 Geometry Details for Houses Used in LCA

\begin{tabular}{llllll}
\hline $\begin{array}{l}\text { Nominal House } \\
\text { Size }\left(\mathrm{m}^{2} \text { iCFA }\right)\end{array}$ & $\begin{array}{l}\text { Modeled House } \\
\text { Size }\left(\mathrm{m}^{2} \text { iCFA }\right)\end{array}$ & $\begin{array}{l}\text { Nominal House } \\
\text { Size }\left(\mathrm{ft}^{2} \text { iCFA }\right)\end{array}$ & $\begin{array}{l}\text { Modeled House } \\
\text { Size }\left(\mathrm{ft}^{2} \text { iCFA }\right)\end{array}$ & $\begin{array}{l}\text { Number of } \\
\text { Stories }\end{array}$ & $\begin{array}{l}\text { Number of } \\
\text { Bedrooms }\end{array}$ \\
\hline 230 & 228.9 & 2,500 & 2,464 & 2 & 3 \\
190 & 188.4 & 2,000 & 2,028 & 2 & 3 \\
140 & 139.0 & 1,500 & 1,496 & 2 & 3 \\
85 & 84.7 & 900 & 912 & 1 & 2 \\
65 & 64.4 & 700 & 693 & 1 & 1 \\
45 & 46.8 & 500 & 504 & 1 & 1 \\
30 & 27.3 & 300 & 294 & 1 & 1 \\
\hline
\end{tabular}

The number of stories and bedrooms chosen for each house size are based on house design norms within North America and are also presented in Table 3 Geometry Details for Houses Used in LCA.

Three locations were chosen for the LCA including Toronto, ON, Halifax, NS and Lethbridge, $\mathrm{AB}$. The number of locations available for analysis is limited in Athena, and these location choices represent locations spaced across Canada and allow for the consideration of regional differences in the results. Additionally, these locations reside in the same ASHRAE climate zone (6A). Choosing locations is the same climate zone allows a proper comparison as they share a similar passive design level and corresponding insulation values and material quantities. It is for this reason that, though Lethbridge lies in the same climate zone as Toronto and Halifax, Calgary was used for the Athena LCA analysis as it is the closest location to Lethbridge available, at only 212 
kilometers away. This represents a minor but necessary substitution due to the limitations of the software used.

Heat pumps with electricity as their energy source are used in all house models, so electrical grid emissions intensity has a significant effect the results. Grid emission intensities are presented in Table 4 Grid Emissions Intensities for Locations Used in LCA based on Athena Impact Estimator Inputs.

Table 4 Grid Emissions Intensities for Locations Used in LCA based on Athena Impact Estimator Inputs

\begin{tabular}{lc}
\hline Location & Grid Emission Intensity $\left(\mathrm{g} \mathrm{CO}_{2} \mathrm{e} / \mathrm{kWh}\right)$ \\
\hline Toronto & 320 \\
Halifax & 886 \\
Lethbridge & 971 \\
\hline
\end{tabular}

Table 5 Nominal R-values of Building Envelopes of Houses Used in LCA

\begin{tabular}{llll}
\hline & Exterior Walls & Attic & Slab \\
\hline Nominal $\mathrm{R}_{\mathrm{si}}$ & 8.1 & 14.1 & 4.2 \\
Nominal R-value & 46 & 80 & 24 \\
\hline
\end{tabular}

Envisioneer software was used to build models based on the details presented in Table 3 Geometry Details for Houses Used in LCA and Table 5 Nominal R-values of Building Envelopes of Houses Used in LCA. The nominal Rsi values used in the envelope are taken from the PHIUS +2015 guidelines for designers (PHIUS, 2017). Envisioneer allows users to build 3D models of house designs (See Appendix A) and pull detailed material quantity takeoff inventories (See Appendix B). Material quantities are gathered for the seven house sizes presented in Table 3 Geometry Details for Houses Used in LCA. Envisioneer was chosen as it allows for the creation of accurate and consistent material quantity inventories for each house size analysed in this study.

Material quantity takeoff inventories include the following components:

- Concrete foundation footings 
- Floor systems

- Structural and non-structural framing

- Wall and envelope systems

- Interior finishes

- Windows and doors

- Ceiling and roof assemblies

Not included in material quantity takeoff inventories is:

- Appliances

- HVAC systems

- Plumbing and fixtures

- Electrical and lighting systems

- Kitchen and bathroom cabinetry and fixtures

The above components and systems not included were not available in Athena's database. This is likely due to a lack of publicly available primary data on these components (Bowick, 2011). Some studies have estimated the embodied impacts from these systems are 7-13\% of total embodied GHG emissions, and 7-11\% of total embodied energy (CMHC, 2015). They are not included in this study due to a lack of reliable data, which carries a risk of reducing the reliability of the results (Soust-Verdaguer et al., 2016)

The material quantity takeoff list for each house was then imported into Athena, a software tool available to LCA practitioners that includes the high-quality material database required for consistent LCA results.

To understand and account for the effects that different material choices available to designers and builders have on embodied energy use and GHG emissions results, each house size and location 
was modeled using high, medium, and low embodied energy material build packages. The material choices selected for each of the build packages is presented in Table 6 Material Choices for High, Medium, and Low Embodied Energy Build Packages.

Table 6 Material Choices for High, Medium, and Low Embodied Energy Build Packages

\begin{tabular}{|c|c|c|c|c|c|c|c|c|}
\hline $\begin{array}{l}\text { High } \\
\text { Embodied } \\
\text { Energy }\end{array}$ & $\begin{array}{l}\text { Embodied } \\
\text { Energy }\end{array}$ & $\begin{array}{l}\text { GHG } \\
\text { Emissions }\end{array}$ & $\begin{array}{l}\text { Medium } \\
\text { Embodied } \\
\text { Energy }\end{array}$ & $\begin{array}{l}\text { Embodied } \\
\text { Energy }\end{array}$ & $\begin{array}{l}\text { GHG } \\
\text { Emissions }\end{array}$ & $\begin{array}{l}\text { Low } \\
\text { Embodied } \\
\text { Energy }\end{array}$ & $\begin{array}{l}\text { Embodie } \\
\text { d Energy }\end{array}$ & $\begin{array}{l}\text { GHG } \\
\text { Emissions }\end{array}$ \\
\hline Clay Tile & $\begin{array}{l}635 \\
\left(\mathrm{MJ} / \mathrm{m}^{2}\right)\end{array}$ & $\begin{array}{l}39.2 \\
\left(\mathrm{~kg} \mathrm{CO} \mathrm{CO}_{2} \mathrm{e} \mathrm{m}^{2}\right)\end{array}$ & $\begin{array}{l}\text { Metal Roof } \\
\text { Cladding }\end{array}$ & $\begin{array}{l}326 \\
\left(\mathrm{MJ} / \mathrm{m}^{2}\right)\end{array}$ & $\begin{array}{l}17.4 \\
\left(\mathrm{~kg} \mathrm{CO} 2 \mathrm{e} / \mathrm{m}^{2}\right)\end{array}$ & $\begin{array}{l}\text { Cedar } \\
\text { Shakes }\end{array}$ & $\begin{array}{l}321 \\
\left(\mathrm{MJ} / \mathrm{m}^{2}\right)\end{array}$ & $\begin{array}{l}17.2 \\
\left(\mathrm{~kg} \mathrm{CO} 2 \mathrm{e} / \mathrm{m}^{2}\right)\end{array}$ \\
\hline $\begin{array}{l}\text { XPS Foam } \\
\text { Board }\end{array}$ & $\begin{array}{l}76.3 \\
\left(\mathrm{MJ} / \mathrm{m}^{2}[25\right. \\
\mathrm{mm}])\end{array}$ & $\begin{array}{l}3.9 \\
\left(\mathrm{~kg} \mathrm{CO} \mathrm{CO}_{2} \mathrm{e} / \mathrm{m}^{2}\right. \\
[25 \mathrm{~mm}])\end{array}$ & $\begin{array}{l}\text { Blown } \\
\text { Fiberglass }\end{array}$ & $\begin{array}{l}7.2 \\
\left(\mathrm{MJ} / \mathrm{m}^{2}[25\right. \\
\mathrm{mm}])\end{array}$ & $\begin{array}{l}0.3 \\
\left(\mathrm{~kg} \mathrm{CO}{ }_{2} \mathrm{e} / \mathrm{m}^{2}\right. \\
[25 \mathrm{~mm}])\end{array}$ & $\begin{array}{l}\text { Blown } \\
\text { Cellulose }\end{array}$ & $\begin{array}{l}2.5 \\
\left(\mathrm{MJ} / \mathrm{m}^{2}\right. \\
[25 \mathrm{~mm}])\end{array}$ & $\begin{array}{l}0.2 \\
\left(\mathrm{~kg} \mathrm{CO}_{2} \mathrm{e} / \mathrm{m}^{2}\right. \\
[25 \mathrm{~mm}])\end{array}$ \\
\hline $\begin{array}{l}\text { Advanced } \\
\text { Softwood }\end{array}$ & $\begin{array}{l}2,570 \\
\left(\mathrm{MJ} / \mathrm{m}^{3}\right)\end{array}$ & $\begin{array}{l}103 \\
\left(\mathrm{~kg} \mathrm{CO}{ }_{2} \mathrm{e} / \mathrm{m}^{3}\right)\end{array}$ & $\begin{array}{l}\text { Advanced } \\
\text { Softwood }\end{array}$ & $\begin{array}{l}2,570 \\
\left(\mathrm{MJ} / \mathrm{m}^{3}\right)\end{array}$ & $\begin{array}{l}103 \\
\left(\mathrm{~kg} \mathrm{CO} 2 \mathrm{e} / \mathrm{m}^{3}\right)\end{array}$ & $\begin{array}{l}\text { Advanced } \\
\text { Softwood }\end{array}$ & $\begin{array}{l}2,570 \\
\left(\mathrm{MJ} / \mathrm{m}^{3}\right)\end{array}$ & $\begin{array}{l}103 \\
\left(\mathrm{~kg} \mathrm{CO} \mathrm{CO}_{2} / \mathrm{m}^{3}\right)\end{array}$ \\
\hline $\mathrm{n} / \mathrm{a}$ & $\mathrm{n} / \mathrm{a}$ & $\mathrm{n} / \mathrm{a}$ & $\begin{array}{l}\text { Mineral Wool } \\
\text { Batt }\end{array}$ & $\begin{array}{l}27.1 \\
\left(\mathrm{MJ} / \mathrm{m}^{2}[25\right. \\
\mathrm{mm}])\end{array}$ & $\begin{array}{l}1.6 \\
\left(\mathrm{~kg} \mathrm{CO} \mathrm{CO}_{2} \mathrm{e} / \mathrm{m}^{2}\right. \\
[25 \mathrm{~mm}])\end{array}$ & $\begin{array}{l}\text { Blown } \\
\text { Cellulose }\end{array}$ & $\begin{array}{l}2.5 \\
\left(\mathrm{MJ} / \mathrm{m}^{2}\right. \\
[25 \mathrm{~mm}])\end{array}$ & $\begin{array}{l}0.2 \\
\left(\mathrm{~kg} \mathrm{CO}_{2} \mathrm{e} / \mathrm{m}^{2}\right. \\
[25 \mathrm{~mm}])\end{array}$ \\
\hline $\begin{array}{l}\text { XPS Foam } \\
\text { Board }\end{array}$ & $\begin{array}{l}76.3 \\
\left(\mathrm{MJ} / \mathrm{m}^{2}[25\right. \\
\mathrm{mm}])\end{array}$ & $\begin{array}{l}3.9 \\
\left(\mathrm{~kg} \mathrm{CO} \mathrm{CO}_{2} \mathrm{e} \mathrm{m}^{2}\right. \\
[25 \mathrm{~mm}])\end{array}$ & $\begin{array}{l}\text { Mineral Wool } \\
\text { Board }\end{array}$ & $\begin{array}{l}27.1 \\
\left(\mathrm{MJ} / \mathrm{m}^{2}[25\right. \\
\mathrm{mm}])\end{array}$ & $\begin{array}{l}1.6 \\
\left(\mathrm{~kg} \mathrm{CO}{ }_{2} \mathrm{e} / \mathrm{m}^{2}\right. \\
[25 \mathrm{~mm}])\end{array}$ & $\mathrm{n} / \mathrm{a}$ & $\mathrm{n} / \mathrm{a}$ & $\mathrm{n} / \mathrm{a}$ \\
\hline Brick Veneer & $\begin{array}{l}504 \\
\left(\mathrm{MJ} / \mathrm{m}^{2}\right)\end{array}$ & $\begin{array}{l}36.1 \\
\left(\mathrm{~kg} \mathrm{CO}_{2} \mathrm{e} / \mathrm{m}^{2}\right)\end{array}$ & Vinyl & $\begin{array}{l}220 \\
\left(\mathrm{MJ} / \mathrm{m}^{2}\right)\end{array}$ & $\begin{array}{l}8.9 \\
\left(\mathrm{~kg} \mathrm{CO}{ }_{2} \mathrm{e} / \mathrm{m}^{2}\right)\end{array}$ & Pine Wood & $\begin{array}{l}156 \\
\left(\mathrm{MJ} / \mathrm{m}^{2}\right)\end{array}$ & $\begin{array}{l}8.2 \\
\left(\mathrm{~kg} \mathrm{CO} \mathrm{CO}_{2} \mathrm{e} / \mathrm{m}^{2}\right)\end{array}$ \\
\hline $\begin{array}{l}\text { Gypsum Wall } \\
\text { Board }\end{array}$ & $\begin{array}{l}45.0 \\
\left(\mathrm{MJ} / \mathrm{m}^{2}\right)\end{array}$ & $\begin{array}{l}2.6 \\
\left(\mathrm{~kg} \mathrm{CO}{ }_{2} \mathrm{e} / \mathrm{m}^{2}\right)\end{array}$ & $\begin{array}{l}\text { Gypsum Wall } \\
\text { Board }\end{array}$ & $\begin{array}{l}45.0 \\
\left(\mathrm{MJ} / \mathrm{m}^{2}\right)\end{array}$ & $\begin{array}{l}2.6 \\
\left(\mathrm{~kg} \mathrm{CO} 2 \mathrm{e} / \mathrm{m}^{2}\right)\end{array}$ & $\begin{array}{l}\text { Gypsum } \\
\text { Wall Board }\end{array}$ & $\begin{array}{l}45.0 \\
\left(\mathrm{MJ} / \mathrm{m}^{2}\right)\end{array}$ & $\begin{array}{l}2.6 \\
\left(\mathrm{~kg} \mathrm{CO} 2 \mathrm{e} / \mathrm{m}^{2}\right)\end{array}$ \\
\hline Hardwood & $\begin{array}{l}57.3 \\
\left(\mathrm{MJ} / \mathrm{m}^{2}\right)\end{array}$ & $\begin{array}{l}3.2 \\
\left(\mathrm{~kg} \mathrm{CO} \mathrm{CO}_{2} \mathrm{e} / \mathrm{m}^{2}\right)\end{array}$ & Hardwood & $\begin{array}{l}57.3 \\
\left(\mathrm{MJ} / \mathrm{m}^{2}\right)\end{array}$ & $\begin{array}{l}3.2 \\
\left.\mathrm{CO}_{2} \mathrm{e} / \mathrm{m}^{2}\right)\end{array}$ & Hardwood & $\begin{array}{l}57.3 \\
\left(\mathrm{MJ} / \mathrm{m}^{2}\right)\end{array}$ & $\begin{array}{l}3.2 \\
\left(\mathrm{~kg} \mathrm{CO} \mathrm{CO}_{2} \mathrm{e} \mathrm{m}^{2}\right)\end{array}$ \\
\hline $\begin{array}{l}\text { Concrete } \\
\text { Slab-on-grade }\end{array}$ & $\begin{array}{l}3,260 \\
\left(\mathrm{MJ} / \mathrm{m}^{3}\right)\end{array}$ & $\begin{array}{l}349 \\
\left(\mathrm{~kg} \mathrm{CO} \mathrm{CO}_{2} \mathrm{e} / \mathrm{m}^{3}\right)\end{array}$ & $\begin{array}{l}\text { Concrete } \\
\text { Slab-on-grade }\end{array}$ & $\begin{array}{l}3,260 \\
\left(\mathrm{MJ} / \mathrm{m}^{3}\right)\end{array}$ & $\begin{array}{l}349 \\
\left(\mathrm{~kg} \mathrm{CO}_{2} \mathrm{e} / \mathrm{m}^{3}\right)\end{array}$ & $\begin{array}{l}\text { Preserved } \\
\text { Wood }\end{array}$ & $\begin{array}{l}2,570 \\
\left(\mathrm{MJ} / \mathrm{m}^{3}\right)\end{array}$ & $\begin{array}{l}103 \\
\left(\mathrm{~kg} \mathrm{CO}_{2} \mathrm{e} / \mathrm{m}^{3}\right)\end{array}$ \\
\hline EPS Foam & $\begin{array}{l}38.2 \\
\left(\mathrm{MJ} / \mathrm{m}^{2}[25\right. \\
\mathrm{mm}])\end{array}$ & $\begin{array}{l}2.0 \\
\left(\mathrm{~kg} \mathrm{CO} \mathrm{CO}_{2} \mathrm{e} / \mathrm{m}^{2}\right. \\
[25 \mathrm{~mm}])\end{array}$ & EPS Foam & $\begin{array}{l}38.2 \\
\left(\mathrm{MJ} / \mathrm{m}^{2}[25\right. \\
\mathrm{mm}])\end{array}$ & $\begin{array}{l}2.0 \\
\left(\mathrm{~kg} \mathrm{CO}{ }_{2} \mathrm{e} / \mathrm{m}^{2}\right. \\
[25 \mathrm{~mm}])\end{array}$ & $\begin{array}{l}\text { Blown } \\
\text { Cellulose }\end{array}$ & $\begin{array}{l}2.5 \\
\left(\mathrm{MJ} / \mathrm{m}^{2}\right. \\
[25 \mathrm{~mm}])\end{array}$ & $\begin{array}{l}0.2 \\
\left(\mathrm{~kg} \mathrm{CO}_{2} \mathrm{e} / \mathrm{m}^{2}\right. \\
[25 \mathrm{~mm}])\end{array}$ \\
\hline
\end{tabular}

Material choices were constrained to common construction practices and material suitability in North America. General assembly details were kept as consistent as possible between the build packages to help ensure valid comparisons. Though concrete footings and slab-on-grade foundations were modeled with EPS foam insulation for high and medium embodied energy build packages, and preserved wood foundation at-grade with blown cellulose insulation for the low embodied energy build package, all other assemblies are substantially similar. For example, 
gypsum wall board is used as the interior sheathing for all scenarios as this is by far the most common system used in North America.

In addition to material quantities, other inputs into the Athena models included:

- A building life span of 70 years, which represents a reasonably long lifetime for a house and is justified due to the durability, comfort, energy efficiency, and quality inherent in a passive house. In 2012, Aktas and Bilec found the average lifespan of single-detached houses in the US to be 61 years, with a steadily increasing upward trend (Aktas \& Bilec, 2012).

- BEopt software was used to generate operational energy data from an optimization that was run for each location and house size to represent the cost-optimal passive levels of energy use.

The material takeoff quantities, location and operational energy data were entered into Athena models and analysis performed for all 63 size, location, and material build package combinations. The boundaries used for the LCA included the following life cycle stages, as recommended by Chau et al. in 2015 and Wittstock et al. in 2012:

- Product (manufacturing and transport)

- Construction process (construction-installation process and transport)

- Use (replacement manufacturing, replacement transport, and operational energy use total)

- End of life (de-construction, demolition, disposal and waste processing, and transport)

- Beyond building life (bbl material, bbl transport)

The results from the Athena LCA include the embodied carbon (a.k.a. global warming potential in $\mathrm{CO}_{2} \mathrm{e}$ ) and embodied primary energy (in $\mathrm{MJ}$ ).

The results from the Athena LCA were then analysed to answer the first research question and understand how embodied and operational energy use and GHG emissions for passive DADUs 
compares to that of larger houses on a full life cycle basis. Comparisons were then made between house sizes and their embodied energy use and GHG emission impacts. These results were analysed using three different functional units: Per-area, per-occupant, and per-set-occupancy. Results from this analysis are presented in Section 4.1.

\subsection{Part 2: BEopt Cost-Optimization Study}

The BEopt cost-optimization serves two functions. Firstly, operational energy outputs are used to further explore what effect house size has on building energy performance based on the three functional units described in Section 3.1. Secondly, the BEopt analysis seeks to understand how cost-optimal passive design for passive DADUs changes as the floor area is incrementally reduced from the $230 \mathrm{~m}^{2}\left(2,500 \mathrm{ft}^{2}\right)$ national average to $30 \mathrm{~m}^{2}\left(300 \mathrm{ft}^{2}\right)$.

This study builds on the 2014 work of Wright et al. (2014), from which the PHIUS 2015 standard was developed. To maintain comparable results, some of the methods used in the development of the PHIUS+ 2015 BEopt optimization study are followed to create comparable results. The climate-specific cost-optimal approach to passive design taken by Wright et al. (2014) is rigorous from a building science perspective and is well-suited to North American climate zones. These similar methods are applied to a variety of smaller building sizes in order to show how smaller houses designed to the PHIUS+ (2015) passive standard compare to larger ones.

BEopt is a software tool developed by the DOE that uses EnergyPlus as its energy modelling simulation engine. The software allows for, in optimization mode, multi-objective cost-based optimization that finds minimum-cost building designs at various energy-saving levels. Nguyen, Reiter, and Rigo (2014) state that BEopt offers several strengths for optimization as the software allows the user to perform multi-objective optimization runs that feature many year-long energy 
simulations based on used-defined upgrade packages to determine "economically-valid energy saving solutions" (Nguyen, Reiter, \& Rigo, 2014, p. 1056). This study chooses the minimum cost upgrade package that offers the lowest total energy-related costs annualised in combination with the highest energy savings.

The length of the 70-year time frame of this study requires that the time value of money and future fuel cost increases be addressed in the economic analysis performed as part of the BEopt costoptimization study. As such, the fuel escalation rate is set at a $1.04 \%$ increase per year. Annualized costs for the study are calculated by converting them to cash flows based on present worth using the nominal discount rate calculated using the following formula, with the inflation rate set at $2.4 \%$, and the discount rate (real) set at $2.0 \%$ :

\section{Nominal Discount Rate $=(1+$ Real Discount Rate $) \times(1+$ Inflation Rate $)-1$}

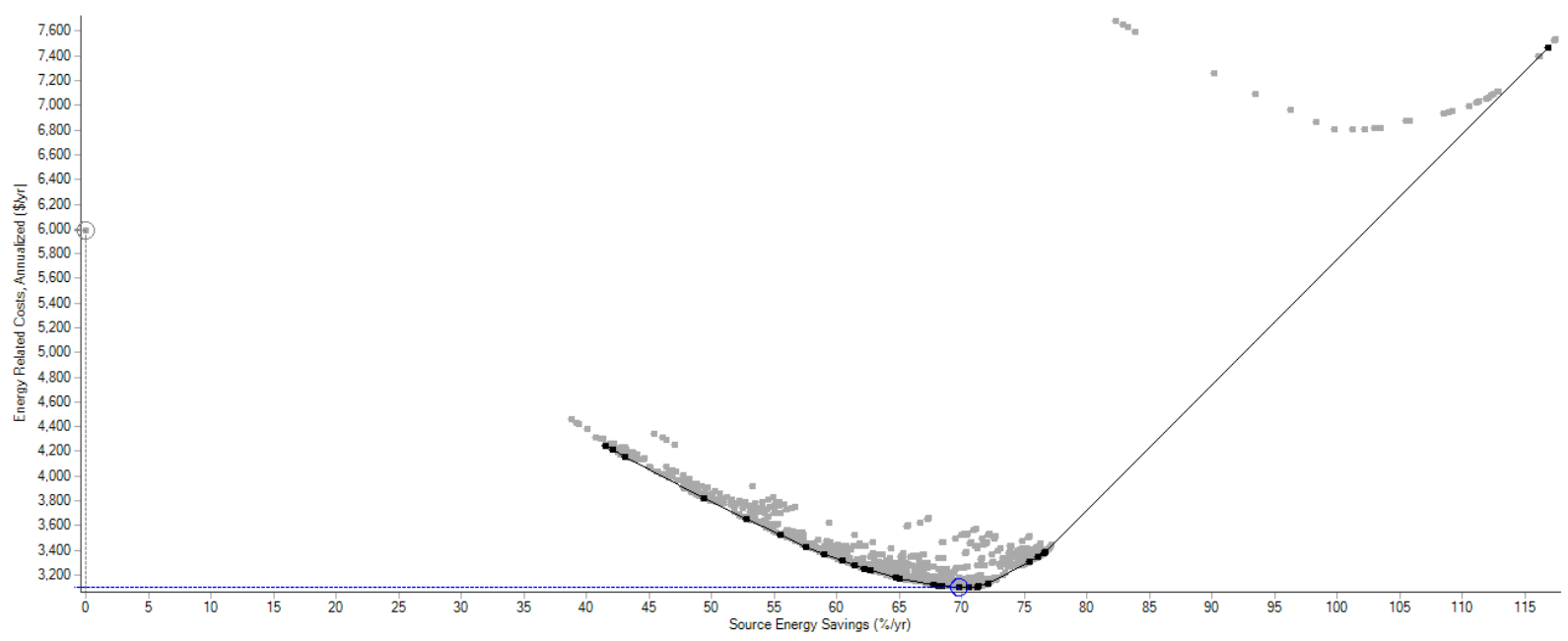

Figure 2 BEopt Cost-Optimization Analysis Output

Table 7 Geometry Details for Houses Used for BEopt Optimization Study presents the geometry details of the various house sizes used in this study. House dimensions follow an aspect ratio of 3:2, with 
the

narrow

sides

facing

North-South.

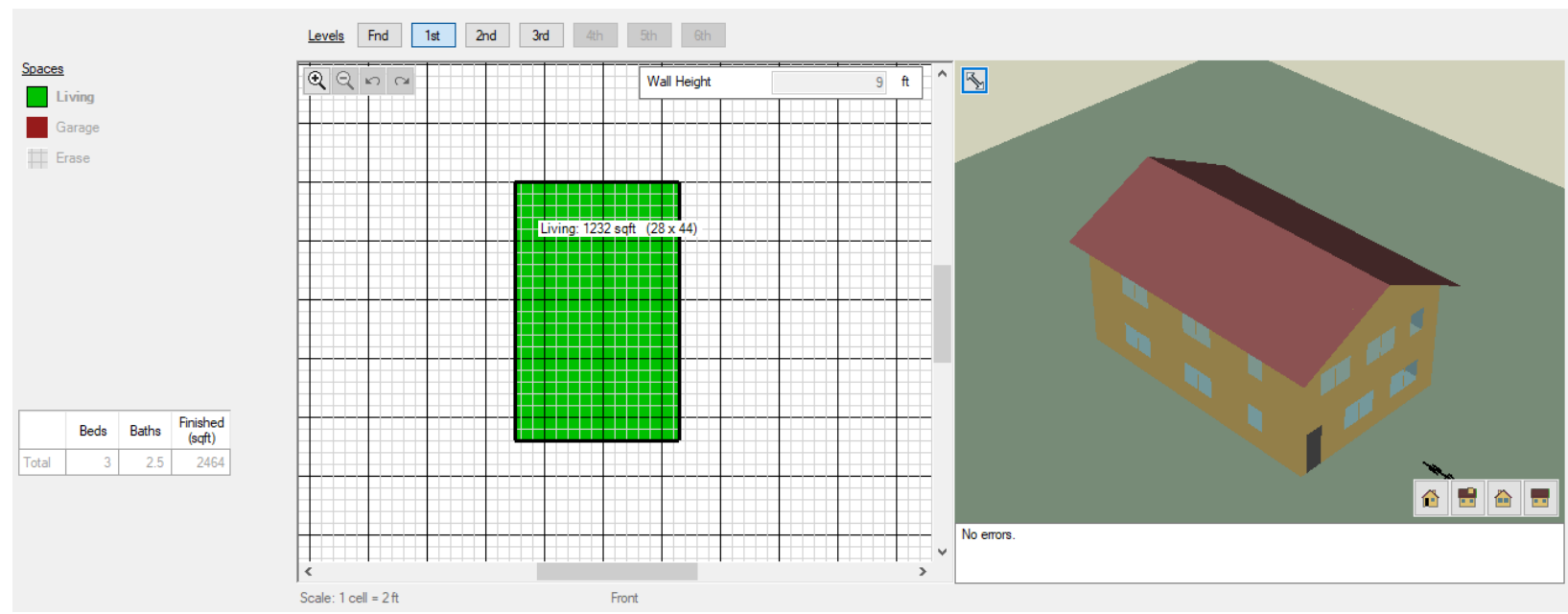

Figure 3 BEopt House Model Design

Table 7 Geometry Details for Houses Used for BEopt Optimization Study

\begin{tabular}{llllll}
\hline $\begin{array}{l}\text { Nominal House } \\
\text { Size }\left(\mathrm{m}^{2} \text { iCFA }\right)\end{array}$ & $\begin{array}{l}\text { Modeled House } \\
\text { Size }\left(\mathrm{m}^{2} \text { iCFA }\right)\end{array}$ & $\begin{array}{l}\text { Nominal House } \\
\text { Size }\left(\mathrm{ft}^{2} \text { iCFA) }\right.\end{array}$ & $\begin{array}{l}\text { Modeled House } \\
\text { Size }\left(\mathrm{ft}^{2} \text { iCFA) }\right.\end{array}$ & $\begin{array}{l}\text { Number of } \\
\text { Stories }\end{array}$ & $\begin{array}{l}\text { Number of } \\
\text { Bedrooms }\end{array}$ \\
\hline 230 & 228.9 & 2,500 & 2,464 & 2 & 3 \\
190 & 188.4 & 2,000 & 2,028 & 2 & 3 \\
140 & 139.0 & 1,500 & 1,496 & 2 & 3 \\
85 & 84.7 & 900 & 912 & 1 & 2 \\
75 & 74.8 & 800 & 805 & 1 & 2 \\
65 & 64.4 & 700 & 693 & 1 & 1 \\
55 & 55.7 & 600 & 600 & 1 & 1 \\
45 & 46.8 & 500 & 504 & 1 & 1 \\
35 & 37.2 & 400 & 400 & 1 & 1 \\
30 & 27.3 & 300 & 294 & 1 & 1 \\
\hline
\end{tabular}

Table 8 Locations and Weather Data Used in BEopt Optimization Study shows the location and weather information for the various locations and their associate climate zone used in the BEopt optimization study. These specific locations were chosen as they represent approximate averages for their respective climate zones (Wright et al., 2014). 
Table 8 Locations and Weather Data Used in BEopt Optimization Study

\begin{tabular}{llll}
\hline ASHRAE Climate Zone & Location & Weather Data & Weather Data Set \\
\hline 1A & Miami, FL & Miami IAP & TMY3, 722020 \\
1B & Riyadh, SAU & Riyadh & IWEC, 404380 \\
2A & Houston, TX & Houston-Bush IAP & TMY3, 722430 \\
2B & Phoenix, AZ & Sky Harbor IAP & TMY3, 722780 \\
3A & Memphis, TN & Memphis IAP & TMY3, 723340 \\
3B & El Paso, TX & El Paso IAP & TMY3, 722700 \\
3C & San Francisco, CA & San Francisco IAP & TMY3, 724940 \\
4A & Baltimore, MD & Baltimore Washington IAP & TMY3, 724060 \\
4B & Albuquerque, NM & Albuquerque IAP & TMY3, 723650 \\
4C & Salem, OR & Salem McNary AP & TMY3, 726940 \\
5A & Chicago, IL & Chicago O'Hare IAP & TMY3, 725300 \\
5B & Boise, ID & Boise AP & TMY3, 726810 \\
5C & Vancouver, BC & Vancouver IAP & CWEK, 718920 \\
6A & Burlington, VT & Burlington IAP & TMY3, 726170 \\
6B & Helena, MT & Helena AP & TMY3, 727720 \\
7 & Duluth, MN & Duluth IAP & TMY3, 727450 \\
8 & Fairbanks, AK & Fairbanks IAP & TMY3, 702610 \\
\hline
\end{tabular}

In order to reduce the large number of calculations required for the BEopt optimization study, upgrade packages were limited to those that are appropriate for passive design in each climate and these upgrades vary with by climate zone (See Appendix C). EnergyPlus simulations were run with 60 minutes time steps. Even with these strategies to limit computational resources required, processor time was significant.

A 32-core workstation computer was used for the BEopt optimization simulations, along with additional cloud-based resources. Even with additional computational resources the 170 cases representing 10 house sizes in 17 climate zones took six weeks to run, as the total number of yearlong energy simulation was over 100,000 . These simulations resulted in large data sets, and the 
results relating to optimal design package details, carbon emissions, and energy use were extracted for further analysis.

Data was analysed to understand how operational energy for passive DADUs compared to that of the average-sized house designed to passive standards. The three functional units described in Section 3.1 were used to understand their influence on the interpretation of building performance results. The occupancy profile used in the BEopt simulation was where the number of occupants of a house is equal to the number of bedrooms plus 1 as described in Section 3.1. For the setoccupancy analysis, cost-optimal packages were re-run with 2.05 occupants per house to ensure correct internal heat gain and occupant energy use.

In order to compare these differences, each house model's cost-optimal wall, ceiling, foundation, door, and window assembly was modeled in HOT2000 software's code editor to determine each envelope component's effective U-value. A weighted average overall U-value for each house was then calculated using each envelope component's U-value contribution calculated based on its share of overall envelope surface area.

Data was also analysed to understand how cost-optimal passive design changes as passive DADUs shrink from the average $230 \mathrm{~m}^{2}\left(2,500 \mathrm{ft}^{2}\right)$ down to $30 \mathrm{~m}^{2}\left(300 \mathrm{ft}^{2}\right)$. To answer this research question, differences between cost-optimal design packages for houses of different sizes within each climate zone are analysed by plotting results. Results from the BEopt study are presented in Section 4.2. 


\section{Results}

\subsection{Part 1: Life Cycle Analysis}

\subsubsection{Embodied Vs. Operational Life Cycle Energy}

Results from the LCA performed as part of this research highlighting differences between embodied and operational life cycle energy for house sizes from $230 \mathrm{~m}^{2}\left(2,500 \mathrm{ft}^{2}\right)$ to $30 \mathrm{~m}^{2}(300$ $\mathrm{ft}^{2}$ ) in Toronto, Halifax, and Lethbridge are presented in Figure 4 Embodied and Operational Life Cycle Energy for Various Passive House Sizes in Toronto through Figure 6 Embodied and Operational Life Cycle Energy for Various Passive House Sizes in Lethbridge.

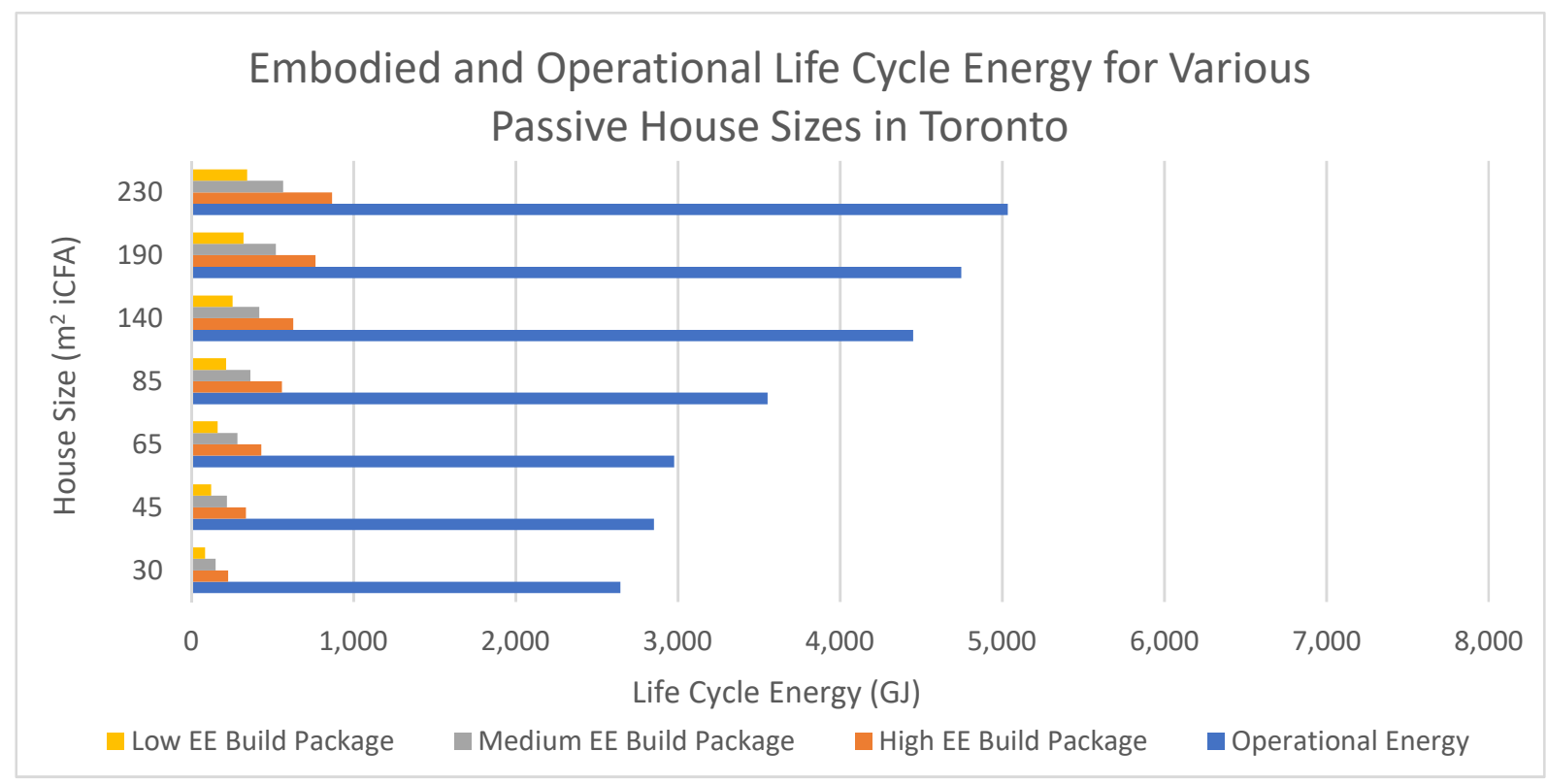

Figure 4 Embodied and Operational Life Cycle Energy for Various Passive House Sizes in Toronto 


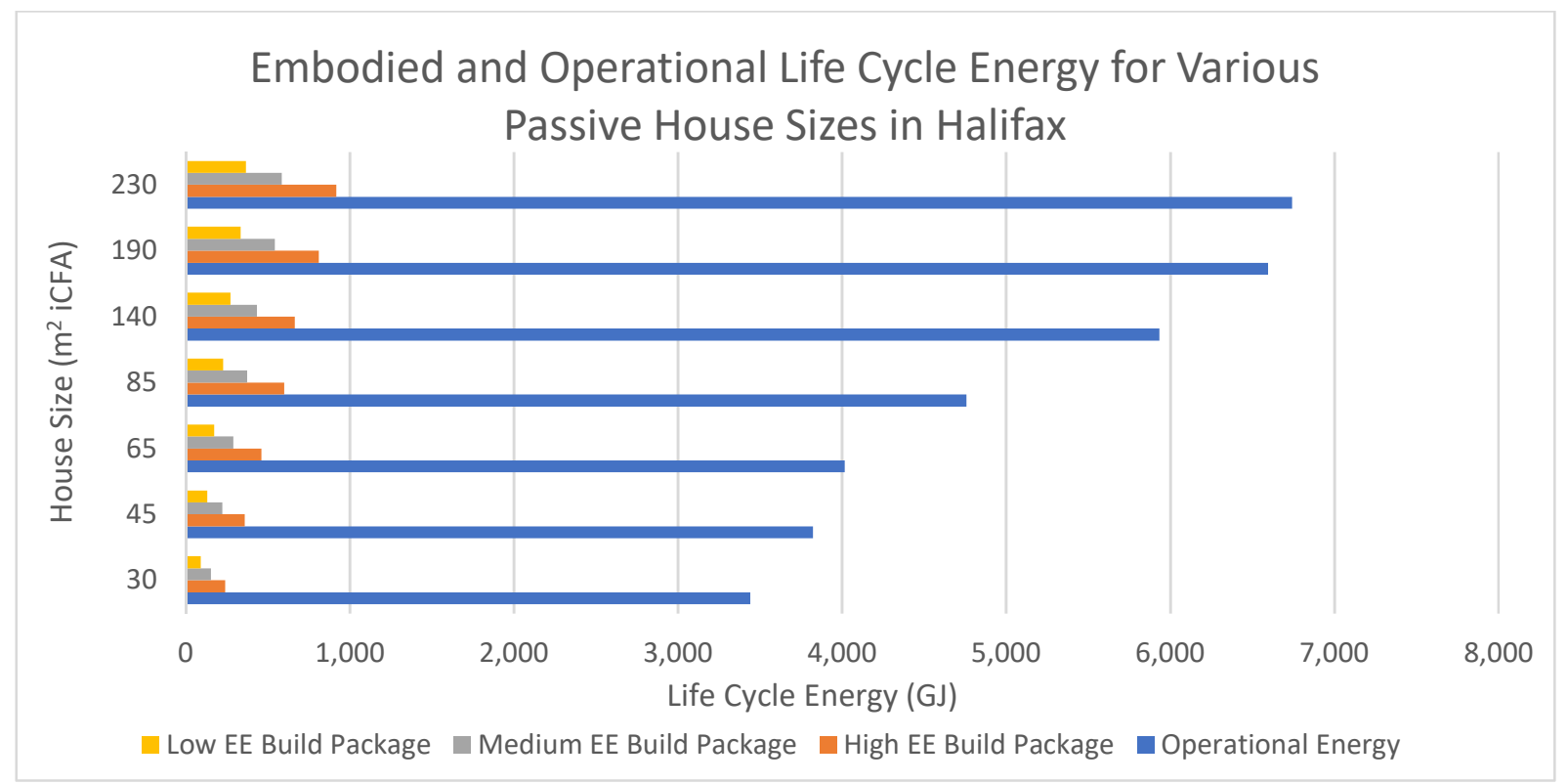

Figure 5 Embodied and Operational Life Cycle Energy for Various Passive House Sizes in Halifax

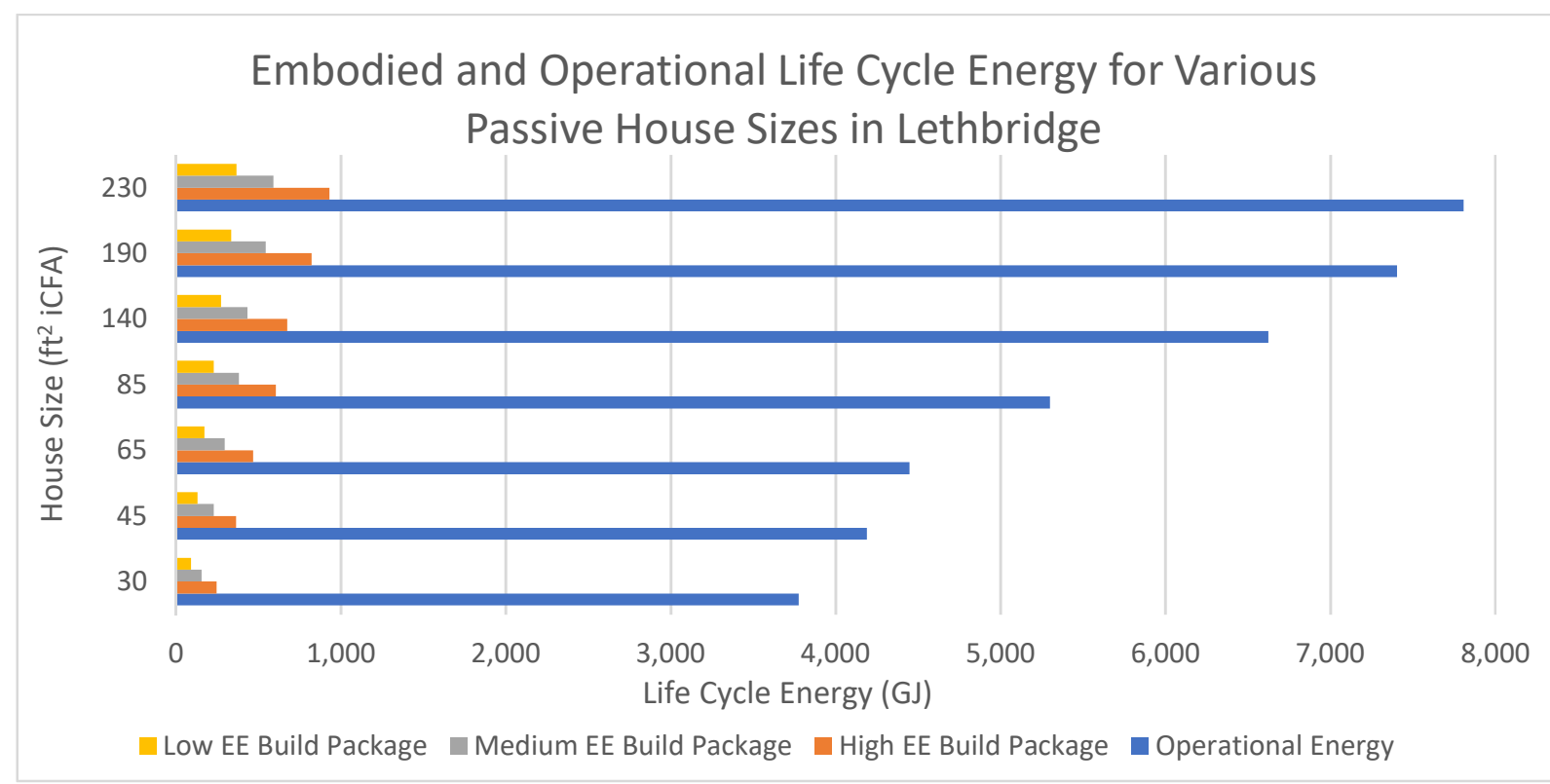

Figure 6 Embodied and Operational Life Cycle Energy for Various Passive House Sizes in Lethbridge

Results from the three locations are consistent, apart from the absolute quantity of life cycle energy use in Toronto being significantly lower than in Halifax or Lethbridge. Results show embodied and operational energy use increasing with house size at a decreasing rate. Embodied energy from 
the medium embodied energy build package results always fall between the high and low embodied build packages results, as expected. The maximum deviation of the medium embodied energy build package from the mean between the high and low build packages is only $1.5 \%$ of the total life cycle energy. The medium build package's embodied energy results consistently lie between the high and low build package results. Therefore, to simplify analysis, the medium embodied energy build package is used throughout, as it represents a good average embodied energy for a given house size.

Embodied energy is found to be significantly lower than operational energy for all locations and house sizes. Average embodied energy results for all house sizes and build packages represent only 7\% of total life cycle energy in Toronto, and 6\% in Halifax and Lethbridge. At such a small share of total life cycle energy, the differences in embodied energy results from the three build packages have little effect on the overall life cycle energy use and GHG emissions results. On their own, the embodied energy results from the three build packages varied significantly. The high embodied energy build package was an average of a 51\% higher than the medium embodied energy build package, while the low embodied energy build package was only an average of $43 \%$ of the medium embodied energy build package. The high embodied energy build package used 2.5 times more embodied energy than the low embodied energy build package.

On average, operational energy is lowest in Toronto, and higher in Halifax by $34 \%$, and in Lethbridge by $51 \%$. Toronto also shows the lowest embodied energy, with Halifax being $3.1 \%$ higher, in Lethbridge $4.2 \%$ higher.

These results are a significant departure from previous studies on the embodied vs. operational energy for passive and low-energy buildings. While this study found that operational energy represents an average of $93.5 \%$ of the total life cycle energy across all house sizes and locations, 
other studies find a lower share for operational energy. In a 2013 study, Stephan et al. found "embodied energy of passive houses can represent up to $77 \%$ of the total embodied and operational energy over 100 years" (Stephan et al., 2013, p. 23). In a 2012 review looking at several studies on embodied vs. operational energy use in buildings, Sartori and Hestnes found in 2012 that Passive buildings' operational energy use represented only $69 \%$ of the total life cycle energy (Sartori \& Hestnes, 2007). This result is discussed further in Section 5.1.

\subsubsection{Embodied Vs. Operational Life Cycle GHG Emissions}

Results from the LCA performed in this study highlighting differences between embodied and operational life cycle GHG emissions for house sizes from $230 \mathrm{~m}^{2}\left(2,500 \mathrm{ft}^{2}\right)$ to $30 \mathrm{~m}^{2}\left(300 \mathrm{ft}^{2}\right)$ in Toronto, Halifax, and Lethbridge are presented in Figure 7 Embodied and Operational Life Cycle GHG Emissions for Various Passive House Sizes in Toronto through Figure 9 Embodied and Operational Life Cycle GHG Emissions for Various Passive House Sizes in Lethbridge.

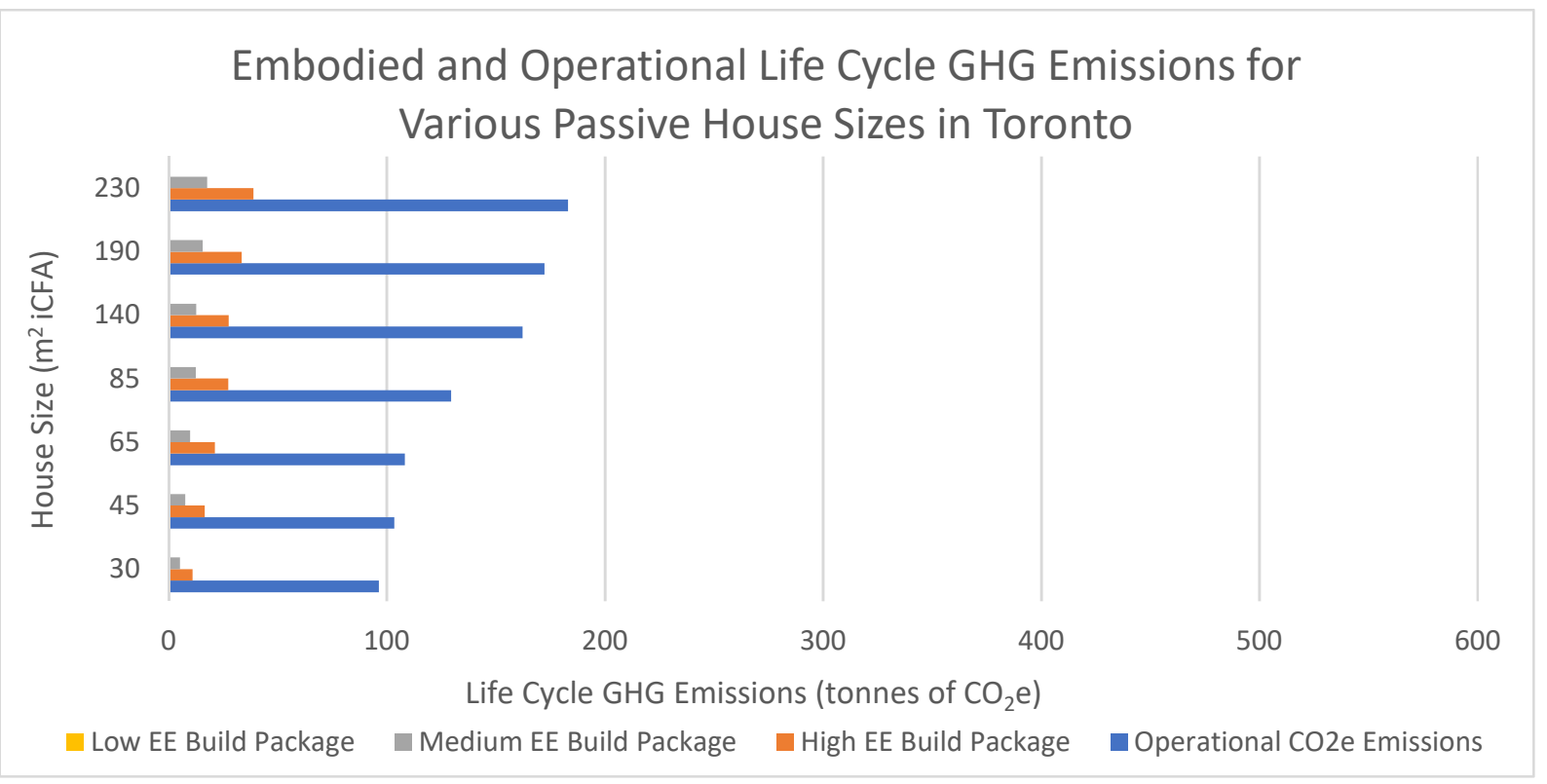

Figure 7 Embodied and Operational Life Cycle GHG Emissions for Various Passive House Sizes in Toronto 


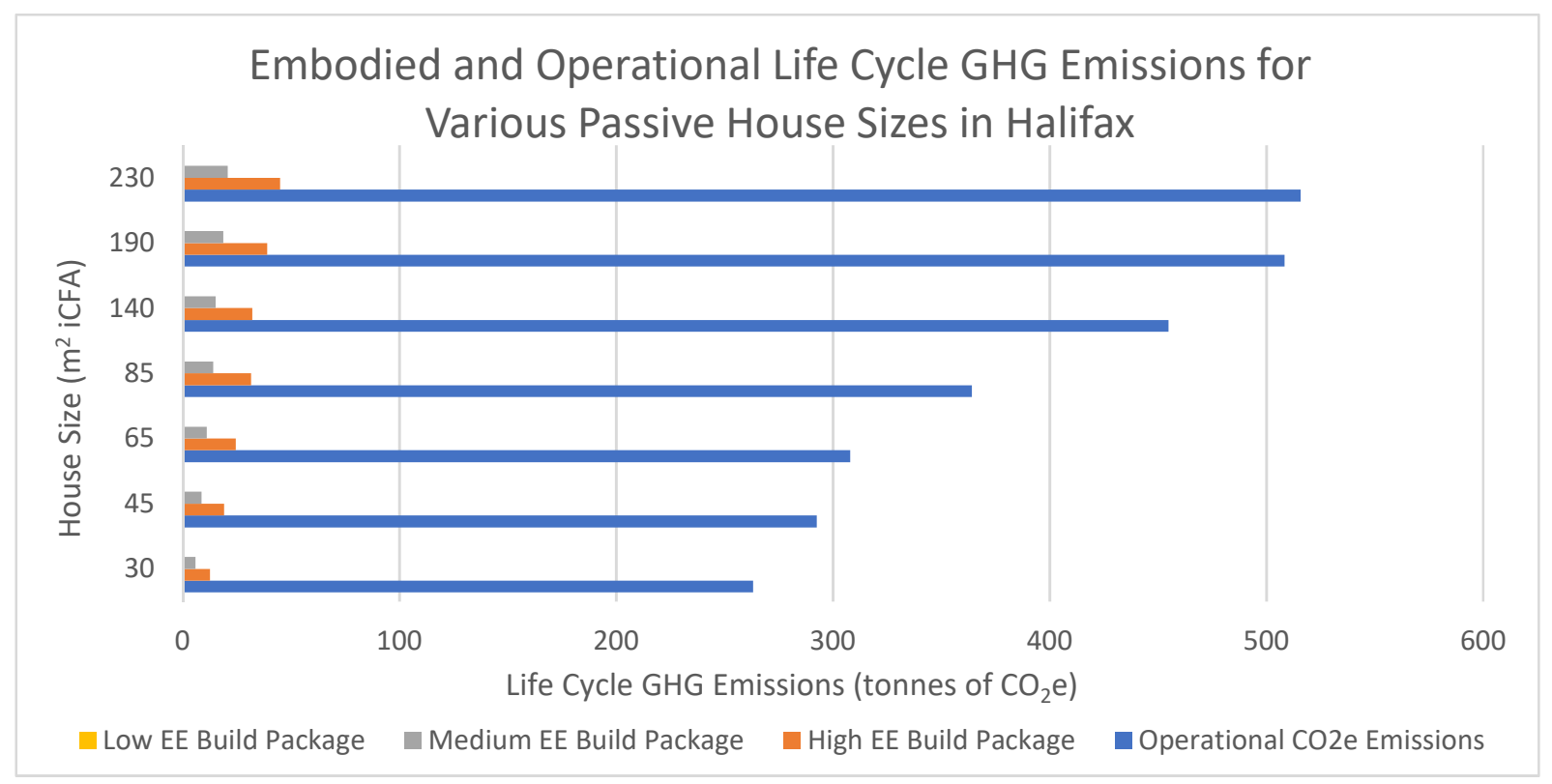

Figure 8 Embodied and Operational Life Cycle GHG Emissions for Various Passive House Sizes in Halifax

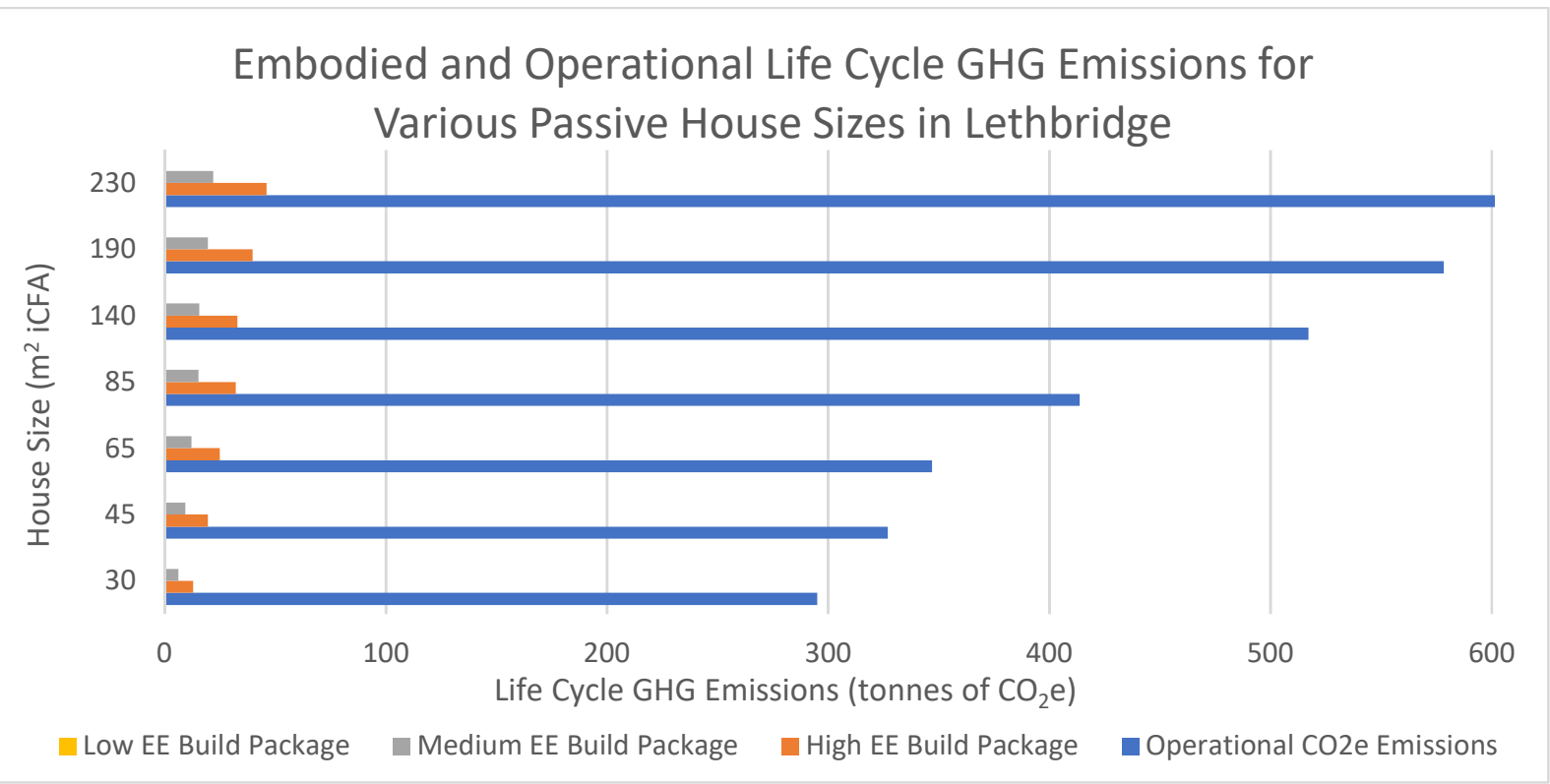

Figure 9 Embodied and Operational Life Cycle GHG Emissions for Various Passive House Sizes in Lethbridge

Results for life cycle GHG emissions are similar to those for life cycle energy, with embodied and operational emissions both increasing as house size increases but at a decreasing rate. Results again 
show that embodied effects are significantly smaller than operational ones. Embodied GHG emissions make up between $2 \%$ and $9 \%$ of total life cycle GHG emissions, with the average being $4.7 \%$ across all house sizes and locations.

On average, operational GHG emissions are lowest in Toronto, with Halifax being higher by $183 \%$, and Lethbridge higher by $223 \%$. Embodied GHG emissions are also lowest in Toronto, with Halifax being $15.7 \%$ higher and Lethbridge being $23.6 \%$ higher. The medium embodied energy build package has GHG emissions that fall consistently between the high and low build packages and represents a good average for the purposes of analysis.

\subsubsection{Total Life Cycle Energy and Emissions Per-Area}

Results from the LCA showing total life cycle energy and emissions for various sizes of costoptimal passive houses constructed using the medium embodied energy build package are presented using a per- $\mathrm{m}^{2}$ functional unit in Figure 10 Total Life Cycle Energy for Cost-Optimal Houses per m2 iCFA and Figure 11 Total Life Cycle GHG Emissions for Cost-Optimal Houses Per m2 iCFA. 


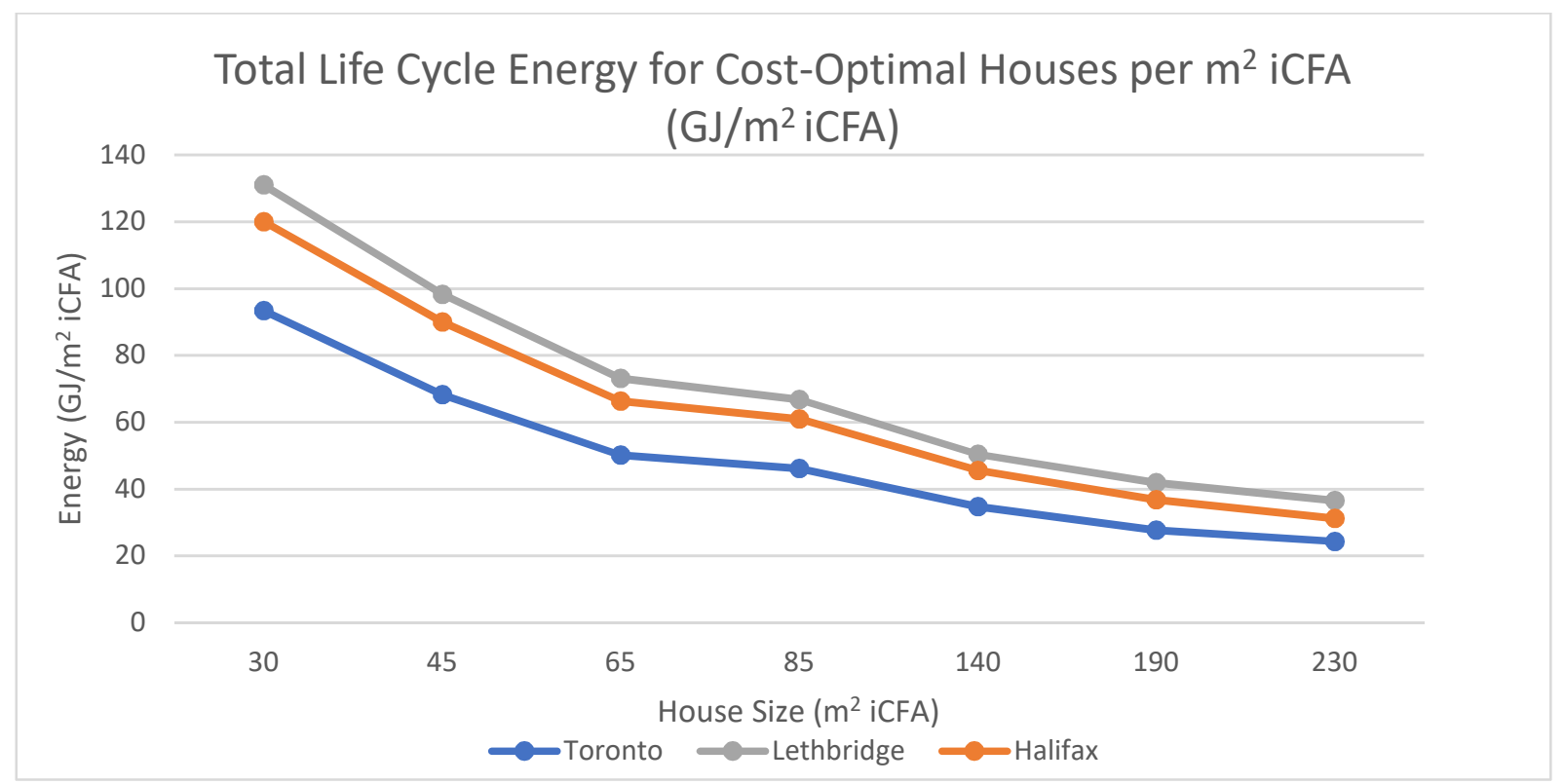

Figure 10 Total Life Cycle Energy for Cost-Optimal Houses per m2 iCFA

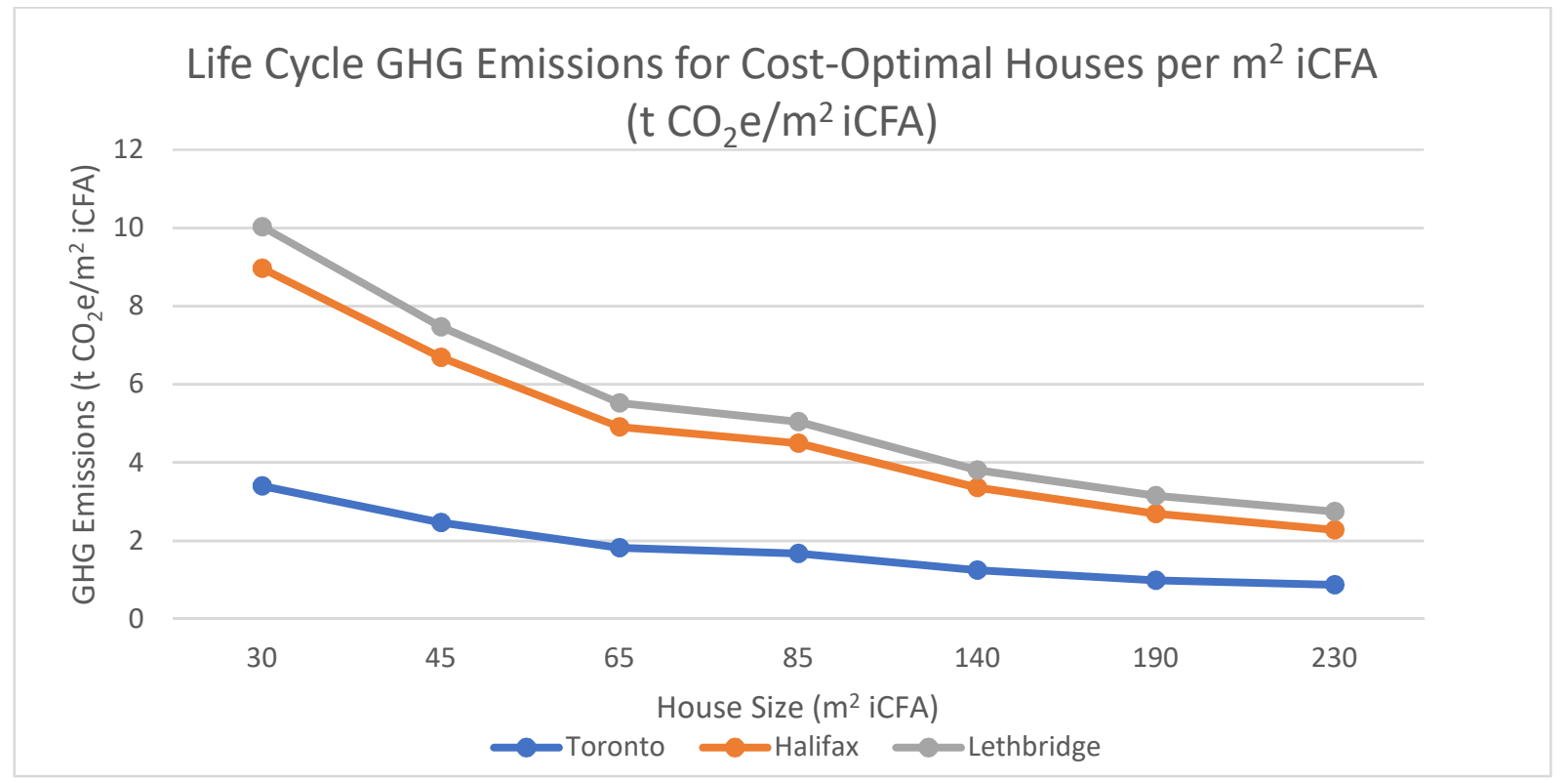

Figure 11 Total Life Cycle GHG Emissions for Cost-Optimal Houses Per m2 iCFA

The results in in Figure 10 Total Life Cycle Energy for Cost-Optimal Houses per m2 iCFA and Figure 11 Total Life Cycle GHG Emissions for Cost-Optimal Houses Per m2 iCFA show that both life cycle energy and GHG emissions per- $\mathrm{m}^{2}$ increase as house size decreases. The results from Toronto show slightly lower life total cycle energy, but significantly lower total GHG emissions than 
Halifax or Lethbridge. This is mainly due to the lower grid emissions intensity in Ontario compared to Nova Scotia and Alberta. According to these results, the $30 \mathrm{~m}^{2}\left(300 \mathrm{ft}^{2}\right)$ house has per- $\mathrm{m}^{2}$ life cycle energy use that is $311 \%$ higher than the $230 \mathrm{~m}^{2}\left(2,500 \mathrm{ft}^{2}\right)$ house, and a $318 \%$ higher GHG emissions per-m².

\subsubsection{Total Life Cycle Energy Use and GHG Emissions Per-Occupant}

Results from the LCA showing total life cycle energy and emissions for various sizes of costoptimal passive houses constructed using the medium embodied energy build package are presented using a per-occupant functional unit in Figure 12 Total Life Cycle Energy for Cost-Optimal Houses per Occupant and Figure 13 Total Life Cycle GHG Emissions for Cost-Optimal Houses per Occupant.

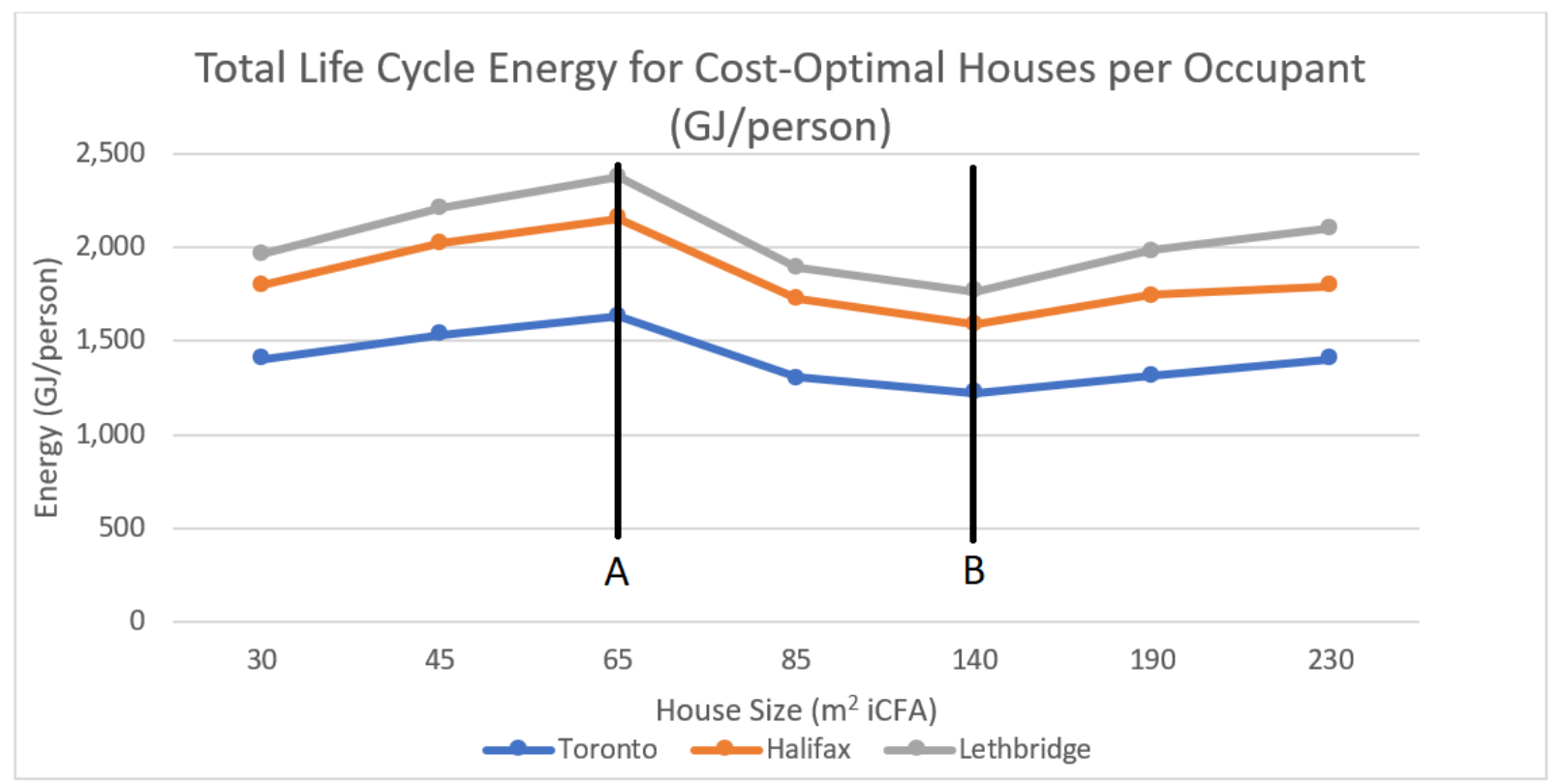

Figure 12 Total Life Cycle Energy for Cost-Optimal Houses per Occupant 


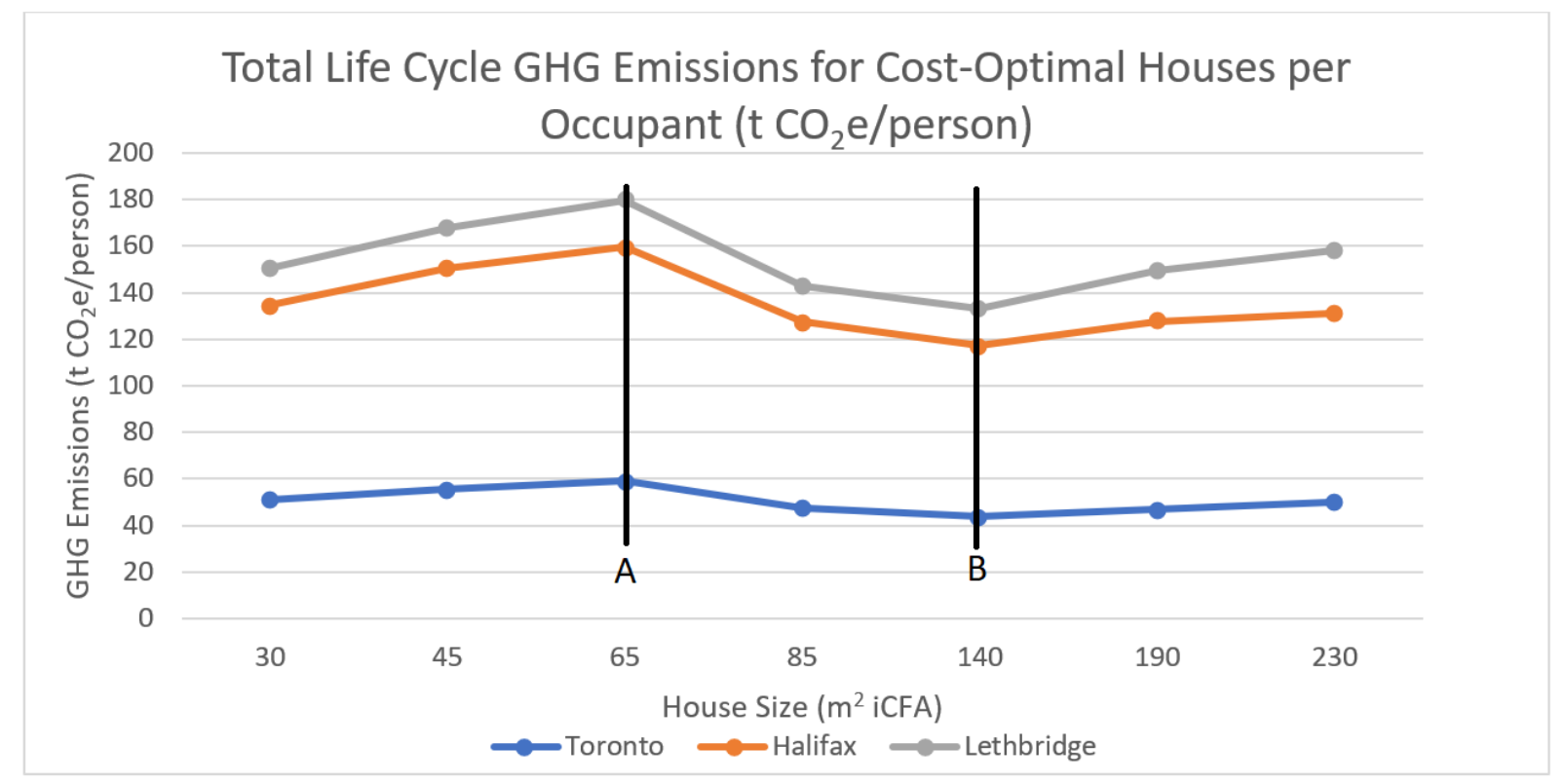

Figure 13 Total Life Cycle GHG Emissions for Cost-Optimal Houses per Occupant

The results in Figure 12 Total Life Cycle Energy for Cost-Optimal Houses per Occupant and Figure 13 Total Life Cycle GHG Emissions for Cost-Optimal Houses per Occupant show that both life cycle energy use and GHG emissions, when represented on a per-occupant basis, are significantly different than when represented on a per- $\mathrm{m}^{2}$ basis. The occupancy changes from two occupants at $65 \mathrm{~m}^{2}\left(700 \mathrm{ft}^{2}\right)$ and below to three at $85 \mathrm{~m}^{2}\left(900 \mathrm{ft}^{2}\right)$ and to four at $140 \mathrm{~m}^{2}\left(1,500 \mathrm{ft}^{2}\right)$. This increase in occupancy leads to the decreasing emissions intensity per occupant shown in Figure 12 Total Life Cycle Energy for Cost-Optimal Houses per Occupant and Figure 13 Total Life Cycle GHG Emissions for Cost-Optimal Houses per Occupant between $65 \mathrm{~m}^{2}\left(700 \mathrm{ft}^{2}\right)$ and $140 \mathrm{~m}^{2}\left(1,500 \mathrm{ft}^{2}\right)$. Though the per-occupant results fluctuate somewhat based on changing occupancy and house sizes as described above, the trend is different than on a per- $\mathrm{m}^{2}$ basis. On average, the $30 \mathrm{~m}^{2}\left(300 \mathrm{ft}^{2}\right)$ house has a $2 \%$ lower life cycle energy than the $230 \mathrm{~m}^{2}\left(2,500 \mathrm{ft}^{2}\right)$ house and has $0.2 \%$ lower GHG emissions when the average for all three locations is taken, meaning that there is no significant 
difference in total life cycle energy and GHG emissions between a $30 \mathrm{~m}^{2}\left(300 \mathrm{ft}^{2}\right)$ and $230 \mathrm{~m}^{2}$ $\left(2,500 \mathrm{ft}^{2}\right)$ house when assessed on a per-occupant basis.

Inflection points A and B are noted in Figure 12 Total Life Cycle Energy for Cost-Optimal Houses per Occupant and Figure 13 Total Life Cycle GHG Emissions for Cost-Optimal Houses per Occupant and discussed in Section 5.3.

\subsubsection{Total Life Cycle Energy and Emissions Per-Set Occupancy Rate}

Results from the LCA showing total life cycle energy and emissions for various sizes of costoptimal passive houses constructed using the medium embodied energy build package are presented using a per-set occupancy rate functional unit in Figures 11 and 12. Due to constraints in BEopt, occupancy is calculated in the models based on the number of bedrooms which allows a limited choice of number of occupants. The set occupancy rate, as defined in Section 3.1, is the equivalent of 2.05 occupants in each house, which remains constant across all house sizes in order to illustrate per-occupant energy use when the same number of occupants live in different sizes of houses. As shown in Table 9, 2.05 occupants is slightly above the Canadian average for number of occupants in a two bedroom house, and was chosen as the average number of bedrooms for houses used in this study is two (Statistics Canada, 2016). Though not as insightful as using a peroccupant functional unit, it does show the effect that a constant, average occupancy rate has on results.

Table 9 Occupants Per Single-Detached House by Number of Bedrooms (Statistics Canada, 2016)

\begin{tabular}{lrrrr}
\hline Number of Bedrooms & 1 & 2 & 3 & $4+$ \\
\hline Number of Occupants & 1.5 & 1.9 & 2.5 & 3.3 \\
\hline
\end{tabular}




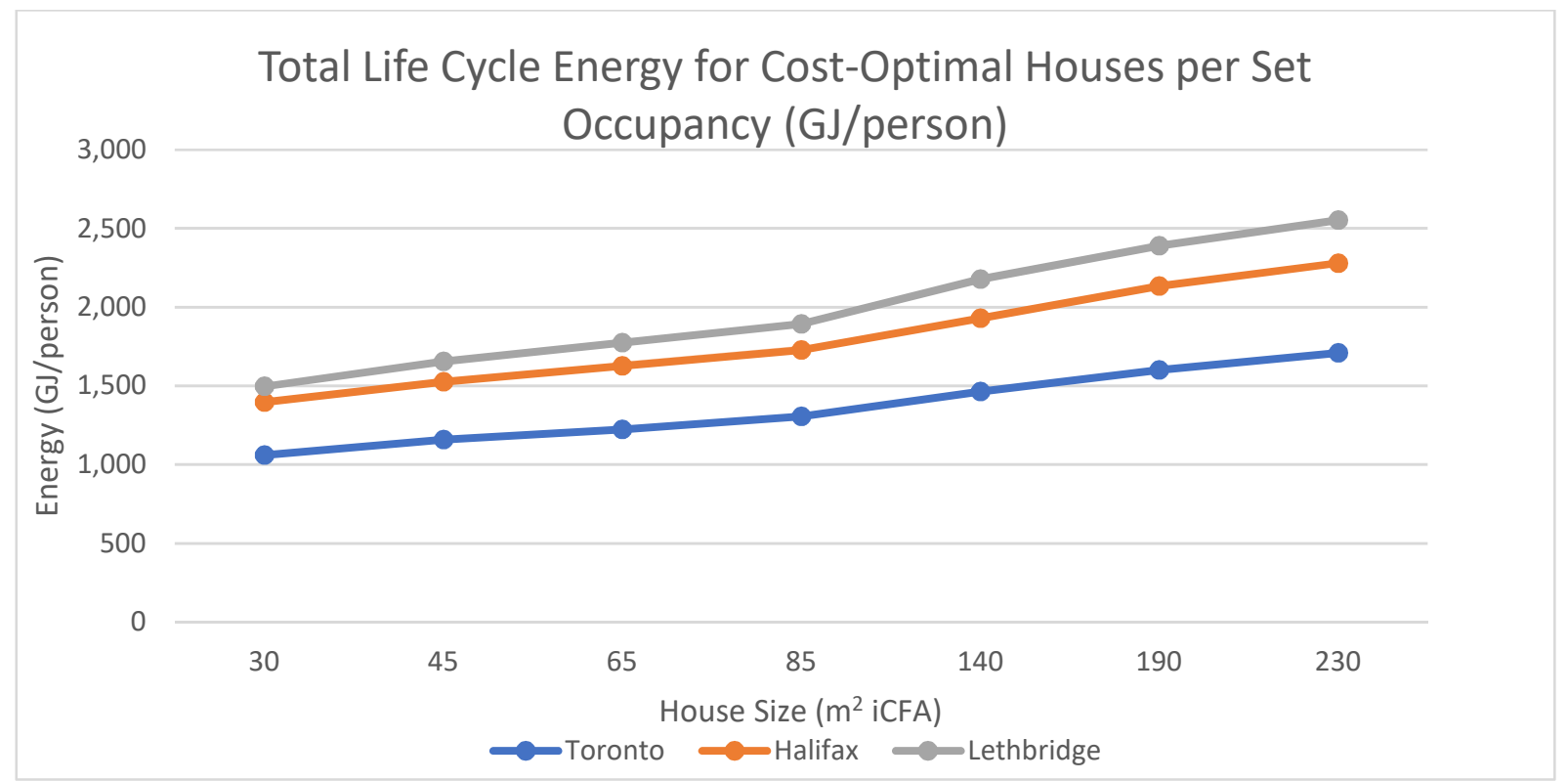

Figure 14 Total Life Cycle Energy for Cost-Optimal Houses per Set Occupancy

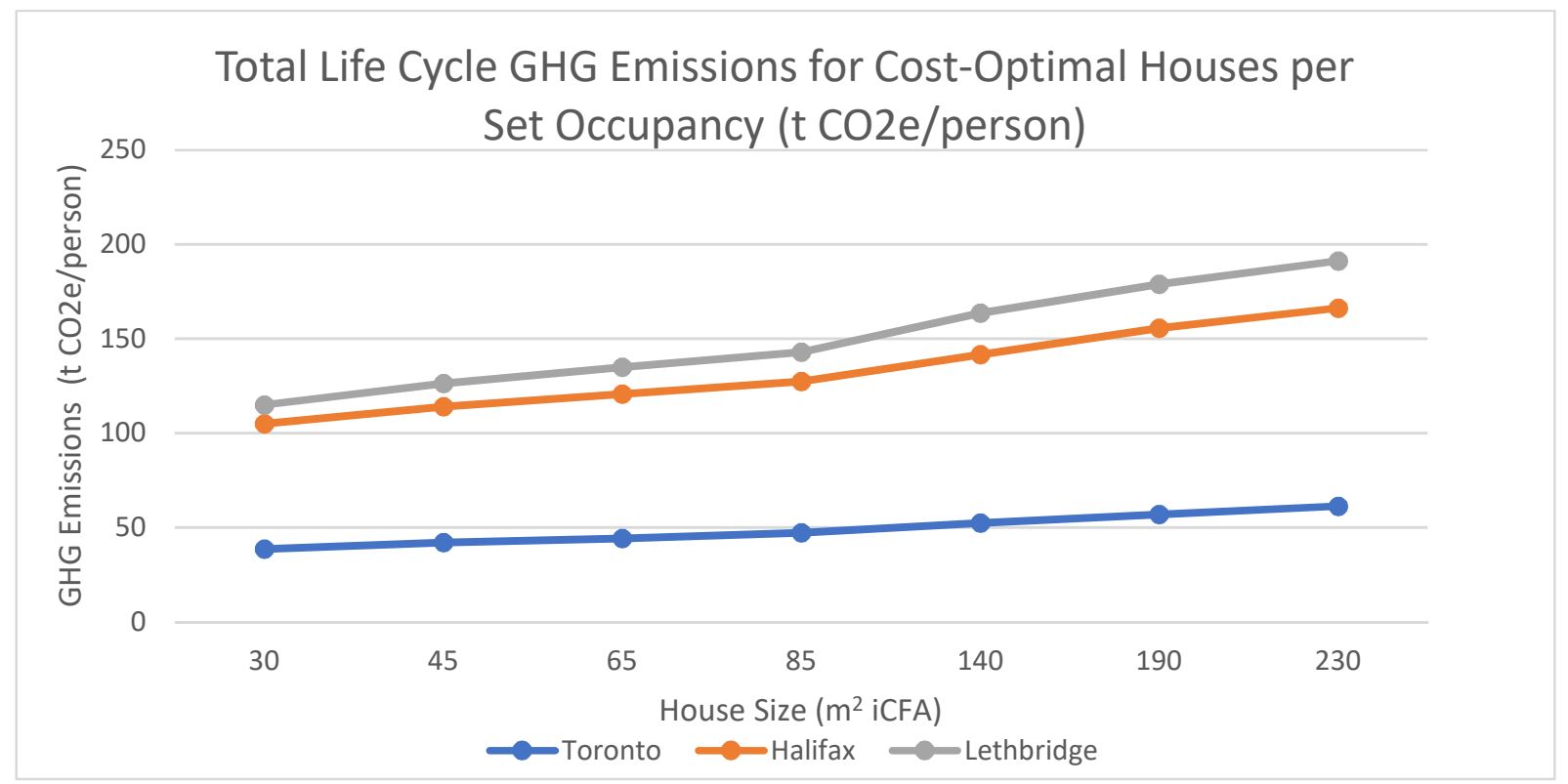

Figure 15 Total Life Cycle GHG Emissions for Cost-Optimal Houses per Set Occupancy

The results in Figure 14 Total Life Cycle Energy for Cost-Optimal Houses per Set OccupancyFigure 15 Total Life Cycle GHG Emissions for Cost-Optimal Houses per Set Occupancy show that both life cycle energy and GHG emissions per-set occupancy rate are significantly different than both on a 
per- $\mathrm{m}^{2}$ and per-occupant basis. The results clearly show that the larger the house, the higher the total life cycle energy use and GHG emissions impact. On average, the $30 \mathrm{~m}^{2}\left(300 \mathrm{ft}^{2}\right)$ house has a $39 \%$ lower life cycle energy use than the $230 \mathrm{~m}^{2}\left(2,500 \mathrm{ft}^{2}\right)$ house, and $38 \%$ lower life cycle GHG emissions.

\subsubsection{Embodied Energy Use and GHG Emissions Impact}

Though operational energy use and GHG emissions dominate the total life cycle energy and emissions, when looking at embodied-only effects, the results presented in Figure 16 Average Embodied Energy for Cost-Optimal Houses and Figure 17 Average Embodied GHG Emissions for CostOptimal Houses follow similar trends to the results presented throughout Section 4.1.

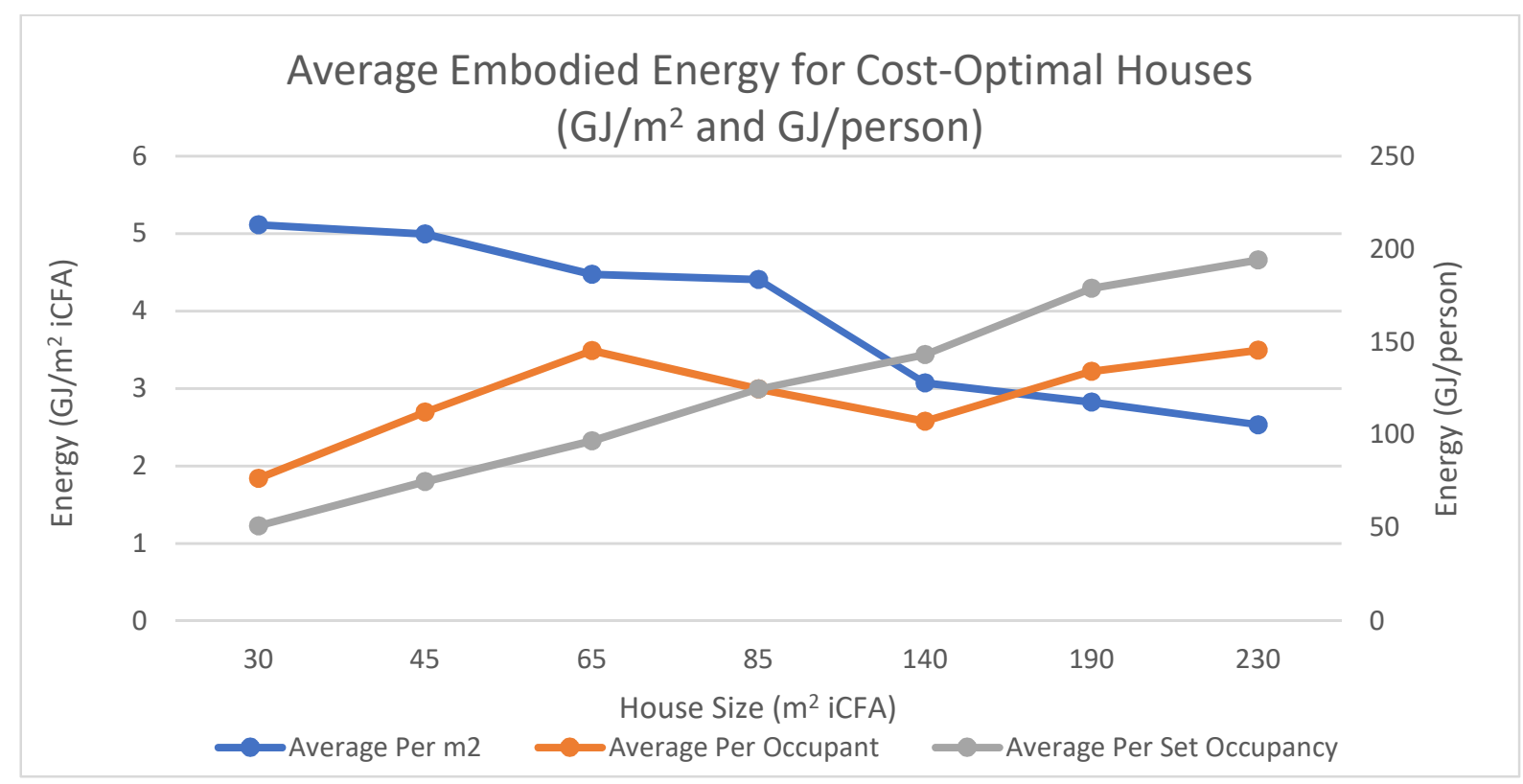

Figure 16 Average Embodied Energy for Cost-Optimal Houses 


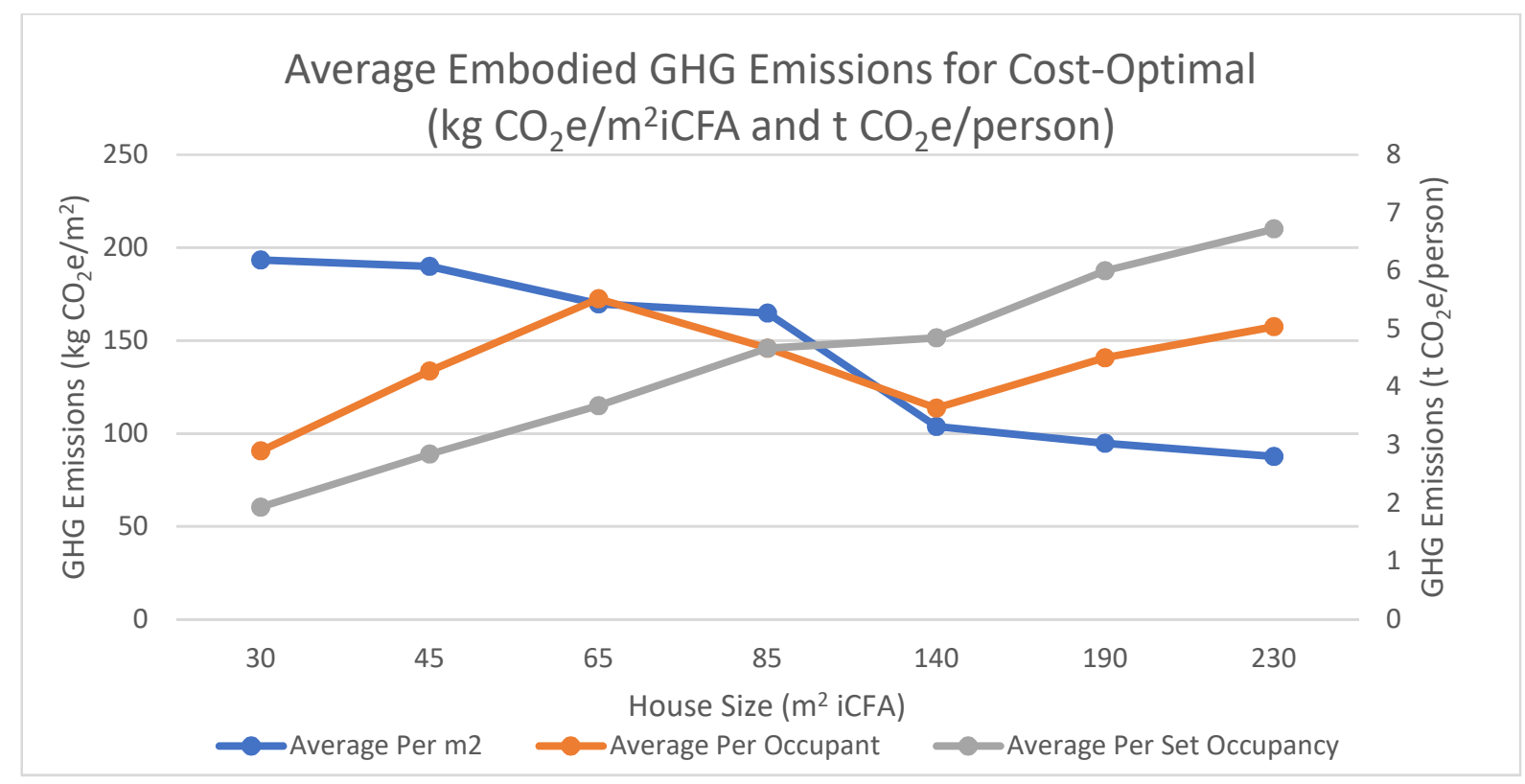

Figure 17 Average Embodied GHG Emissions for Cost-Optimal Houses

The results presented in Figure 16 Average Embodied Energy for Cost-Optimal Houses and Figure 17 Average Embodied GHG Emissions for Cost-Optimal Houses present embodied energy use and GHG emissions based on the same functional units used to analyse total life cycle energy use and GHG emissions (per- $\mathrm{m}^{2}$, per-occupant, and per-set occupancy rate). As with previous analysis, smaller passive houses still perform more poorly on a per- $\mathrm{m}^{2}$ basis with a $121 \%$ higher embodied energy use, and $141 \%$ greater embodied GHG emissions per- $\mathrm{m}^{2}$. However, results analysed on a peroccupant or set-occupancy rate basis both show that smaller houses perform better than larger ones. The $30 \mathrm{~m}^{2}\left(300 \mathrm{ft}^{2}\right)$ house uses $47 \%$ less embodied energy and $42 \%$ less GHG emissions per-occupant, and 74\% better embodied energy and 71\% better GHG emissions per-set occupancy rate.

\subsection{Part 2: BEopt Cost-Optimal Passive Design Study}

The results from the BEopt cost optimization study are used to: 
1. Explore energy implications for various sizes of passive houses below the $230 \mathrm{~m}^{2}(2,500$ $\mathrm{ft}^{2}$ ) average for all climate zones, with results presented using similar functional units as previous analysis (per- $\mathrm{m}^{2}$, per-occupant, per-set occupancy rate).

2. Understand how cost-optimal passive design changes as building size shrinks from the average $230 \mathrm{~m}^{2}\left(2,500 \mathrm{ft}^{2}\right)$ to $30 \mathrm{~m}^{2}\left(300 \mathrm{ft}^{2}\right)$.

Results from the BEopt study only include operational energy, however operational energy dominates the life cycle, at $94 \%$ of total life cycle energy use. Results are generated for all climate zones, offering insights into the effect that climate has on the results.

\subsubsection{Building Energy Use Intensity Per-Area by Size and Climate Zone}

Figures 17 and 18 present operational energy use results from the BEopt study for building sizes from $30 \mathrm{~m}^{2}\left(300 \mathrm{ft}^{2}\right)$ to $230 \mathrm{~m}^{2}\left(2,500 \mathrm{ft}^{2}\right)$ across all 17 ASHRAE climate zones in North America analysed on a per-area functional unit.

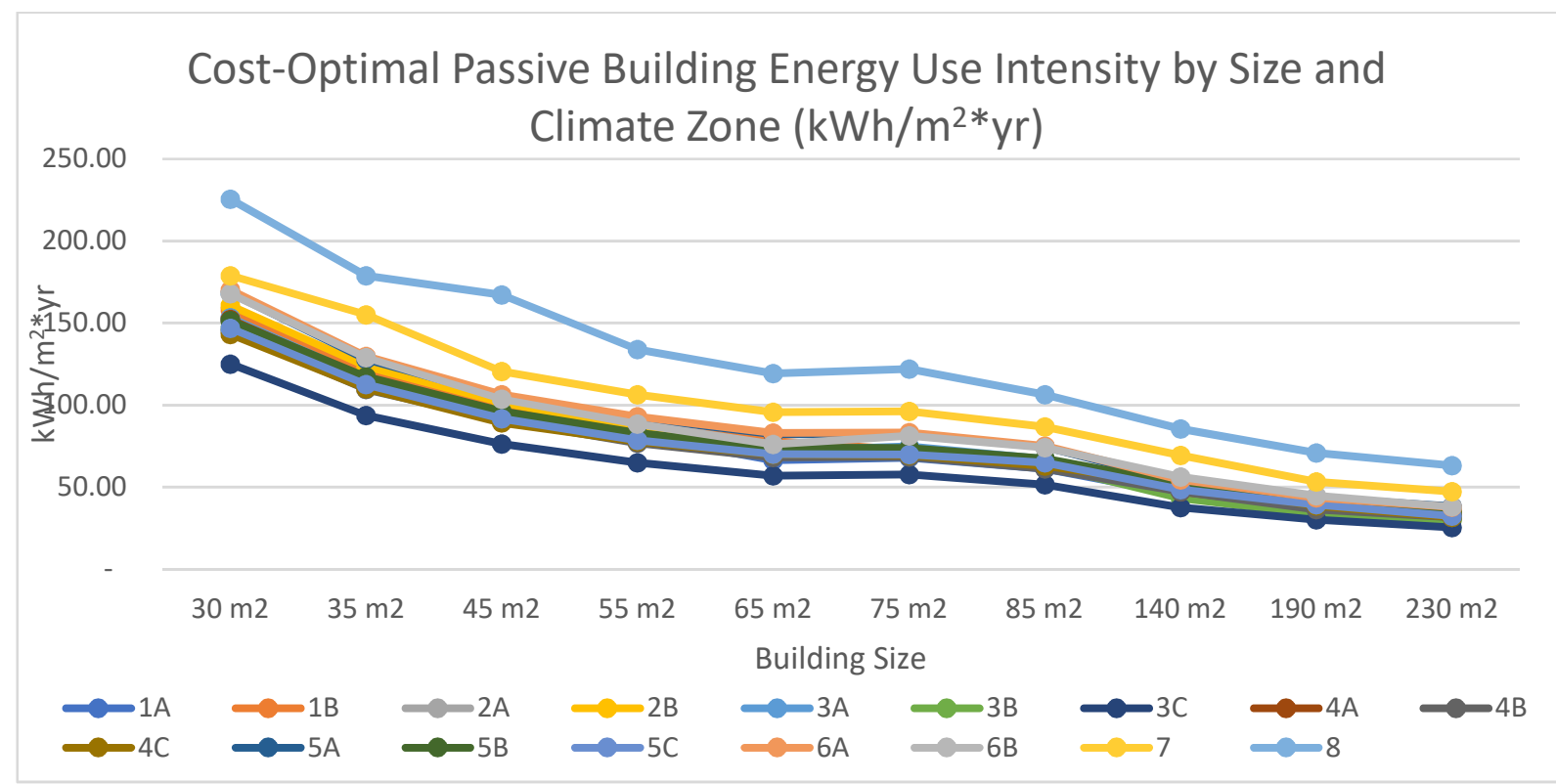

Figure 18 Cost-Optimal Passive Building Energy Use Intensity by Size and Climate Zone 


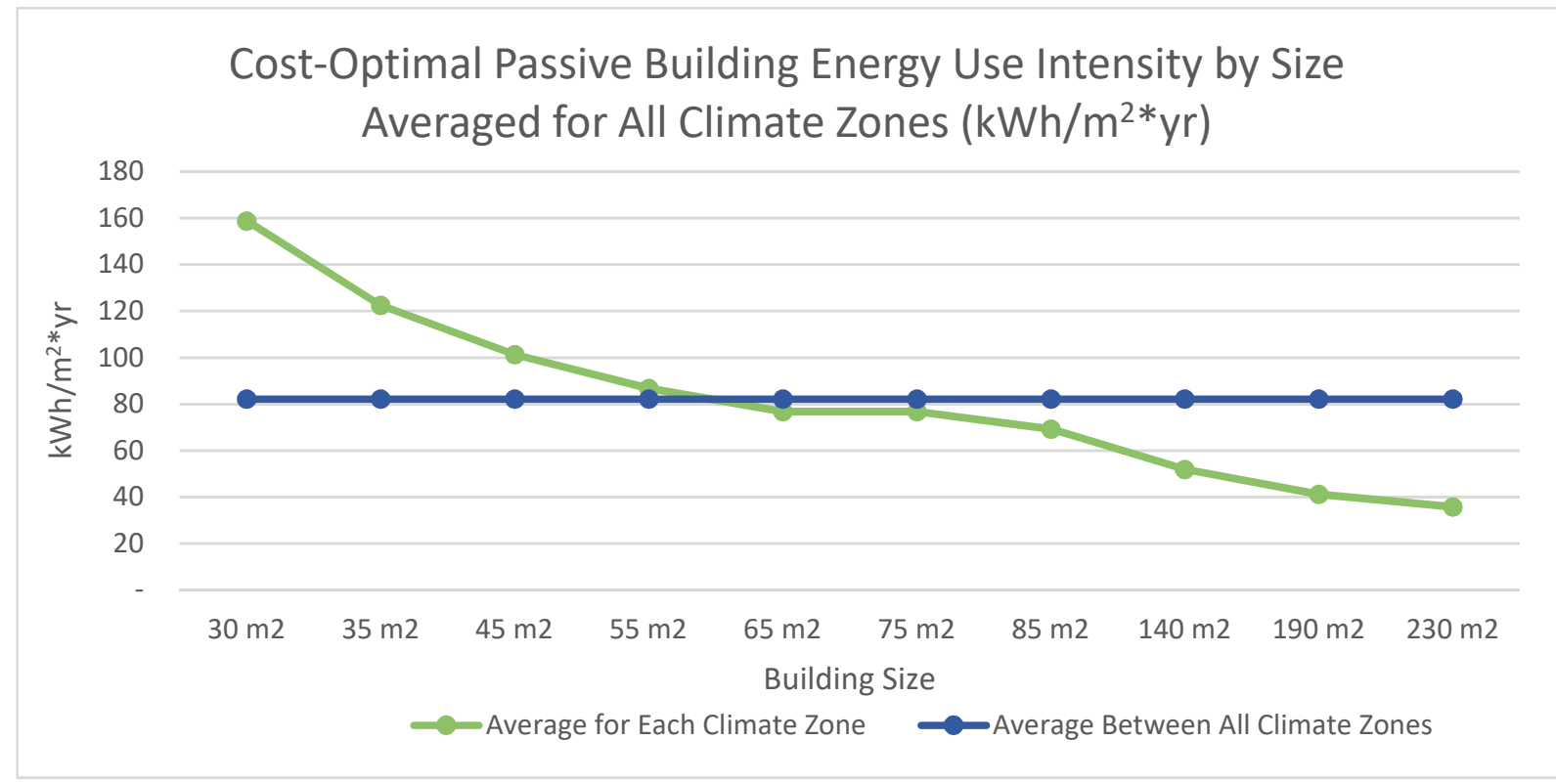

Figure 19 Cost-Optimal Passive Building Energy Use Intensity by Size Averaged for All Climate Zones

Similar to the results from the LCA presented in Section 4.1.3, when operational energy use is analysed on a per- $\mathrm{m}^{2}$ basis as in Figure 18 Cost-Optimal Passive Building Energy Use Intensity by Size and Climate Zone and Figure 19 Cost-Optimal Passive Building Energy Use Intensity by Size Averaged for All Climate Zones, energy use per- $\mathrm{m}^{2}$ decreases as house size increases. Of note is that energy intensity is fairly consistent across many climate zones with a relatively small variation in energy use between all climate zones, with the exception of climate zones 8,7 , and $3 \mathrm{C}$.

\subsubsection{Building Energy Use Intensity Per-Occupant by Size and Climate Zone}

When the results from the BEopt study are presented on a per-occupant basis, as in Figure 20 CostOptimal Passive Building Energy Use Intensity by Occupant and Climate Zone and Figure 21 CostOptimal Passive Building Energy Use Intensity by Occupant Average for All Climate Zones, results are similar to those from the LCA results presented in Section 4.1.4. 


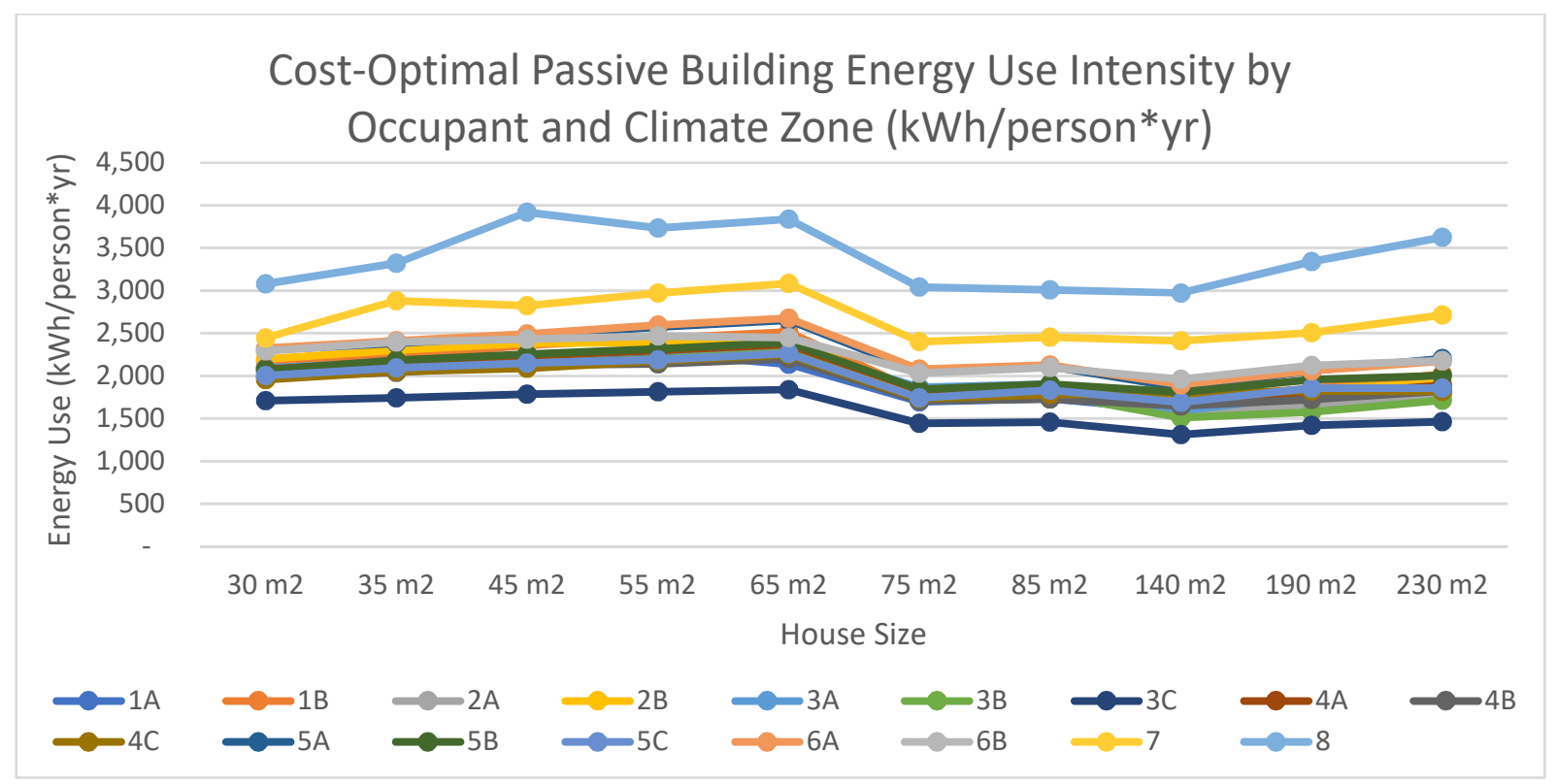

Figure 20 Cost-Optimal Passive Building Energy Use Intensity by Occupant and Climate Zone

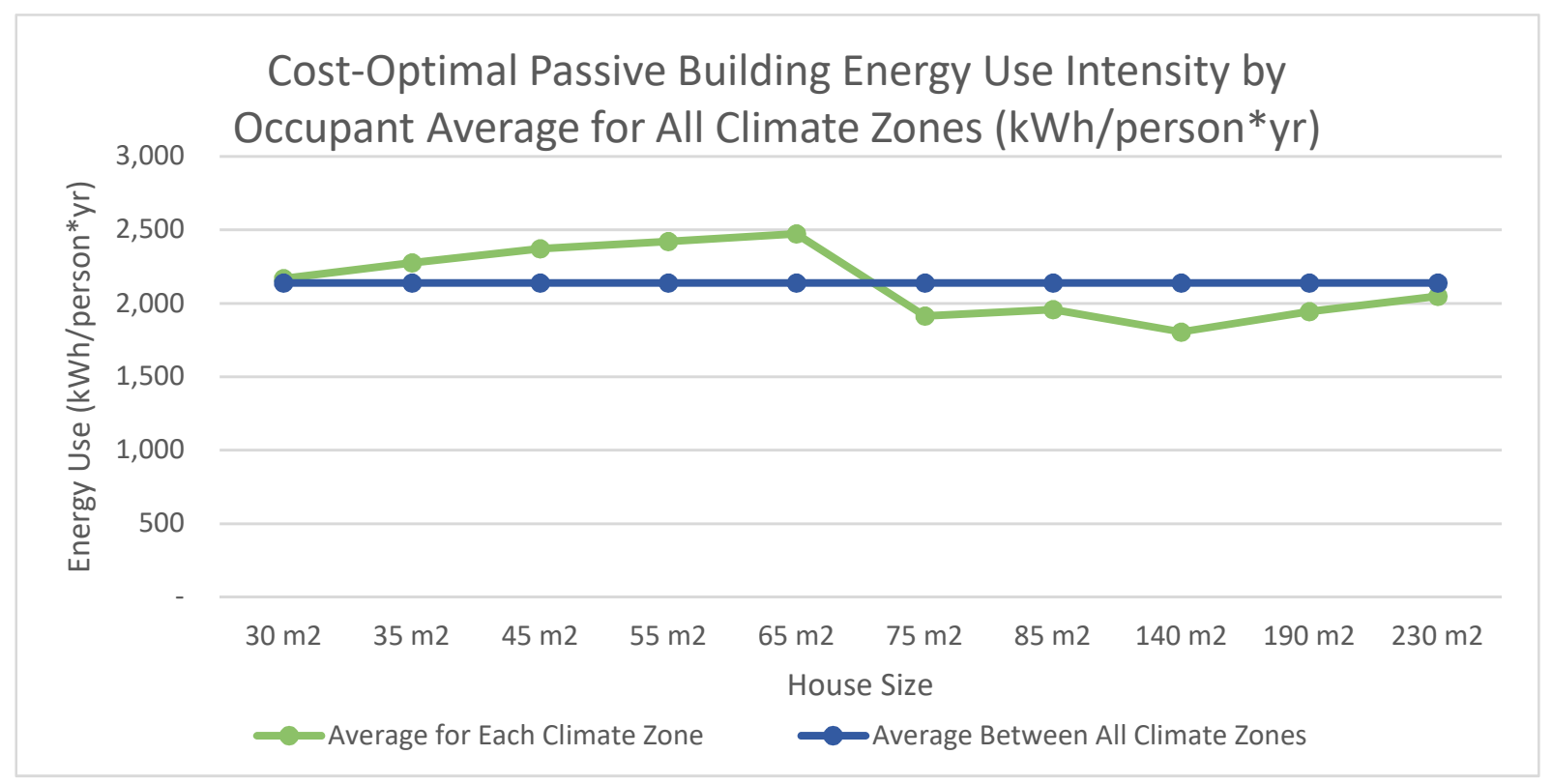

Figure 21 Cost-Optimal Passive Building Energy Use Intensity by Occupant Average for All Climate Zones

Figure 20 Cost-Optimal Passive Building Energy Use Intensity by Occupant and Climate Zone and Figure 21 Cost-Optimal Passive Building Energy Use Intensity by Occupant Average for All Climate Zones show that on a per-occupant basis, results are fairly consistent. While there are variations 
due to changing occupancy with building size, the $30 \mathrm{~m}^{2}\left(300 \mathrm{ft}^{2}\right)$ house has only an average of a $6 \%$ higher energy use per-occupant then a $230 \mathrm{~m}^{2}\left(2,500 \mathrm{ft}^{2}\right)$ house.

\subsubsection{Building Energy Use Intensity Per-Set Occupancy Rate by Size and Climate Zone}

Figure 22 Cost-Optimal Passive Building Energy Use Intensity by Set Occupancy and Climate Zone and Figure 23 Cost-Optimal Passive Building Energy Use Intensity by Set Occupancy Averaged for All Climate Zones show the results from the BEopt study presented on a per-set occupancy rate of 2.05 people per house.

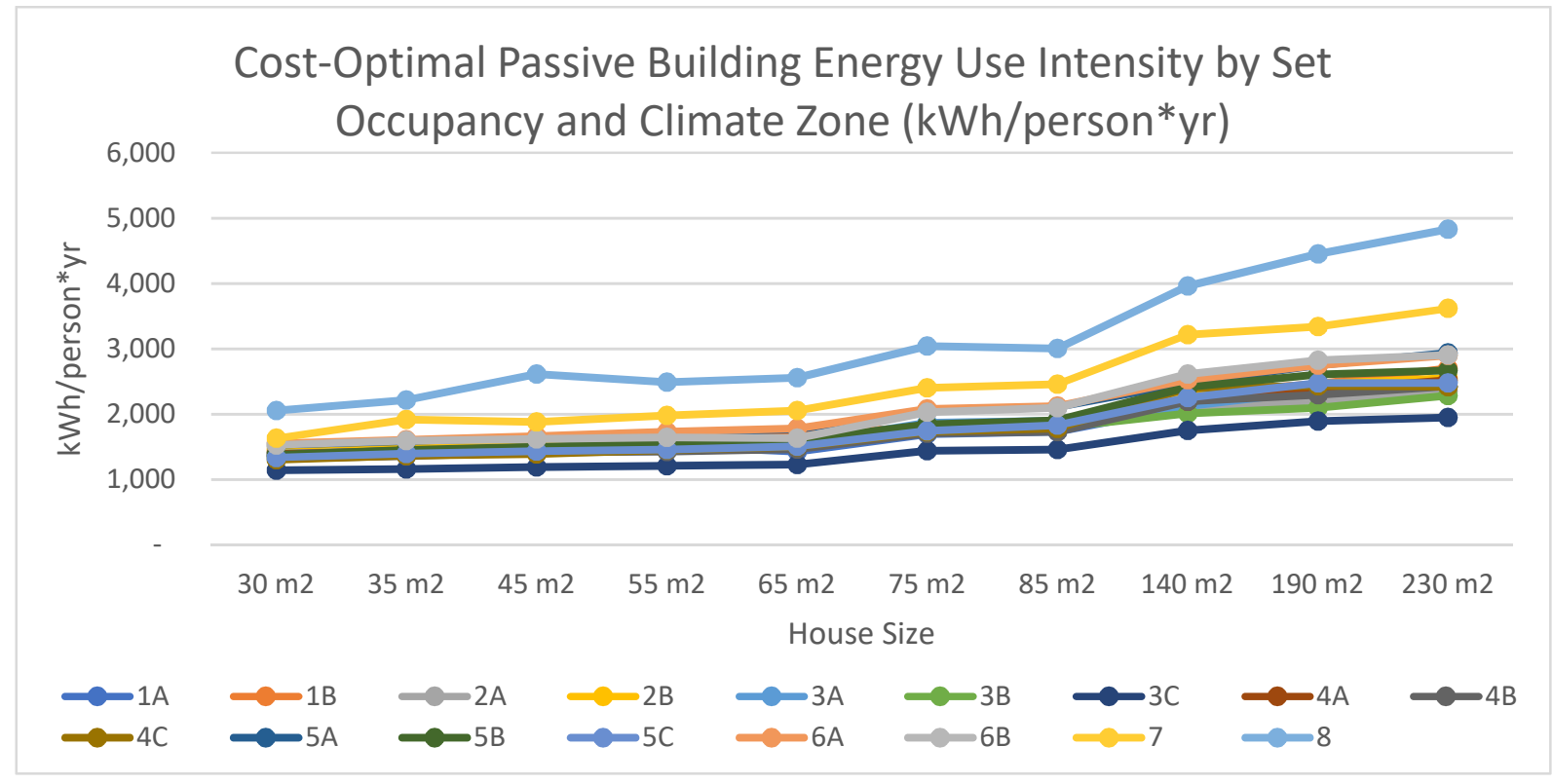

Figure 22 Cost-Optimal Passive Building Energy Use Intensity by Set Occupancy and Climate Zone 


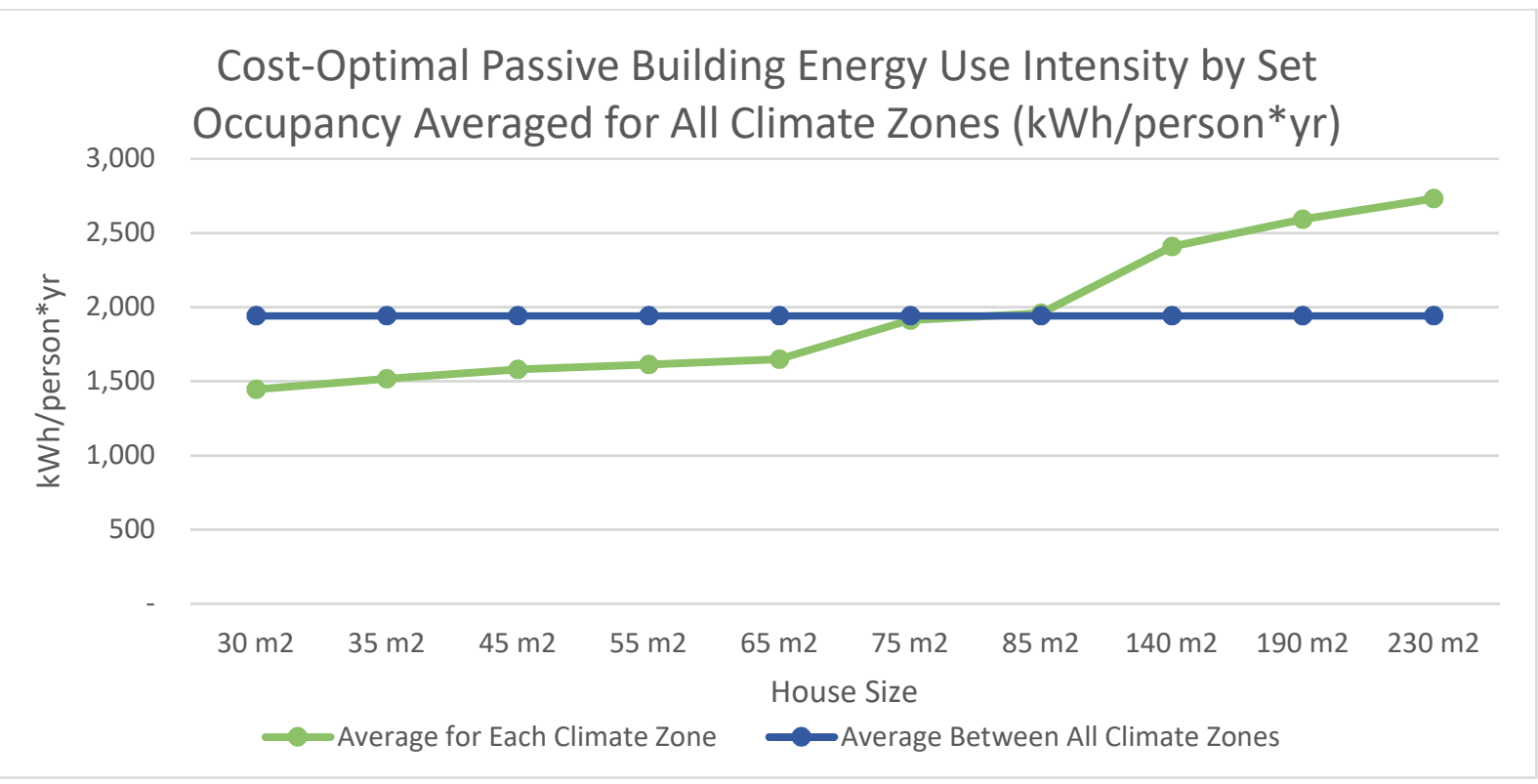

Figure 23 Cost-Optimal Passive Building Energy Use Intensity by Set Occupancy Averaged for All Climate Zones

When analysed on a per-set occupancy rate of 2.05 people per house for all house sizes, Figure 22 Cost-Optimal Passive Building Energy Use Intensity by Set Occupancy and Climate Zone and Figure 23 Cost-Optimal Passive Building Energy Use Intensity by Set Occupancy Averaged for All Climate Zones show a trend of energy use per-occupant steadily rising with increasing building size. In this case, a 230 $\mathrm{m}^{2}\left(2,500 \mathrm{ft}^{2}\right)$ house has an average of an $89 \%$ higher energy use per-occupant than a $30 \mathrm{~m}^{2}(300$ $\mathrm{ft}^{2}$ ) house.

\subsubsection{Cost-optimal Passive Design Differences Based on Building Size}

The results from the BEopt optimization study are presented in Figure 24 Overall Envelope U-value by Building Size and Climate Zone for Cost-Optimal Passive Houses and Figure 25 Overall Cost-Optimal Passive Envelope U-value for Building Size. They represent how envelope design changes with building size by plotting overall envelope U-values for the various house sizes across all climate zones as described in Section 3.3. 


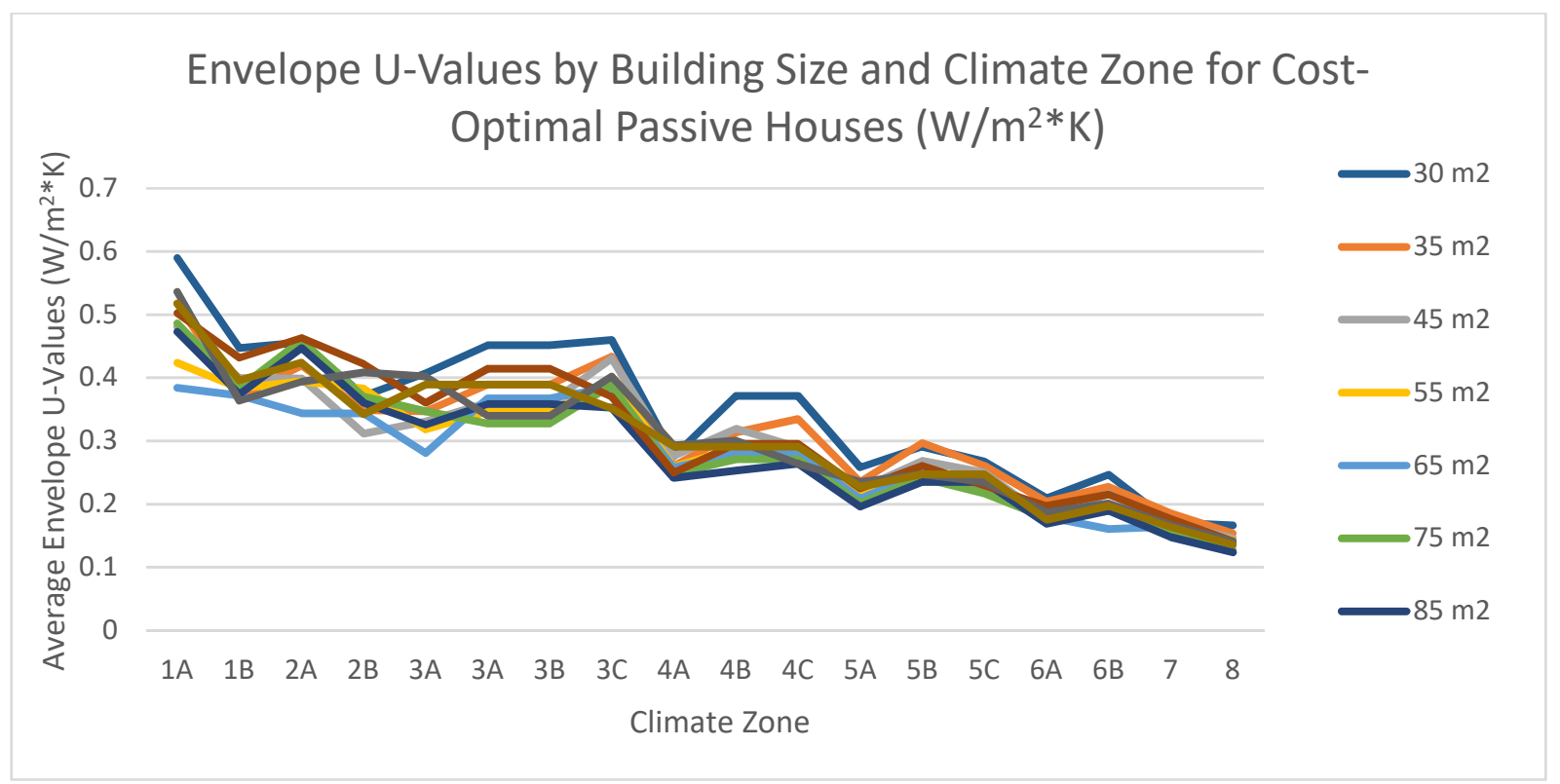

Figure 24 Overall Envelope U-value by Building Size and Climate Zone for Cost-Optimal Passive Houses

Figure 24 Overall Envelope U-value by Building Size and Climate Zone for Cost-Optimal Passive Houses shows that the overall U-values follow the same trend across all climate zones. The overall envelope U-value decrease steadily with colder climate zones, as expected.

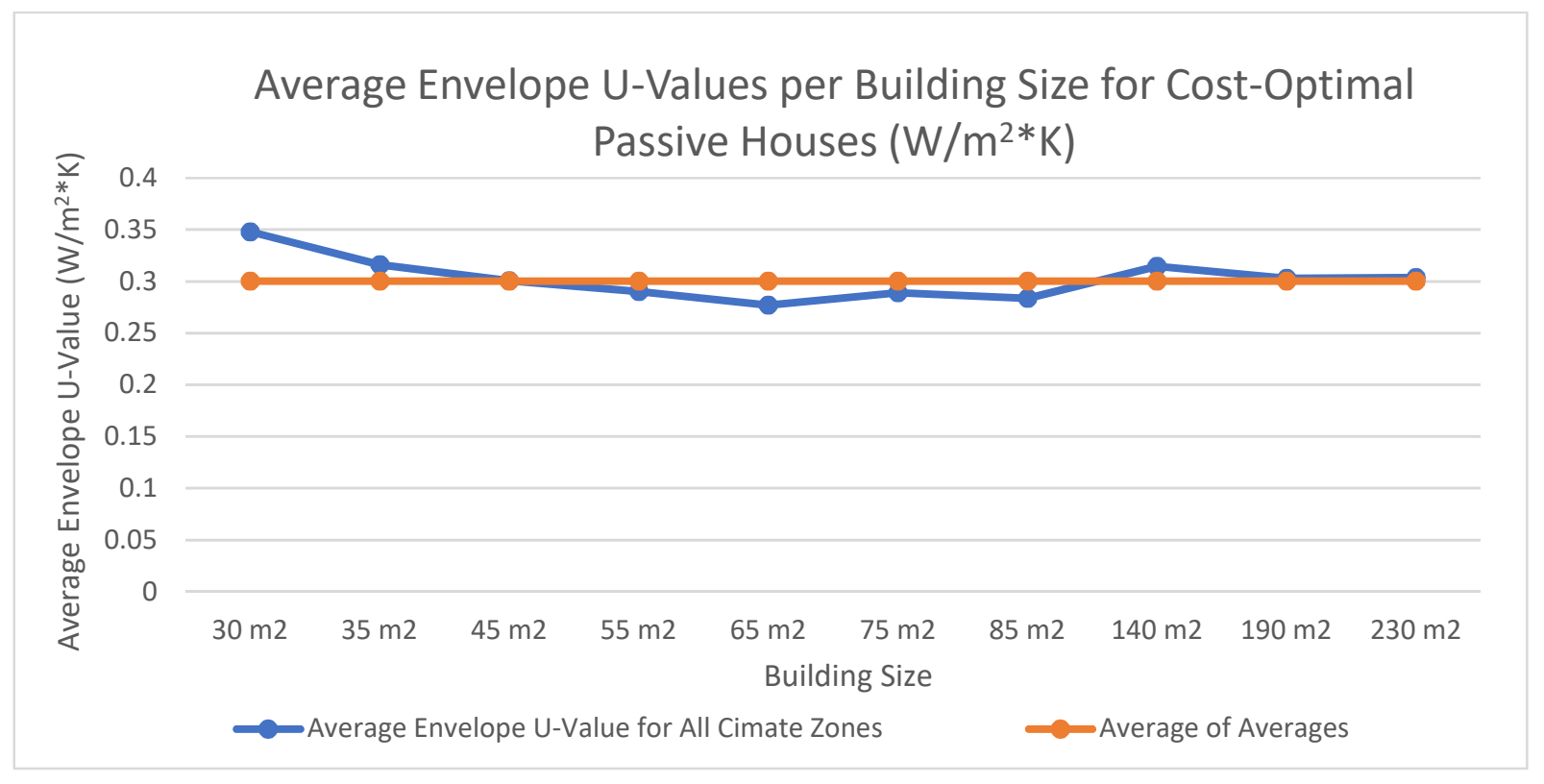

Figure 25 Overall Cost-Optimal Passive Envelope U-value for Building Size 
When the average overall envelope $\mathrm{U}$-value for each climate zone is presented, as in Figure 25 Overall Cost-Optimal Passive Envelope U-value for Building Size, very consistent results around a Uvalue of 0.3 is found. Though the smallest $\left(30 \mathrm{~m}^{2}\right)$ house shows a $16 \%$ deviation from the mean, the other building sizes average U-values fall within $+/-8 \%$ of the mean, with the average deviation being only $1 \%$.

\section{Discussion}

To answer the two research questions, this Section is divided into two parts:

Part 1: An LCA using Envisioneer and Athena Impact Estimator software (Athena) to explore and compare the life cycle energy and carbon impacts of various sizes of houses below the $230 \mathrm{~m}^{2}\left(2,500 \mathrm{ft}^{2}\right)$ average.

Part 2: A cost-optimization analysis using BEopt software to explore energy implications for various sizes of houses below the $230 \mathrm{~m}^{2}\left(2,500 \mathrm{ft}^{2}\right)$ average for all climate zones, as well as to understand how cost-optimal passive design changes with shrinking house size. 


\subsection{LCA Overall Results}

An LCA performed as described in Section 3.1 was designed to determine how life cycle energy use and GHG emissions change based on house size. Different functional units were used to analyse the results to see what impact these have on the interpretation of results. These results help give insight into how embodied and operational energy use and GHG emissions for DADUs compares to the average-sized $230 \mathrm{~m}^{2}\left(2,500 \mathrm{ft}^{2}\right)$ house.

Careful analysis of the operational energy inputs taken from BEopt results and used for the LCA show that the cost-optimal designs meet the energy thresholds for the PHI and PHIUS +2015 passive certification programs for annual heating demand. Further analysis into the base loads and energy use from occupant behaviours from the BEopt is warranted to ensure that differences between those modeled in BEopt are similar to those used in passive certification programs and do not exaggerate the operational energy use in the total life cycle results.

Results from the LCA, presented in Figure 4 Embodied and Operational Life Cycle Energy for Various Passive House Sizes in Toronto through Figure 9 Embodied and Operational Life Cycle GHG Emissions for Various Passive House Sizes in Lethbridge, show that embodied energy and GHG emissions form a relatively small percentage of total life cycle energy use and GHG emissions. In Toronto, embodied energy and GHG emissions are $7 \%$ and $6 \%$ of total life cycle energy use and GHG emissions, respectively, averaged across all building sizes. The second location used in the study, Halifax, has an embodied impact of only $6 \%$ and $3 \%$ compared to the overall life cycle energy use and GHG emissions, respectively, averaged across all building sizes. Finally, in Lethbridge embodied energy use and GHG emissions are $6 \%$ and $3 \%$ of total life cycle energy use and GHG emissions, respectively averaged across all building sizes. The relatively low contribution that embodied energy has to overall life cycle energy is unexpected. Embodied GHG emissions results 
fall within this same range, and results show that operational energy and carbon dominate the life cycle. Reviewed studies, including that by Chastas et al. (2016) have shown that a passive house's embodied energy should be $26 \%$ to $57 \%$ of total life cycle energy. In a 2007 review of 60 cases found in literature, Sartori and Hestnes found that embodied energy's share of total life cycle energy was 5 to $12 \%$ for conventional buildings, 12 to $25 \%$ for low-energy buildings, and $25 \%$ and up for passive houses. The results from this study, where embodied energy accounted for $6 \%$ of total life cycle energy, places it in the same range as that of conventional buildings for other studies. The difference in possible boundary conditions chosen for this study do not make enough of a difference to affect the results dramatically. Including affects beyond the building life and the subsequent handling of carbon sequestration only makes no difference in life cycle energy results and only a $2 \%$ to $7 \%$ difference in GHG emissions, In addition to the possible differences in base loads used for the studies, this difference in the share of total life cycle energy attributed to embodied energy is possibly due to the many challenges associated with the consistent implementation of LCA discussed by Anand and Amor (2017). As described in Section 3.1, efforts were made in this study's design to address these challenges. For example, this study followed the suggestions of Wolf et al. (2017) by implementing good databases, consistent methods, and several of the recommendations for simplification by Soust-Verdaguer et al. (2016) in the design of the study.

Other notable overall results from the LCA are related to the locations used in the study. Toronto is found to have a significantly lower life cycle energy use than the other cities included at an average of $38 \%$ lower. Embodied energy use results for Toronto are relatively close to the other locations, at only $4 \%$ lower, so the difference mainly lies in the operational energy use and GHG emission impacts. The lower operational energy use is likely due to a milder climate in Toronto 
compared to other locations as heating and cooling energy use is $14 \%$ lower in Toronto than Halifax and Lethbridge, and the lower GHG emissions are likely due to lower heating and cooling requirements along with a lower grid emission intensity in Toronto as presented in Section 3.2. Life cycle GHG emissions are 66\% lower in Toronto compared to other locations. Grid emissions intensity is $66 \%$ lower in Toronto, which shows how much of an impact de-carbonization of an electricity grid can have on overall life cycle GHG emissions for a building. Interconnection effects of grids, especially between low and high carbon intensity grids, is challenging to calculate and can add uncertainty to LCA results. The use of software like Athena can help with this challenge, as software designers include these grid interconnection and grid carbon intensity considerations in the back end of the software, creating more accurate LCA results for researchers.

\subsection{Research Question \#1: Life Cycle Impacts of Passive DADUs}

The study is designed to answer the first research question through an LCA. Results are analysed using per- $\mathrm{m}^{2} \mathrm{iCFA}$, per-occupant, and per-set occupancy rate functional units to understand what impact these functional units can have on the interpretation of the results.

As expected, when analysed using a per- $\mathrm{m}^{2}$ functional unit, passive DADUs are found to have a greater life cycle energy use and GHG emissions impact than their larger counterparts. The results in Figure 10 Total Life Cycle Energy for Cost-Optimal Houses per m2 iCFA and Figure 11 Total Life Cycle GHG Emissions for Cost-Optimal Houses Per m2 iCFA show that when the average between all North American climate zones is taken, a $30 \mathrm{~m}^{2}\left(300 \mathrm{ft}^{2}\right)$ passive house has a life cycle energy use and GHG emissions impact of over three times that of a $230 \mathrm{~m}^{2}\left(2,500 \mathrm{ft}^{2}\right)$ passive house. 
As hypothesized, however, results analysed on a per-occupant basis show very different results. On a per-occupant basis, smaller passive houses do not have a significantly higher life cycle energy and carbon impact. As shown in Figure 12 Total Life Cycle Energy for Cost-Optimal Houses per Occupant and Figure 13 Total Life Cycle GHG Emissions for Cost-Optimal Houses per Occupant, a different trend exists for life cycle energy and carbon impacts as building size shrinks from the average $230 \mathrm{~m}^{2}\left(2,500 \mathrm{ft}^{2}\right)$ down to $30 \mathrm{~m}^{2}\left(300 \mathrm{ft}^{2}\right)$ when using a per-occupant functional unit. The overall trend line is neither ascending nor descending, and the variability seen in the trend line is largely attributable to changes in occupancy as house size changes. The trend line increases between $65 \mathrm{~m}^{2}\left(700 \mathrm{ft}^{2}\right)$ and $85 \mathrm{~m}^{2}\left(900 \mathrm{ft}^{2}\right)$, as well as between $85 \mathrm{~m}^{2}\left(900 \mathrm{ft}^{2}\right)$ and $140 \mathrm{~m}^{2}(1,500$ $\mathrm{ft}^{2}$ ). In both these cases, one extra bedroom and associated person is being added, as $65 \mathrm{~m}^{2}$ (700 $\left.\mathrm{ft}^{2}\right)$ has two occupants, $85 \mathrm{~m}^{2}\left(900 \mathrm{ft}^{2}\right)$ has three occupants, and $140 \mathrm{~m}^{2}\left(1,500 \mathrm{ft}^{2}\right)$ has four occupants. Because energy and carbon emissions can be divided by more occupants, a decrease in per-occupant is realized. Otherwise, the energy emissions are shown to decrease as house size shrinks. Though this variability makes the result more challenging to interpret, the overall trend is most important, as is the fact that the $30 \mathrm{~m}^{2}\left(300 \mathrm{ft}^{2}\right)$ house has essentially the same life cycle energy use and GHG emissions per-person as the $230 \mathrm{~m}^{2}\left(2,500 \mathrm{ft}^{2}\right)$ house.

On a set-occupancy basis of 2.05 occupants per house, passive DADUs have a significantly lower life cycle energy use and GHG emissions impact than larger ones. Figure 14 Total Life Cycle Energy for Cost-Optimal Houses per Set OccupancyFigure 15 Total Life Cycle GHG Emissions for CostOptimal Houses per Set Occupancy present a different trend than either of the functional units discussed previously. As house size increases, so do life cycle energy and carbon impacts, with the $30 \mathrm{~m}^{2}\left(300 \mathrm{ft}^{2}\right)$ house having a 39\% lower life cycle energy use and a 38\% lower life cycle GHG emissions than the $230 \mathrm{~m}^{2}\left(2,500 \mathrm{ft}^{2}\right)$ house. 
When analysed on an embodied-only energy use and GHG emissions basis as shown in Figure 16 Average Embodied Energy for Cost-Optimal Houses and Figure 17 Average Embodied GHG Emissions for Cost-Optimal Houses, results are consistent with those found for overall life cycle energy use and GHG emissions impact. Though operational energy use and GHG emissions dominate the life cycle in the study, this finding is relevant for near net-zero and net-zero buildings where embodied effects dominate the life cycle.

\subsection{LCA Discussion}

The results from the LCA show different trends depending on the functional unit used to interpret the results with different conclusions that can be reached based on the same results data, the benefits and drawbacks of each functional unit must be understood. The per-area functional unit is the traditional way to look at buildings' energy and carbon performance. Buildings are often very different in shape, size, function, and occupancy profile, so the traditional per-area functional unit interpretation allows for better comparison between different types of buildings. This functional unit, however, does not fully address the concerns related to sustainability. In understanding a single building's performance, it can be helpful. When used to compare between buildings, by its very nature, it creates a size bias towards larger buildings, as, all other things being equal, energy use is spread out more across a larger floor area, leading to lower per- $\mathrm{m}^{2}$ energy use. If per-floor area functional units are used exclusively when considered building energy performance in codes and certification standards, designers and builders will be incentivised to build larger. This will lead to greater absolute energy consumption in the built environment and higher GHG emissions related to urban sprawl. 
Sustainability and energy efficiency programs need a different functional unit for interpreting building performance, as these programs' goals are often focused on reducing energy use and carbon emissions in the built environment as a whole. Understanding the buildings' energy use on a per-occupant basis better addresses the needs of these programs. Using only the per-area functional unit as the metric for judging a building's energy performance which could lead to larger houses for everyone, which doesn't necessarily lead to absolute emissions reductions. People living in larger, albeit more efficient, houses on a per-area basis will have greater absolute energy use and GHG emissions.

Ensuring the lowest energy use and carbon emissions per-person is the best way to encourage GHG emissions reductions in the built environment as a whole. If the trend towards larger houses shown by Nichols and Adams (2013) is allowed to continue, it is unlikely that we will meet Paris Climate Accord emission reduction commitments.

The other functional unit that can be used to look at building efficiency and climate impacts is life cycle energy use and GHG emissions for a building on a per-occupant basis. This, however, is challenging to researchers and policy makers, as occupancy of buildings varies due to many factors. Families grow and change overtime, as do demographic trends and socio-economic factors which affect the occupancy of a house over time. One can, however, use designed occupancy or even average occupancies for the purposes of policy analysis and program development. The results shown in Figure 12 Total Life Cycle Energy for Cost-Optimal Houses per Occupant and Figure 13 Total Life Cycle GHG Emissions for Cost-Optimal Houses per Occupant present results on a peroccupant basis. These results show that based on a design occupancy of bedrooms +1 , passive DADUs and smaller houses perform nearly as well or better than larger ones. This does, however, fluctuate based on house size and number of bedrooms. When analysis is performed using set 
occupancy as the functional unit, results favour smaller passive houses as seen in Figure 14 Total Life Cycle Energy for Cost-Optimal Houses per Set OccupancyFigure 15 Total Life Cycle GHG Emissions for Cost-Optimal Houses per Set Occupancy. On a set occupancy of 2.05 occupants per house, smaller houses are clearly superior to large ones from an energy and carbon performance perspective, as they have lower embodied and total life cycle energy use and GHG emissions.

At the inflection points in Figure 12 Total Life Cycle Energy for Cost-Optimal Houses per Occupantand Figure 13 Total Life Cycle GHG Emissions for Cost-Optimal Houses per Occupantmarked by lines A and $\mathrm{B}$, occupancy is changing, which accounts for some of the variation in the trend lines shown in the figures. At point A and left occupancy is 2 people, between point A and B occupancy is 3 people, and at point $\mathrm{B}$ and right occupancy is 4 people. Additionally, at $140 \mathrm{~m} 2$ and above, the geometry of the houses changes to 2 stories.

Following the trend lines in Figure 12 Total Life Cycle Energy for Cost-Optimal Houses per Occupantand Figure 13 Total Life Cycle GHG Emissions for Cost-Optimal Houses per Occupant from left to right, a few different dynamics are at play. As expected, as house size increases from 30 $\mathrm{m}^{2}$ to $65 \mathrm{~m}^{2}$, the amount of energy use per occupant increases with house size up to point A. At $85 \mathrm{~m}^{2}$, the number of occupants has changed from 2 to 3 , leading to a reduction in energy use per occupant due to a greater number of occupants. The same trend continues to point $B$, where the number of occupants has increased to 4 and the house has changed from 1 story to 2 stories. This leads to a more efficient form due to a lower surface to volume ratio. In combination, these lead to the lowest energy use per-occupant at point B, after which the trend that larger houses use more energy per-occupant continues.

This variability in results due to changing occupancy and building form makes the results less clear and more challenging to interpret. This changing occupancy and form are necessary, however. 
As house size increases, so does the number of bedrooms and therefore the designed occupancy rate. The same thing happens with the number of stories in a house. The cost of land and efficient forms dictate that as house size increases, 2-story houses are preferred and become far more common than single-story houses. For this reason, the research and results are governed by the practical and the optimal.

When considering embodied energy only implications, as is critical with near net-zero and netzero houses, the same considerations discussed above are relevant. Per-area-only analysis will lead to potentially incorrect conclusions on how house size affects a building's energy, emissions, and sustainability performance.

Conclusions reached using the traditional functional unit of per-area for analysis and the resulting view that smaller houses are less efficient forms of construction are not incorrect. They represent an incomplete understanding. Bastos et al. (2014) state that different conclusions are reached on a building energy and carbon performance based on the functional unit used in analysis and these conclusions are confirmed in this study. This points to the need for future building codes and standards to incorporate occupancy and size as important factors in determining the performance targets for energy and emissions and to eliminate the size bias against smaller houses caused by using only per-area functional units to set performance criteria.

A large scale LCA using multiple climate zones and building sizes is beyond the scope of this study. For the LCA in this study, one climate zone was chosen (6A), and an appropriate passive envelope design suitable for it was used in models. Three locations within climate zone $6 \mathrm{~A}$ were chosen to represent different locations across North America to understand how location affects results. For expanded analysis, future research should replicate the methods used in this LCA to understand embodied energy and carbon impacts for passive houses for all climate zones and 
should also include house size above the $230 \mathrm{~m}^{2}\left(2,500 \mathrm{ft}^{2}\right)$ average. Additionally, only three build packages were used for the houses, which represented high, medium, and low embodied energy materials. Though this helps understand the difference that material selection makes to the results and help create more reliable results, there are many more building techniques, construction methods, and material choices that were not included that would have an effect on the embodied energy and carbon impacts of the houses analysed.

\subsection{BEopt Cost-Optimization Discussion}

Results from the BEopt cost-optimization study serve two functions. Firstly, it helps explore energy implications for various sizes of passive houses below the $230 \mathrm{~m}^{2}\left(2,500 \mathrm{ft}^{2}\right)$ average for all climate zones, as well as to understand how cost-optimal passive design changes with shrinking house size. Table 7 lists the 10 house sizes analysed for each of the 17 ASHRAE climate zones in North America (locations listed in Table 8) using BEopt to find the cost-optimal passive design for each size of house in each climate zone.

Though focusing only on operation energy, which dominates the life cycle, the wider-ranging BEopt study helps confirm conclusions drawn from the LCA results that passive DADUs have better energy and emissions performance than their larger counterparts when analysed based on a per-occupant function unit. These trends are consistent across all climate zones. When analysed based on different functional units, passive DADUs and smaller houses are found to be less efficient on a per- $\mathrm{m}^{2}$ basis, as or more efficient on a per-occupant basis, and more efficient on a set-occupancy rate functional unit compared to the average size house built to passive standards.

As the BEopt study was a cost-optimization analysis, the annual energy use results pulled from the analysis represent cost-optimal passive designs across all climate zones. Results presented in 
Figure 18 Cost-Optimal Passive Building Energy Use Intensity by Size and Climate Zone show that most climate zones have cost-optimal per- $\mathrm{m}^{2}$ energy use that are clustered fairly closely. This adds some credibility to the claim that the PHI's PH certification program works across various climate zones, as cost-optimal passive design for most climate zones follow roughly the same energy use intensity. This result shows that there is some validity to the concept that cost-optimal passive design energy use is similar across most climate zones. That being said, the cost-optimal design energy intensity per-unit area changes with house size as seen in Figure 18 Cost-Optimal Passive Building Energy Use Intensity by Size and Climate Zone. The PH system, however sets a single target of $15 \mathrm{kWh} / \mathrm{m}^{2} \mathrm{yr}$ regardless of house size, and changing optimal energy use proves that the $\mathrm{PH}$ approach includes a size bias against smaller houses, and is not a cost-optimal approach to passive design. The PHIUS+ 2015 approach to passive certification has some of the same issues. It does, however, prove itself to be a better approach to dealing with the outliers (climate zones 7, 8, 3C) shown in Figure 18 Cost-Optimal Passive Building Energy Use Intensity by Size and Climate Zone as well as the average variation in energy results between different climate zones (excluding 7, 8, 3C). The climate-specific approach of PHIUS +2015 effectively eliminates the variation seen in optimal energy intensity results through its climate-specific energy targets. It is therefore a better cost-optimal approach in spite of its inherent size bias against smaller buildings.

The results from Figure 20 Cost-Optimal Passive Building Energy Use Intensity by Occupant and Climate Zone and Figure 21 Cost-Optimal Passive Building Energy Use Intensity by Occupant Average for All Climate Zones show how, once again, when analysed on a per-occupant basis, energy performance is generally neither better nor worse as house size shrinks. On a set-occupancy of 2.05 occupants per house, energy performance improves as house size shrinks, as shown in Figure 
22 Cost-Optimal Passive Building Energy Use Intensity by Set Occupancy and Climate Zone and Figure 23 Cost-Optimal Passive Building Energy Use Intensity by Set Occupancy Averaged for All Climate Zones.

Due to the limited scope of this study and the computational intensity needed to perform large BEopt analyses, the effects of more widely-varying occupancy levels for the 170 combinations of house sizes and climate zones was not possible. Energy usage, internal gains, and other effects change with occupancy, and this has an effect on the cost-optimal design for each of the house. This represents a limitation to this study. Another limitation is how it focuses on average and below-average house sizes, and further insight could be gained from understanding all housing sizes up to reasonable limit.

These results confirm Wilson and Boehland (2015) finds showing how smaller houses can make a bigger reduction in life cycle energy use and GHG emissions than a larger house using low embodied energy materials.

\subsection{How Cost-Optimal Passive Design Changes Based On Housing Size}

This study addresses the question of how cost-optimal passive design for passive DADUs and small single-detached houses changes as house size shrinks from the average of $230 \mathrm{~m}^{2}\left(2,500 \mathrm{ft}^{2}\right)$ down to $30 \mathrm{~m}^{2}\left(300 \mathrm{ft}^{2}\right)$. Though modeling the cost-optimal upgrade package using the modeling tools required for passive certification to confirm energy threshold have been reached is out of the scope of this study, the energy outputs from the BEopt study are confirmed to generally meet passive design thresholds.

The envelope designs from each of the 170 houses included in the BEopt study were converted to a weighted-average of overall envelope $\mathrm{U}$-value, which were then compared based on climate zone and house size. 
This comparison reveals how cost-optimal passive design does not change significantly as house size shrinks, as average overall envelope U-values do not change significantly across various house sizes as shown in Figure 25 Overall Cost-Optimal Passive Envelope U-value for Building Size. Results are reasonably consistent across all house sizes with the exception of the smallest house size of 30 $\mathrm{m}^{2}\left(300 \mathrm{ft}^{2}\right)$. The lower overall insulation value for the $30 \mathrm{~m}^{2}\left(300 \mathrm{ft}^{2}\right)$ house size is offset by more efficient mechanicals in the cost-optimal design package calculated as optimal through BEopt analysis. This is likely due to more efficient mechanicals being required to deal with the increasing effect of internal heat gains from occupant energy use in a small space in the summer. In the winter, higher internal heat gains may also reduce the need for higher insulation levels in the envelope and shift the optimal design towards more efficient mechanical systems.

Average results from the analysis of 170 houses of various sizes in the 17 North American climate zones, as shown in Figure 25 Overall Cost-Optimal Passive Envelope U-value for Building Size, point to cost-optimal passive design not being size-dependent. The results shown in Figure 25 Overall Cost-Optimal Passive Envelope U-value for Building Size are unexpected. Higher internal heat gains from occupants and their energy use inside the home becomes more concentrated in smaller homes, which could lead to a bias away from lower U-values in the envelope and towards higher efficiency mechanicals. This effect, however is only seen in the smallest, $30 \mathrm{~m}^{2}$ DADUs. This has significant implication for passive designers and builders. Passive DADUs should be designed with envelope U-values, mechanicals efficiencies, and other design parameters similar to those used for larger houses. Unlike with energy targets, passive design principles are not house size dependent.

This also provides an interesting insight for researchers, as future research on how building size affects energy use can be simplified to focus not on how cost-optimal design changes with size, 
but on how house size and occupancy affects appropriate cost-optimal energy use certification thresholds.

The implications of this finding means that existing passive designers and builders do not need to significantly adjust their approach to passive design for smaller sized passive houses, and can rely on their existing experience and knowledge. This also simplifies the adoption of DADUs into the passive market. Along with the findings that smaller houses are no less efficient, this will help the adoption of this advantageous typology. Passive building standards can now focus on integrating occupancy rates and building size into their programs, with the understanding that passive design principles are consistent for passive DADUs.

\subsection{Future Research Implications}

To further investigate the implications the findings of this study have on the passive design industry, future research should be carried out. To understand how to integrate the insight that cost-optimal passive design does not change with housing size into passive certification programs, as well as understand how energy thresholds for certification in current passive design standards can be adjusted to reduce or eliminate the size bias that currently exists against houses below the $230 \mathrm{~m}^{2}\left(2,500 \mathrm{ft}^{2}\right)$ average size.

Steps for this research should include:

1. Run a BEopt cost-optimization study for a wide range of house sizes and occupancy profiles to generate energy usage data.

2. This energy usage data is then plotted, and a regression analysis performed to develop costoptimal energy usage equations across all passive house sizes. 
3. These equations are then used to adjust the energy thresholds required to meet passive certification to account for a variety of house sizes.

\section{Conclusions}

Though an increasing number of municipalities are encouraging the wider adoption of DADUs through policy and zoning changes due to their many social, economic. And environment benefits, the passive design industry has been slow in its adoption of passive DADUs. The GHG emissionreducing goals of passive certification systems are cemented at the core of their founding principles. The adoption of passive design principles and certifications is paramount to creating the drastic cuts to GHG emissions are needed to prevent irreparable harm to the earth's climate and the catastrophic effects this will have on human civilization. These principles and certifications offer clear guidance to reducing the $25 \%$ of GHG emissions associated with buildings (Lucon et al., 2014).

The two most practical ways of accomplishing a drastic reduction in emissions from the built environment is to first encourage the construction of building typologies that are most efficient, and second, build and retrofit buildings to very low-energy or passive standards. Passive design strategies and certification systems are instrumental in reducing emissions in buildings, and with proper design they have been shown to be effective in even the most extreme climates. The present 
challenge, therefore, is not a technical one. It is an economic one, as new buildings are not being built to passive or net-zero standard due to their marginally higher costs. Cost-optimal, climatespecific passive design standards, like that of PHIUS +2015 are an attempt to address these issues.

This paper identifies and explorers the size bias against passive DADUs, which is one of hurdles facing cost-optimal passive design standards, and discusses its origins, consequences, and implications. Though analysis performed as part of this study, passive DADUs are found to be an efficient typology that should be encouraged along the path to net-zero by reducing climate change causing GHG emissions. Passive design certification programs set emissions targets and energy use certification thresholds based on per-floor area targets. Through the effects of their geometry, DADUs are significantly more challenging to design to reach stringent energy targets on a perarea basis. These challenges include greater surface to volume ratios leading to greater proportional heat loss, through the envelope as well as base loads from occupant (hot water, cooking, laundry, electrical appliance use, etc.) that add proportionally more energy per unit area of floor for smaller houses.

Analysing building energy and emissions performance based on per-unit floor area has been the conventional way of comparing between buildings of very different size and shape as it simplifies the comparison. When building performance is looked at only on this basis, a conclusion that larger houses perform better is reached. Certification criteria based on this functional unit create a size bias against DADUs in current passive certification programs and discourages their adoption. If this is allowed to continue, an emerging typology that could help significantly reduce carbon emissions through the reduction of urban sprawl and lower absolute emissions on a per-capita basis will be discouraged to the detriment of our climate goals. 
This research has shown through a detailed LCA that the common perception that smaller housing typologies are less efficient forms of housing is incorrect and has added to the BOK in this regard. On a per-occupant basis, passive DADUs have lower life cycle energy use and GHG emissions than larger ones, and a size bias against them based on poor per- $\mathrm{m}^{2}$ performance is unjustified.

Results from this research study also show that overall cost-optimal design does not change significantly as house size shrinks. Current passive certification standards that require increasing envelope insulation levels to meet energy targets as house size shrinks are not appropriate. This study also finds that passive design principles are universal and that simpler methods can be employed to eliminate size bias in passive certification programs. Additionally, designers and builders of passive houses can rely on their years of experience and existing knowledge in passive design even with DADUs. This insight can help researchers in technical committees develop more effective building standards and codes that eliminate the unwarranted bias against small houses by understanding house size affects cost-optimal passive design and will allow passive designers and builders understand how to best design passive DADUs.

Passive certification programs should be adjusted to eliminate the size bias against DADUs and embrace them as a beneficial typology, especially given the fact that small cost-optimal passive houses are not significantly different in design to larger ones. Future research can help better understand and eliminate size bias against small passive houses. 


\section{References}

Aktas, C. B., \& Bilec, M. M. (2012). Impact of lifetime on US residential building LCA results. International Journal of Life Cycle Assessment, 17(3), 337-349. https://doi.org/10.1007/s11367-011-0363-x

Anand, C. K., \& Amor, B. (2017). Recent developments, future challenges and new research directions in LCA of buildings: A critical review. Renewable and Sustainable Energy Reviews. https://doi.org/10.1016/j.rser.2016.09.058

Andres, P. W. (2015). Investigation of the Life Cycle Carbon Impact of Passive House.

Bady, S. (2017). Much Ado About ADUs. Arlington Heights, (May, 2017). https://doi.org/10.1093/analys/anq087

Bastos, J., Batterman, S. A., \& Freire, F. (2014). Life-cycle energy and greenhouse gas analysis of three building types in a residential area in Lisbon. Energy and Buildings, 69, 344-353. https://doi.org/10.1016/j.enbuild.2013.11.010

Bowick, M. F. (2011). A life cycle assessment model of Canadian residential dwellings and building stocks.

Bronwyn Barry. (n.d.). PHIUS-BSC Climate-Specific Proposal is Incomplete | NYPH. Retrieved September 28, 2018, from https://www.nypassivehouse.org/phius-bsc-climate-specific-proposal-unsupportedby-data-and-incomplete/

Brown, M. J., \& Watkins, T. (2012). Understanding and Appraising Properties with Accessory Dwelling Units. The Appraisal Journal, 297-309.

Canada Mortgage and Housing Corporation. (2016). Housing Observer: Tiny Houses: Article 3-July 2016, (July).

Chastas, P., Theodosiou, T., \& Bikas, D. (2016). Embodied energy in residential buildings-towards the nearly zero energy building: A literature review. Building and Environment, 105, 267-282. https://doi.org/10.1016/j.buildenv.2016.05.040

Clark, T. A. (2013). Metropolitan density, energy efficiency and carbon emissions: Multi-attribute tradeoffs and their policy implications. Energy Policy, 53, 413-428. https://doi.org/10.1016/j.enpol.2012.11.006

CMHC. (2015). A Life-Cycle Environmental Assessment Benchmark Study of Six CMHC EQuilibrium Housing Initiative Projects, (June).

Cox, W., \& Pavletich, H. (2017). 13th Annual Demographia International Housing Affordability Survey. Retrieved from http://www.demographia.com/dhi.pdf

Dahlstrøm, O., Sørnes, K., Eriksen, S. T., \& Hertwich, E. G. (2012). Life cycle assessment of a single-family residence built to either conventional- or passive house standard. Energy and Buildings, 54, 470479. https://doi.org/10.1016/j.enbuild.2012.07.029

De Wolf, C., Pomponi, F., \& Moncaster, A. (2017). Measuring embodied carbon dioxide equivalent of buildings : A review and critique of current industry practice. Energy \& Buildings, 140, 68-80. https://doi.org/10.1016/j.enbuild.2017.01.075 
Dequaire, X. (2012). Passivhaus as a low-energy building standard: Contribution to a typology. Energy Efficiency, 5(3), 377-391. https://doi.org/10.1007/s12053-011-9140-8

Devlin, J. (2017). Vancouver's housing crisis. RICS Land Journal - Housing Market, (August/September 2017).

Galassini, L. M. (2014). Hidden Density: A Proposal for Single-Family Infill Housing. University of Washington.

Galvin, R. (2014). Are passive houses economically viable? A reality-based, subjectivist approach to costbenefit analyses. Energy and Buildings, 80, 149-157. https://doi.org/10.1016/j.enbuild.2014.05.025

Georges, L., Haase, M., Houlihan Wiberg, A., Kristjansdottir, T., \& Risholt, B. (2015). Life cycle emissions analysis of two nZEB concepts. Building Research \& Information, 43(1), 82-93. https://doi.org/10.1080/09613218.2015.955755

Gudipudi, R., Fluschnik, T., Ros, A. G. C., Walther, C., \& Kropp, J. P. (2016). City density and CO2 efficiency. Energy Policy, 91, 352-361. https://doi.org/10.1016/j.enpol.2016.01.015

Klingenberg, K., Kernagis, M., \& Knezovich, M. (2016). Zero energy and carbon buildings based on climate-specific passive building standards for North America. Journal of Building Physics, 39(6), 503-521. https://doi.org/10.1177/1744259115621800

Lucon, O., Ürge-Vorsatz, D., Zain Ahmed, A., Akbari, H., Bertoldi, P., Cabeza, L. F., ... VilariñoLucon, M. V. (2014). Buildings. In: Climate Change 2014: Mitigation of Climate Change. Contribution of Working Group III to the Fifth Assessment Report of the Intergovernmental Panel on Climate Change. Cambridge, United Kingdom and New York, NY, USA. https://doi.org/10.2753/JES1097$203 \times 330403$

Morrissey, J., \& Horne, R. E. (2011). Life cycle cost implications of energy efficiency measures in new residential buildings. Energy and Buildings, 43(4), 915-924.

https://doi.org/10.1016/j.enbuild.2010.12.013

National Renewable Energy Laboratory. (2019). Building Energy Optimization (BEopt) Software I Department of Energy. Retrieved January 23, 2019, from https://www.energy.gov/eere/buildings/building-energy-optimization-beopt-software

Neufeld, L. (2017). Edmonton urged to take a new view of back alleys | CBC News. Retrieved November 8, 2018, from https://www.cbc.ca/news/canada/edmonton/suites-garage-garden-alley-lanewaycity-edmonton-development-infill-1.4097921

Nguyen, A. T., Reiter, S., \& Rigo, P. (2014). A review on simulation-based optimization methods applied to building performance analysis. Applied Energy, 113, 1043-1058. https://doi.org/10.1016/j.apenergy.2013.08.061

Nichols, J. L., \& Adams, E. (2013). The Flex-Nest: The Accessory Dwelling Unit as Adaptable Housing for the Life Span. Interiors: Design, Architecture and Culture, 4(1), 31-52. https://doi.org/10.2752/204191213X13601683874136

Passive House Institute. (2016). Criteria for the Passive House, EnerPHit and PHI Low Energy Building Standard Criteria. Darmstadt: Passive House Institute. 
PHIUS. (2017). PHIUS+ 2015 Certification Guidebook. Chicago: Passive House Institute US.

Roy, J., Maynard, M., \& Weiss, E. (2008). The Hidden cost of the housing crisis: The long-term impact of housing affordability and quality on young children's odds of success. The Partnership for America's Economic Success.

Sartori, I., \& Hestnes, A. G. (2007). Energy use in the life cycle of conventional and low-energy buildings: A review article. Energy and Buildings, 39(3), 249-257. https://doi.org/10.1016/j.enbuild.2006.07.001

Schnieders, J., Feist, W., \& Rongen, L. (2015). Passive Houses for different climate zones. Energy and Buildings, 105, 71-87. https://doi.org/10.1016/j.enbuild.2015.07.032

Soust-Verdaguer, B., Llatas, C., \& García-Martínez, A. (2016). Simplification in life cycle assessment of single-family houses: A review of recent developments. Building and Environment, 103, 215-227. https://doi.org/10.1016/j.buildenv.2016.04.014

Statistics Canada. (2016). 2016 Census - Structural Type of Dwelling, Tenure, Household Size, and Number of Bedrooms for Provate Households. Catalogue Number 98-400-X2016220.

Stephan, A., Crawford, R. H., \& de Myttenaere, K. (2013). A comprehensive assessment of the life cycle energy demand of passive houses. Applied Energy, 112, 23-34. https://doi.org/10.1016/j.apenergy.2013.05.076

The Environmental Literacy Council. (2015). Life Cycle Analysis - The Environmental Literacy Council. Retrieved November 1, 2018, from https://enviroliteracy.org/environment-society/life-cycleanalysis/

United States Census Bureau. (2017). Survey of Construction: Median and Average Square Feet of Floor Area in New Single-Family Houses Completed by Location. Retrieved from https://www.census.gov/const/C25Ann/sftotalmedavgsqft.pdf

Wegmann, J., \& Chapple, K. (2014). Hidden density in single-family neighborhoods: backyard cottages as an equitable smart growth strategy. Journal of Urbanism, 7(3), 307-329. https://doi.org/10.1080/17549175.2013.879453

Wilson, \& Boehland. (2005). Small is Beautiful: U.S. House Size, Resource Use, and the Environment. Journal of Industrial Ecology, 9(1-2), 277-287. https://doi.org/10.1038/nmeth.1895

Wright, G., Klingenberg, K., \& Pettit, B. (2014). Climate-Specific Passive Building Standards, (July). Retrieved from http://www.nrel.gov/docs/fy15osti/64278.pdf 
Appendix A: LCA Material Quantity Take-Off Models

$30 \mathrm{~m}^{2}\left(300 \mathrm{ft}^{2}\right)$ Take-off Model
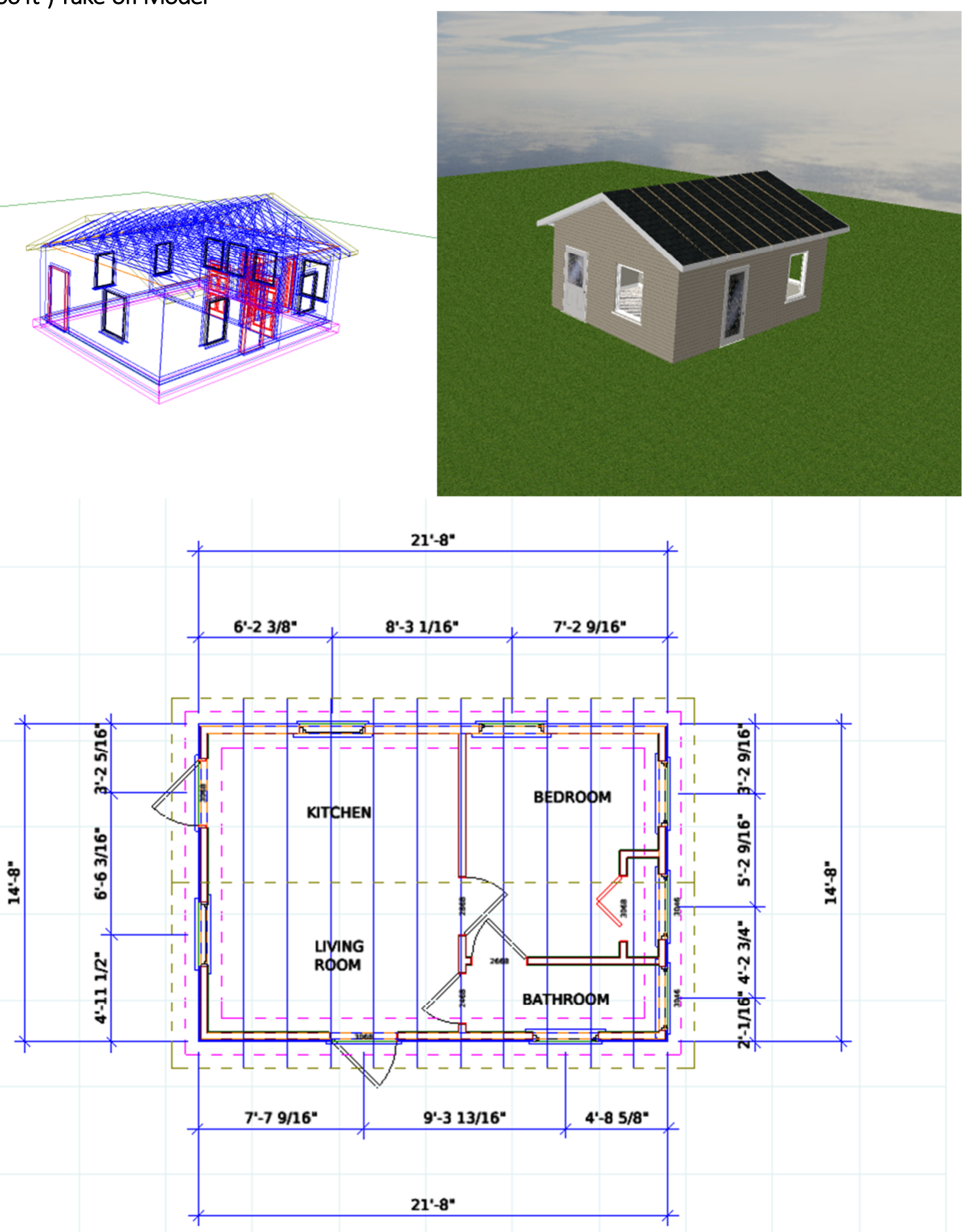
$45 \mathrm{~m}^{2}\left(500 \mathrm{ft}^{2}\right)$ Take-off Model
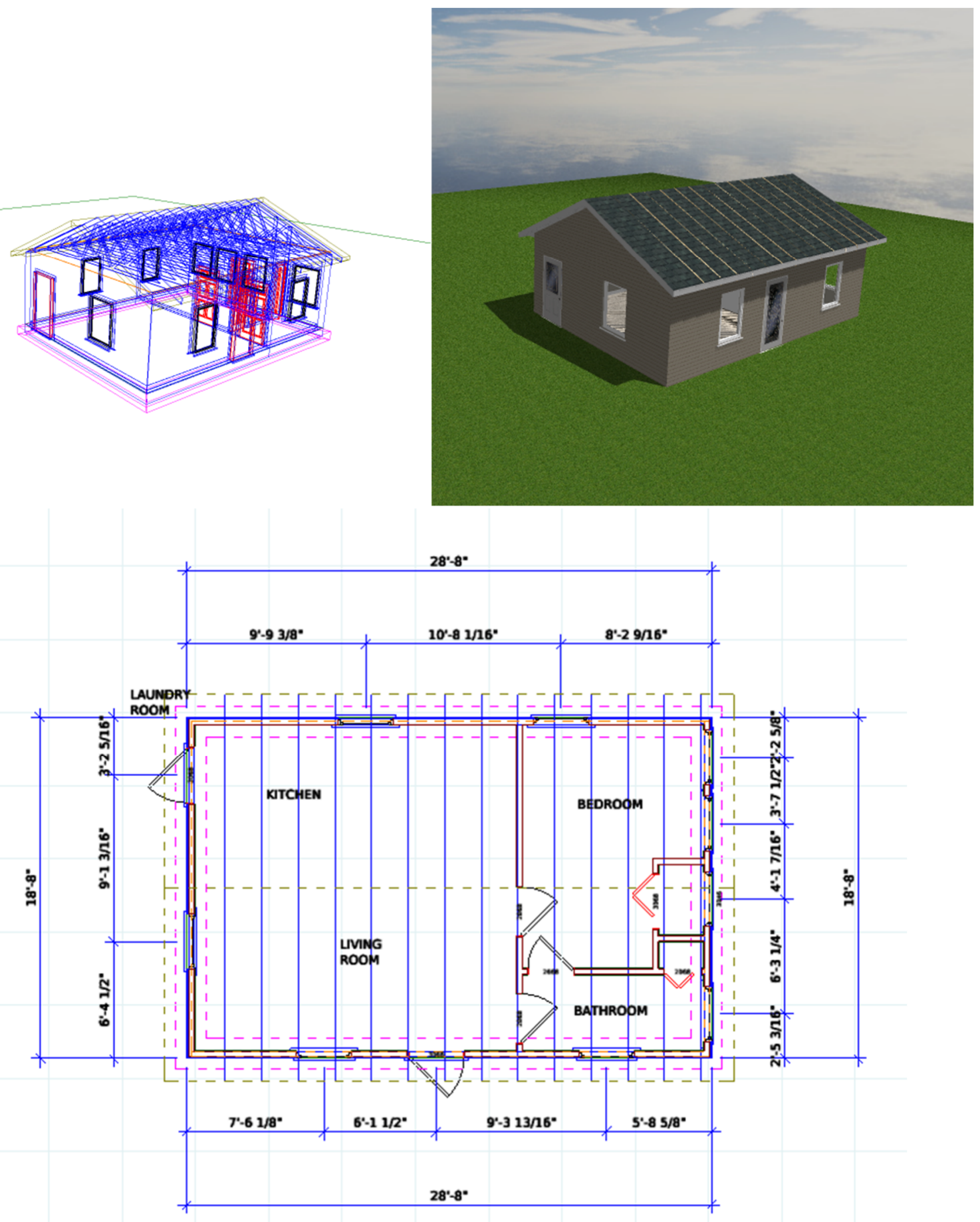

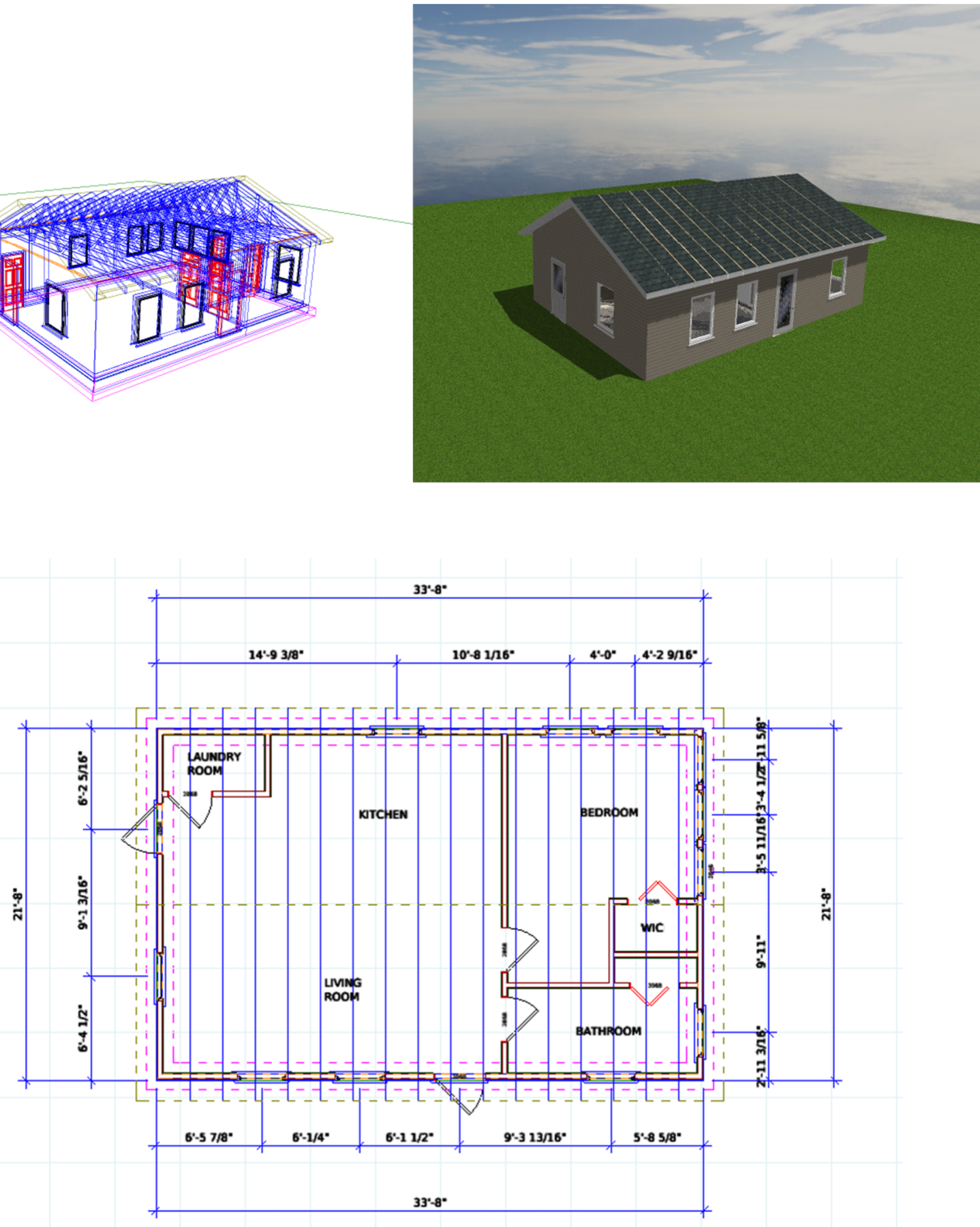
$85 \mathrm{~m}^{2}\left(900 \mathrm{ft}^{2}\right)$ Take-off Model
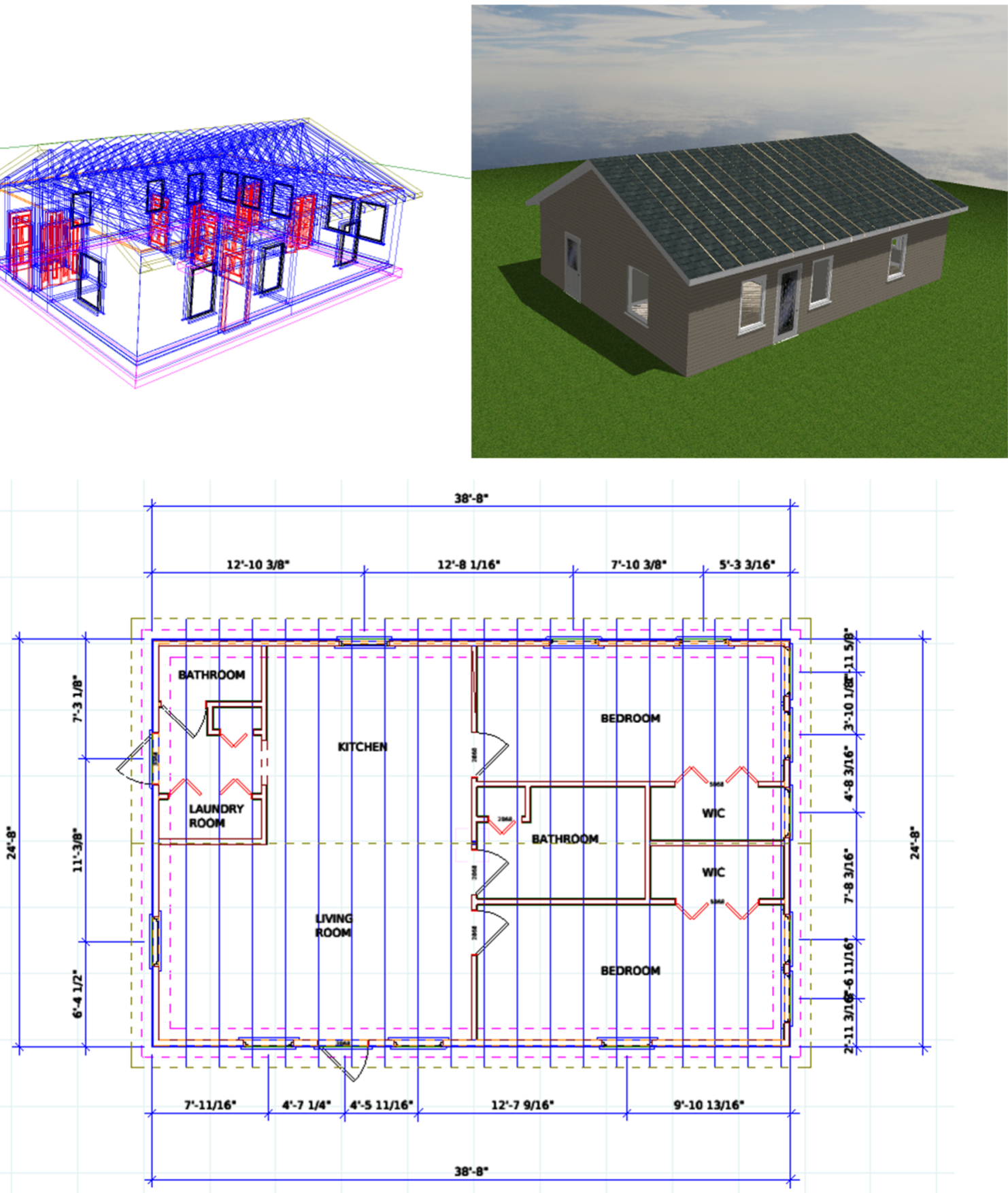

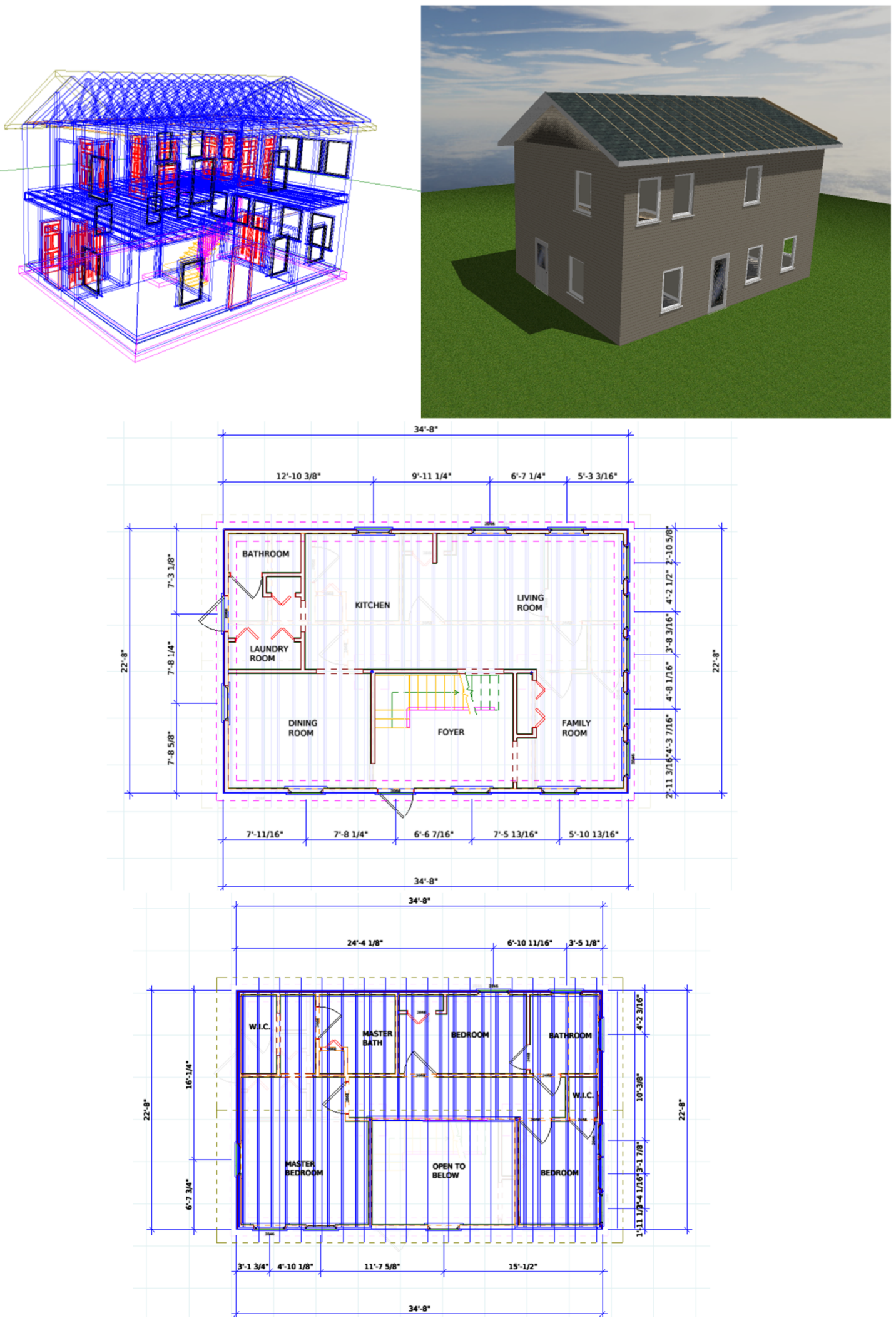
$190 \mathrm{~m}^{2}\left(2,000 \mathrm{ft}^{2}\right)$ Take-off Model
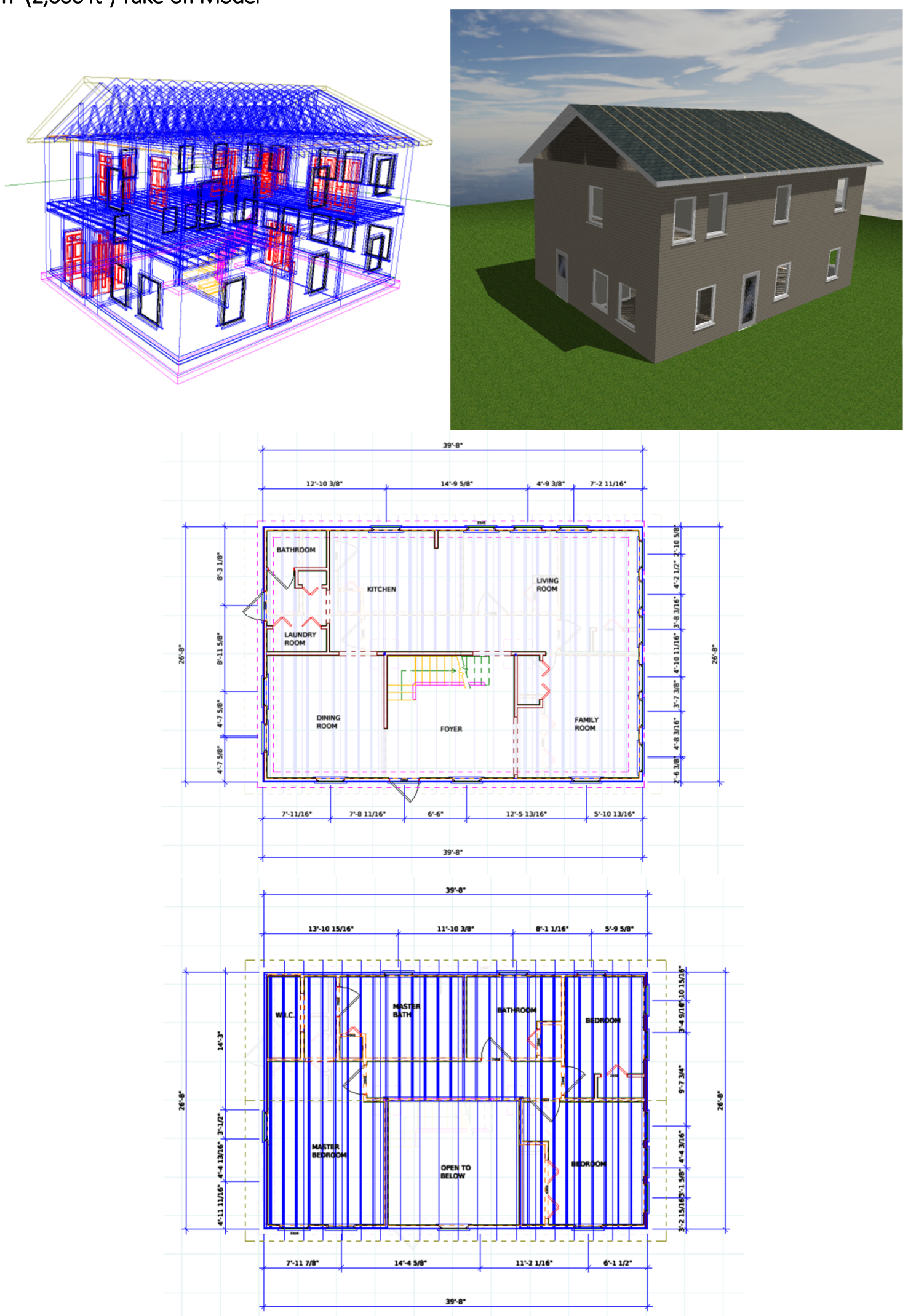
$230 \mathrm{~m}^{2}\left(2,500 \mathrm{ft}^{2}\right)$ Take-off Model
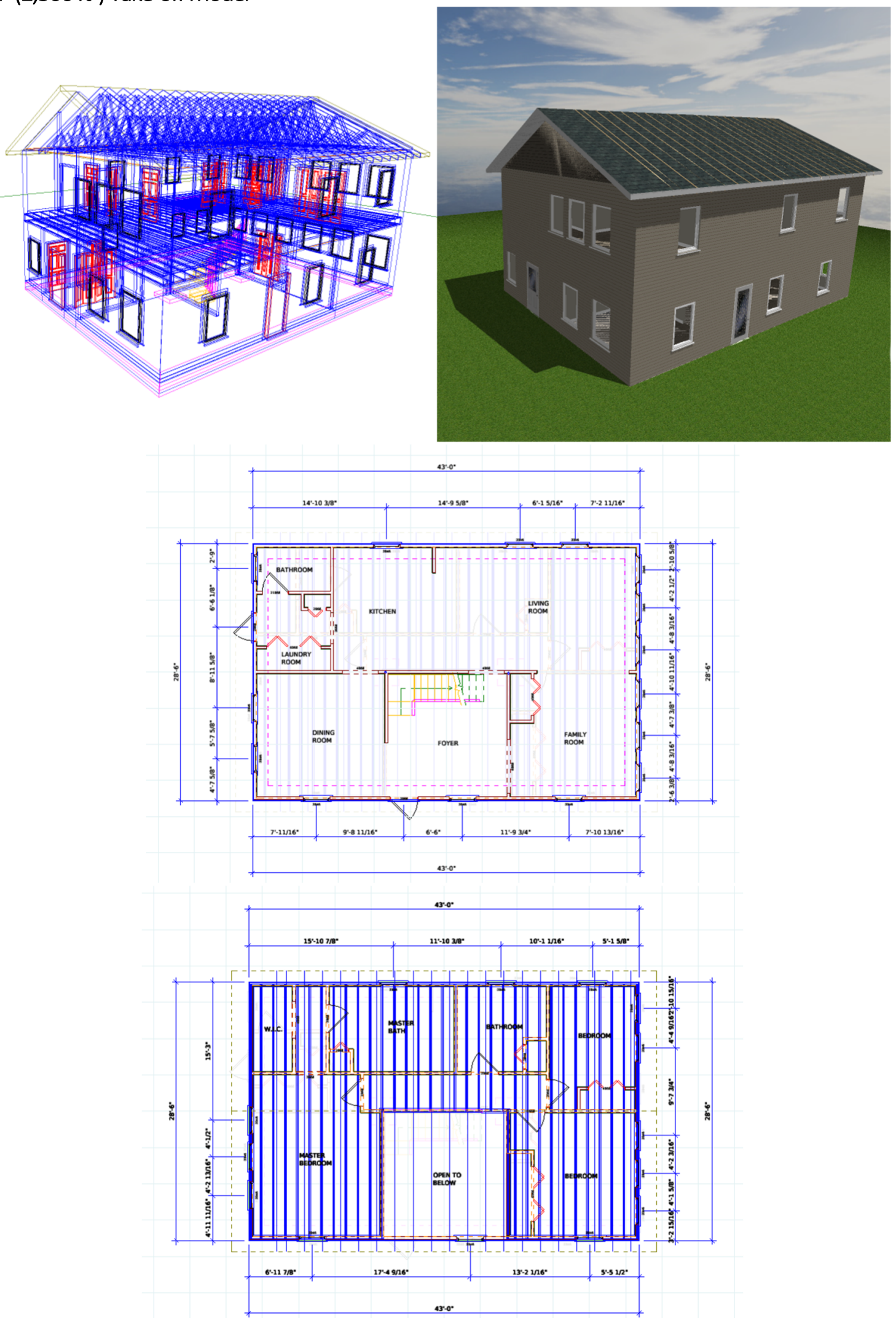
Appendix B: Material Take-Off Quantities

\begin{tabular}{|c|c|c|c|c|c|c|c|}
\hline \multirow{2}{*}{ Material and Component } & \multicolumn{7}{|c|}{ Nominal House Size $\left(\mathrm{ft}^{2}\right.$ iCFA) } \\
\hline & 2,500 & 2,000 & 1,500 & 900 & 700 & 500 & 300 \\
\hline Shingles $\left(\mathrm{m}^{2}\right)$ & 150 & 131 & 100 & 172 & 130 & 95 & 56 \\
\hline PVC for Ridge Vent (kg) & 3.3 & 3.3 & 3.3 & 3.3 & 3.3 & 3.3 & 1.6 \\
\hline Felt Paper $\left(\mathrm{m}^{2}\right)$ & 161 & 161 & 80 & 120 & 80 & 80 & 40 \\
\hline Ice and Water Shield (kg) & 44 & 44 & 44 & 44 & 44 & 44 & 44 \\
\hline Aluminum for Flashing (kg) & 30 & 28 & 24 & 23 & 21 & 18 & 14 \\
\hline Aluminum for Trim $\left(\mathrm{m}^{2}\right)$ & 1.2 & 1.2 & 1.0 & 1.1 & 1.0 & 0.9 & 0.7 \\
\hline Attic Insulation $\left(\mathrm{m}^{2}\right)$ & 68 & 54 & 41 & 49 & 38 & 27 & 16 \\
\hline Siding $\left(\mathrm{m}^{2}\right)$ & 248 & 228 & 198 & 113 & 97 & 82 & 62 \\
\hline Exterior Insulation $\left(\mathrm{m}^{2}\right)$ & 43 & 39 & 34 & 20 & 17 & 14 & 10 \\
\hline SBPO House Wrap $\left(\mathrm{m}^{2}\right)$ & 334 & 251 & 167 & 167 & 84 & 84 & 84 \\
\hline Wood for Framing $\left(\mathrm{m}^{2}\right)$ & 14.1 & 13.1 & 11.0 & 7.3 & 5.3 & 4.2 & 3.1 \\
\hline Steel for Fasteners (kg) & 136 & 122 & 103 & 76 & 50 & 43 & 29 \\
\hline Fiberglass Insulation $\left(\mathrm{m}^{3}\right)$ & 19.8 & 18.1 & 15.4 & 9.0 & 7.6 & 6.4 & 4.7 \\
\hline 6mil Poly $\left(m^{2}\right)$ & 263 & 242 & 205 & 207 & 170 & 136 & 94 \\
\hline Gypsum Wall Board $\left(\mathrm{m}^{2}\right)$ & 829 & 746 & 606 & 452 & 312 & 232 & 158 \\
\hline Joint Tape (kg) & 16.5 & 14.2 & 11.8 & 9.4 & 7.1 & 4.7 & 2.4 \\
\hline Joint Compound (kg) & 598 & 523 & 430 & 336 & 224 & 168 & 112 \\
\hline Primer \& Paint (L) & 265 & 265 & 208 & 151 & 114 & 76 & 57 \\
\hline Hardwood for Railings $\left(\mathrm{m}^{3}\right)$ & 0.1 & 0.1 & 0.1 & 0 & 0 & 0 & 0 \\
\hline Plywood for Stairs (m²) & 12.3 & 12.3 & 12.3 & 0 & 0 & 0 & 0 \\
\hline $9.5 \mathrm{~mm}$ OSB $\left(\mathrm{m}^{2}\right)$ & 834 & 734 & 588 & 342 & 277 & 221 & 153 \\
\hline Steel for Columns (kg) & 318 & 318 & 318 & 79 & 0 & 0 & 0 \\
\hline Foundation Concrete $\left(\mathrm{m}^{3}\right)$ & 18.3 & 15.9 & 12.6 & 14.5 & 11.6 & 9.1 & 6.1 \\
\hline Foundation EPS Foam $\left(\mathrm{m}^{3}\right)$ & 24.2 & 20.6 & 16.1 & 18.8 & 14.9 & 11.4 & 7.5 \\
\hline
\end{tabular}

